\title{
Identification of Physical Properties for the Retrieval Data Quality Objective Process
}

C. M. Gates

M. R. Beckette

June 1995

Pacific Northwest Laboratory

Richland, Washington 99352

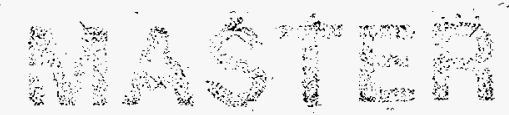




\section{DISCLAIMER}

This report was prepared as an account of work sponsored by an agency of the United States Government. Neither the United States Government nor any agency thereof, nor any of their employees, make any warranty, express or implied, or assumes any legal liability or responsibility for the accuracy, completeness, or usefulness of any information, apparatus, product, or process disclosed, or represents that its use would not infringe privately owned rights. Reference herein to any specific commercial product, process, or service by trade name, trademark, manufacturer, or otherwise does not necessarily constitute or imply its endorsement, recommendation, or favoring by the United States Government or any agency thereof. The views and opinions of authors expressed herein do not necessarily state or reflect those of the United States Government or any agency thereof. 


\section{DISCLAIMER}

Portions of this document may be illegible in electronic image products. Images are produced from the best available original document. 


\section{Acknowledgments}

The authors of this report wish to thank M. R. Powell for providing the preliminary theory for sluicing which is attached in Appendix A, and F. F. Erian for providing the sections on pneumatic conveyance and slurry transport which are in Appendices B and C. This work was funded by a finance plan from the Tank Waste Remediation Systems (TWRS) Retrieval Program Office. 


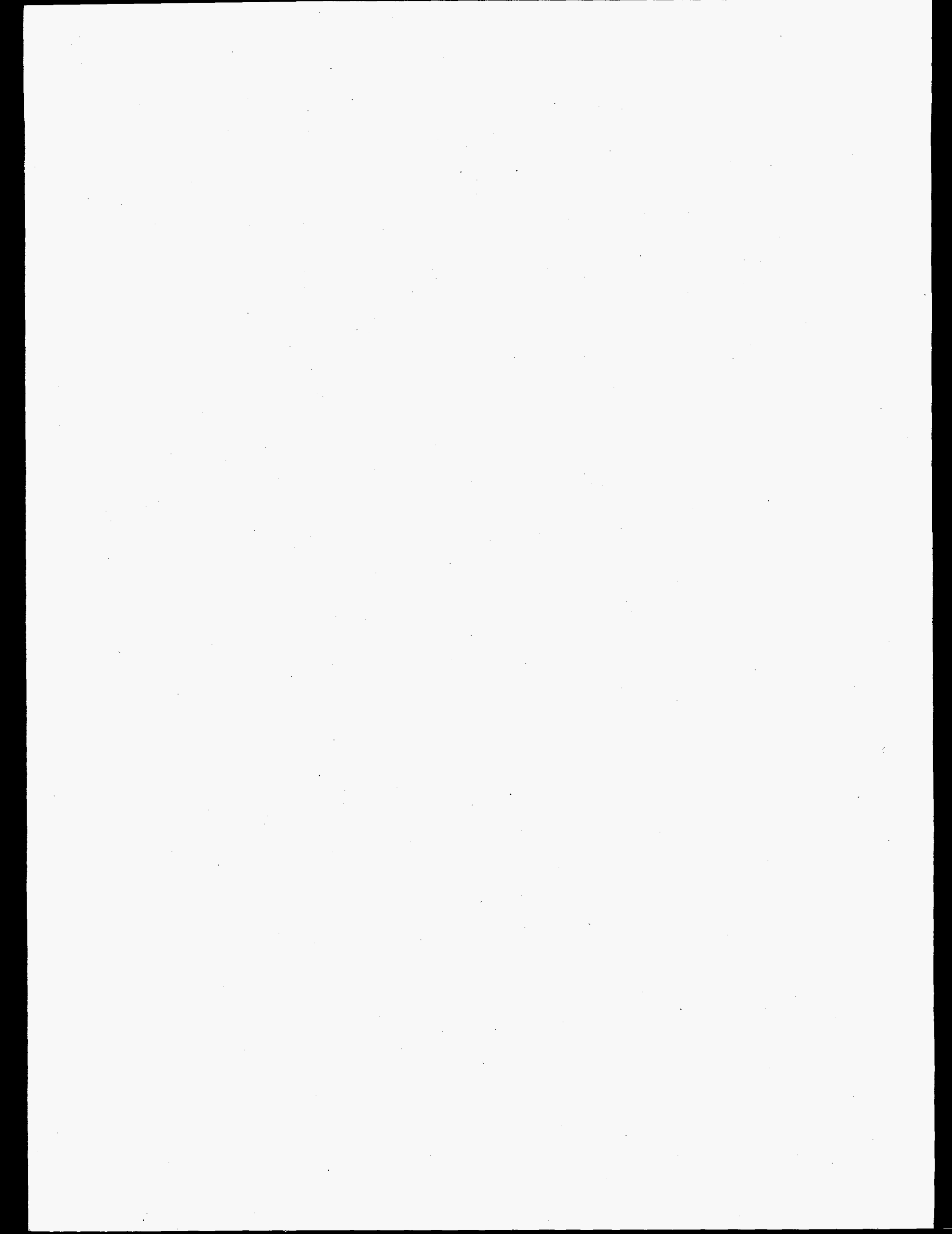




\section{Summary}

The objective of this document is to provide specific information determining the data quality objectives (DQOs) for the remediation process to be used in the tank waste remediation systems (TWRS): information describing the mechanisms, correlations, and material properties critical to the retrieval, conveyance, and transport of tank waste. The DQO process defines those required waste properties, and their allowable uncertainties, that must be characterized before any waste is retrieved. This process is employed to make certain that proper characterization data are requested for use in making critical decisions about the retrieval of tank waste.

The report "Characterization Data Needs for Development, Design and Operation of Retrieval Equipment Developed through the Data Quality Objective (DQO) Process" (WHC-SD-WM-DQO008 Rev. 0) has satisfied several steps of the DQO process. To complete the DQO process, critical information in the following four areas needs to be developed: historical data collection and assessment, definition of a sampling strategy, determination of the value of information, and determination of allowable data uncertainty. This document serves to provide justification for the requested characterization data by providing a mechanistic description of the different processes, the correlations with which the data will be used, and, where possible, uncertainty expressions for the correlations based on the uncertainty of the characterization measurements. Provided herein is the information needed to satisfy the remaining steps in the DQO process. The key points to each of the retrieval processes are listed below:

- The key parameters in the sluicing technology are thought to be shear strength, salt dissolution, particle/grain size distribution, and porosity.

Sluicing technology is reviewed in Section 3.1, and a preliminary sluicing model is described in Appendix A. This model is not based on experiment, but provides a basis on which to request characterization data; it depends on the characteristics of the jet profile, the operating conditions of the retrieval system, and shear strength of the material. The model was developed for sludge sluicing, but includes a parameter that is expected to take into account the effects of saltcake dissolution and porosity, which is related to the grain size of some materials.

Important mixer pump parameters include tensile strength, specific surface area or particle size distribution, and shear strength.

Tensile strength is a direct measure of the interparticle attraction, but is difficult to measure. Shear strength measurements can be used to estimate the volume of waste mobilized if the material's specific surface area can be characterized. Powell et al. (1995b) refers to a cohesive material as one with a specific surface area greater than $35 \mathrm{~m}^{2} / \mathrm{g}$. Should a reliable laboratory technique not be available, specific surface area can be approximated by knowing particle size and shape. So, in the absence of measured tensile strength, a combination of shear strength and specific surface area, or particle size, is used to estimate the sludge cohesiveness and the volume of waste that can be mobilized with a mixer pump.

- Slurry formation parameters are shear strength and solubility rate.

Slurry formation occurs after the waste has been dislodged, and it is transported to the treatment facilities. Section 4.3 provides a description of the slurry formation process and its importance to the retrieval system.

- Water-jet cutting technology parameters are tensile strength, grain or crystal size, density, porosity, fracture toughness, and hardness.

There is no model that relates water-jet cutting waste retrieval to material properties. A description of the dislodging mechanism, however, is given in Section 3.4. 
The solubility of the different salts present in Hanford tank waste relative to the concentration of $\mathrm{NaOH}$ is important because of the need to prevent the precipitation of crystals during the transport phase of retrieval operations.

Barney (1976) performed dissolution experiments by saturating an aqueous solution with the major non-radioactive salts present in Hanford tanks. The solubility curves are provided in Section 3.5, and can be used to estimate the optimum $\mathrm{NaOH}$ concentration for transport operations.

- Pneumatic conveyance key parameters are density and viscosity of each of the three phases, the particle size distribution, and the liquid surface tension.

The pneumatic conveyance of dry solid particles is a well-studied process; however, the conveyance of wet sticky materials, such as tank waste, is not. Erian(a) recommends combining a pneumatic conveyance model with a model that describes liquid flow in an annular dispersed condition. Annular dispersed flow is a two-phase flow condition with a gas phase in the core of the pipe and a liquid film flowing along the walls of the pipe with droplets of liquid dispersed throughout the gas core. The condition of annular dispersed flow is required to prevent sticky materials from accumulating on the pipe wall and clogging the pipe.

- Slurry transport key properties are the densities for all phases, viscosity, solids concentration, particle size distribution, $\mathrm{pH}$, temperature, and concentration of soluble species.

The critical concerns for slurry transport design, with respect to Hanford waste, are related to chemical and physical properties. Changes in solution chemistry during transport can affect the apparent viscosity by the increase of solids loading in the form of crystalline structures and by the formation of gels. The gel forms as colloidal particles agglomerate and collide. When these aggregates collide, a matrix of colloidal particles is formed. This matrix increases the viscosity by orders of magnitude and exhibits an elastic behavior: Gelation and crystallization are not the only chemical phenomena that must be considered: particle agglomeration and scale formation are also concerns. Particle agglomeration can result from changes in solution chemistry, and may produce non-colloidal particles that settle to form a stationary bed in the pipe. For larger particles $(>10 \mu \mathrm{m})$, the parameter that must be calculated for slurry transport is the critical velocity. During multi-phase flow, solid particles can settle to form a bed of solids; this phenomenon is related to the intensity of turbulence in the stream. As the mixture velocity is increased, the kinetic energy of the stream is increased, which causes the solid phase to maintain a uniform solids concentration velocity across the section of pipe. As the mixture velocity is reduced, however, the kinetic energy of the stream is reduced, and particles start to settle beginning the formation of a moving bed of solids. Further velocity reduction results in the formation of a stationary bed, which occurs at a velocity called the critical velocity.

This document supports the DQO by providing a basis for the specified retrieval processes; should other processes be considered, a technical basis for requesting characterization data must be developed. The areas that are not addressed in this document include aerosol formation at the point of generation; erosion and corrosion of equipment inside of the tank; additional in-tank processing not accounted for in each technology model; aerosol generation; gas/waste separation at the end of the conveyance line; and slurry pretreatment. These issues, while important, were not considered to be vital to this document but should be considered and incorporated into future design work.

Table S.1 lists the key properties or the major retrieval technologies and related processes. Sample calculations are provided in Appendix D.

(a) Erian, Fadel F. March 6, 1995. "On the Design of Pneumatic Transport Pipelines." Attached as Appendix B of this document. 
Table S.1. Key Properties of Retrieval Technologies and Processes

\begin{tabular}{|l|l|}
\hline \multicolumn{1}{|c|}{ Processes and Technologies } & \multicolumn{1}{|c|}{ Key Properties } \\
\hline \hline Sluicing & $\begin{array}{l}\text { Shear strength, salt dissolution, particle or grain size } \\
\text { distribution, and porosity }\end{array}$ \\
\hline Mixer Pump & $\begin{array}{l}\text { Tensile strength, specific surface area ( or particle size } \\
\text { distribution), and shear strength }\end{array}$ \\
\hline Slurry Formation & Shear strength, solubility rate \\
\hline Water-Jet Cutting & $\begin{array}{l}\text { Tensile strength, grain or crystal size, density, porosity, } \\
\text { fracture toughness, hardness }\end{array}$ \\
\hline Waste Dissolution & Salt solubility relative to NaOH concentration \\
\hline Pneumatic Conveyance & $\begin{array}{l}\text { Density, viscosity, surface tension, particle size } \\
\text { distribution }\end{array}$ \\
\hline Slurry Transport & $\begin{array}{l}\text { Density, viscosity, chemical concentrations, particle } \\
\text { size distribution, solids concentration, pH }\end{array}$ \\
\hline
\end{tabular}




\section{Contents}

Acknowledgment.

Summary

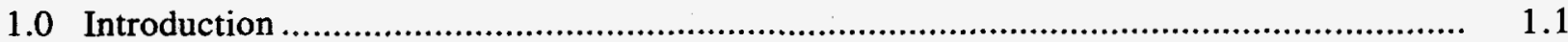

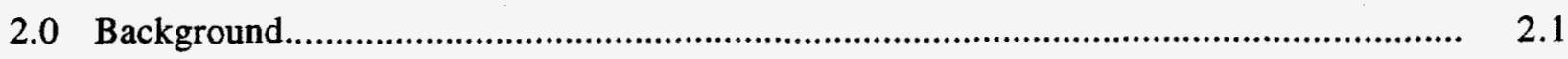



2.1.1 The First Campaign (1952-1957) ..................................................... 2.1

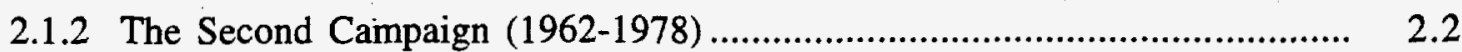

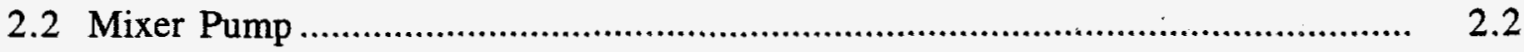

2.3 Scarifier End Effector (Water Jet Cutting) ................................................ 2.3

3.0 Retrieval Processes and Technologies....................................................................... 3.1

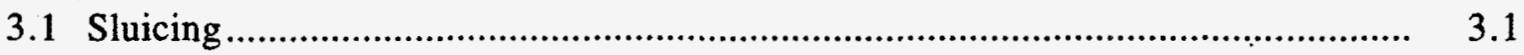

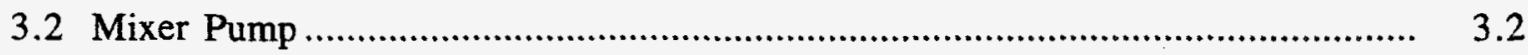

3.3 Slurry Formation ............................................................................

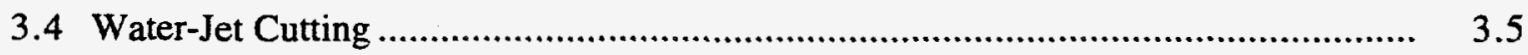

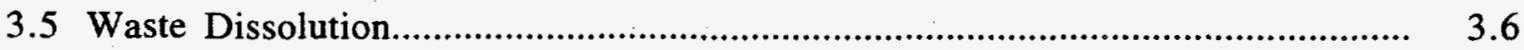

3.6 Pneumatic Conveyance................................................................................ 3.9







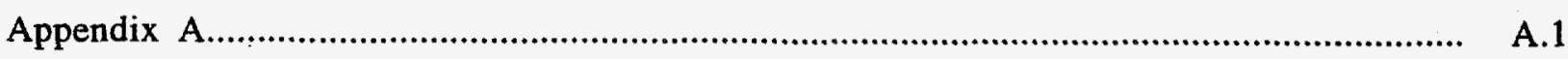

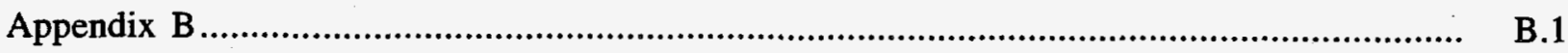

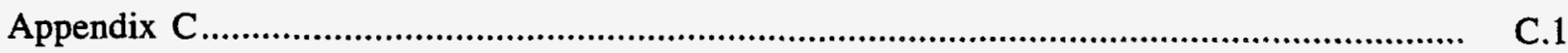

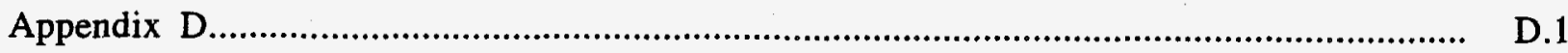




\section{Figures}

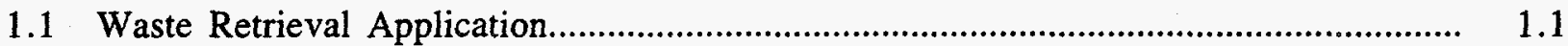

3.1 Retrieval Rate Versus Shear Strength $(\mathrm{Pa})$ Initial Jet Pressure $=1 \mathrm{MPa}$,

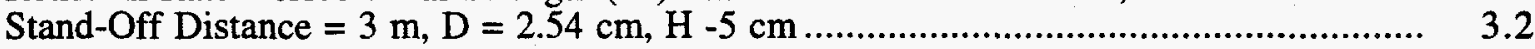

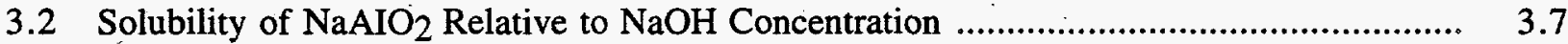

3.3 Solubility of $\mathrm{NaNO}_{2}$ Relative to $\mathrm{NaOH}$ Concentration - Taken from Barney (1976) ARH-ST-133

3.4 Solubility of $\mathrm{NaNO}_{3}$ Relative to $\mathrm{NaOH}$ Concentration - Taken from Barney (1976) ARH-ST-133

3.5 Solubility of $\mathrm{Na}_{2} \mathrm{SO}_{4}$ Relative to $\mathrm{NaOH}$ Concentration - Taken from Barney (1976) ARH-ST-133

3.6 Solubility of $\mathrm{Na}_{2} \mathrm{CO}_{3}$ Relative to $\mathrm{NaOH}$ Concentration - Taken from Barney (1976) ARH-ST-133

\section{Tables}

S.1 Key Properties of Retrieval Technologies and Processes

vii 


\subsection{Introduction}

This activity supports the retrieval data quality objective (DQO) process by identifying the material properties that are important to the design, development, and operation of retrieval equipment; the activity also provides justification for characterizing those properties. These properties, which control tank waste behavior during retrieval operations, are also critical to the development of valid physical simulants for designing retrieval equipment.

Figure 1.1 shows an example of a waste retrieval application. The waste is retrieved in a series of four steps. . First, a selected retrieval technology breaks up or dislodges the waste into subsequently smaller pieces. Then, the dislodged waste is conveyed out of the tank through the conveyance line. Next, the waste flows into a separator unit that separates the gaseous phase from the liquid and solid phases. Finally, a unit may be present to condition the slurried waste before transporting it to the treatment facility. This document describes the characterization needs for the proposed processes to accomplish waste retrieval.

Through the analysis of previous work, the phenomena that control the performance of retrieval technologies are broken down to the contributing mechanisms, the critical properties that govern mobilization, and the effects of data uncertainty. This document defines the mechanisms and properties important both to the development of physical simulants for retrieval testing and the retrieval of actual waste. By defining these phenomena, process limits can be identified and data quality needs can be determined as some insight is gained about how important any particular property is to process performance. Baseline mobilization technologies include mixer pump technology, sluicing, and high-pressure water-jet cutting. Other processes that are discussed in this document include slurry formation, pneumatic conveyance, and slurry transport.

Section 2.0 gives a background of the DQO process and the different retrieval technologies. Section 3.0 provides the mechanistic descriptions and material properties critical to the different technologies and processes. Supplemental information on specific technologies and processes is provided in the appendices. Appendix A contains a preliminary sluicing model, and Appendices B and $C$ cover pneumatic transport and slurry transport, respectively, as prepared for this document. Appendix D contains sample calculations for various equations.

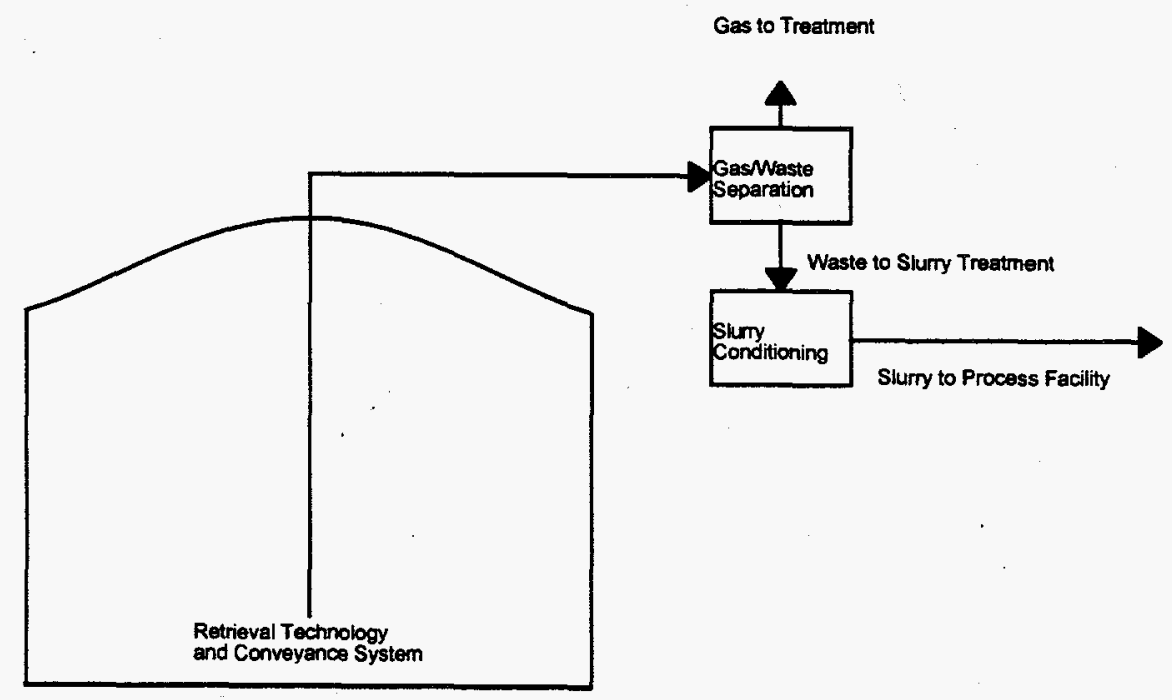

Figure 1.1. Waste Retrieval Application 


\subsection{Background}

Since 1989, the use of data quality objectives (DQO) has been part of the Hanford Federal Facility Agreement and Consent Order (Tri-Party Agreement) under Quality Assurance. DQOs are established to ensure that the data collected are sufficient and of adequate quality and accuracy for their intended uses for site-specific remedial response activities.

Three activities in particular have been identified as key retrieval processes. These are the sluicing, mixer pump, and scarifier end effector (water-jet cutting) technologies. Sluicing and waterjet cutting applications will be employed to retrieve waste from the SSTs (single-shell tanks); the mixer pumps will be used for the retrieval of waste from the DSTs (double-shell tanks). The background information for these technologies is described in the following sections.

\subsection{Sluicing}

All of the past retrieval operations on the Hanford Site used the sluicing method for tank cleanout. The principle behind medium-pressure (approximately $150 \mathrm{psi}$ ) sluicing is to use kinetic energy, delivered by the sluice jet, to fluidize and/or dissolve the waste. It is also used to move the waste as a slurry to a discharge pump, from which the slurry is transferred out of the tank. The equipment and technologies used were based on mining industry practices and adapted for use in radioactive service. Although equipment failures and process limitations occurred, the campaigns were generally successful and achieved a high overall removal efficiency. The materials retrieved during sluicing were a variety of sludges. Salt-cake, which constitutes more than two-thirds of the current SST inventory, was not a waste form involved in these early retrieval efforts.

Two major tank waste retrieval sluicing campaigns have taken place at the Hanford Site. From 1952 to 1957, retrieval operations were conducted in seven tank farms involving forty-three SSTs as part of a process to recover uranium from the Bismuth Phosphate Plant waste. The materials retrieved were sludges that ranged in density from 1.8 to $2 \mathrm{~g} / \mathrm{ml}$. A total of $3.57 \mathrm{Mgal}$ of sludges and 18.64 Mgal of supernatant were retrieved during this campaign. A second campaign, from 1962 to 1978 , involved the retrieval of strontium-bearing waste from ten SSTs at the 241-A and AX tank farms. The purpose of these sluicing operations was to provide adequate confinement for high-level waste (separation of strontium and cesium from the bulk of the waste for separate storage), to reduce waste volumes, and to remove single-shell tanks from liquid storage. The sludge densities from these tanks ranged from 1.3 to $1.99 \mathrm{~g} / \mathrm{ml}$ and a total of $1.235 \mathrm{Mgal}$ was retrieved during the campaign. Three tanks from the A-farm and two from the AX-farm were cleaned to the degree that they were approved for salt-cake storage. The remaining tanks.were stabilized and isolated.

The next two sections provide a brief history of the conditions leading to the sluicing campaigns.

\subsubsection{The First Campaign (1952-1957)}

The Bismuth Phosphate Plants (BPP), T-plant and B-plant, recovered plutonium from the irradiated uranium slugs beginning in 1944 and 1945 , respectively. The uranium slugs were processed in B-plant until 1953, and in T-plant until 1956. In 1952, the Redox Process came on-line, and uranium slugs were processed using both the Redox and the Bismuth Phosphate process until 1956. Since uranium was not recovered in the BPPs, it was discharged along with the bulk of the radioactive fission products and stored in the single-shell underground tanks (SSTs). One of the processes of recovering uranium from the effluents of the BPP's involved sluicing the underground storage tanks.

Before the sluicing operations began, supernatant, or water, was transferred to a sludge accumulation tank in one of the four process vaults located at the BX-, C-, TX-, and U-farms. The supernatant or water from the sludge accumulation tank was then pumped back into the tank being cleaned through nozzles that produced a high-velocity jet. The action of the jet on the surface of the 
sludge resulted in the formation of a slurry, which was pumped back to the accumulation tank. Some of the solids in the slurry settled in the accumulation tank, and the supernatant, along with any remaining solids, were recirculated to the tank being cleaned. Recirculation continued until the desired concentration of solids was obtained in the accumulation tank, which is when sluicing was halted, and the slurry in the accumulation tank was transferred to a blend tank. The accumulation tank was then refilled with supernatant, and sluicing continued. This procedure was repeated until the underground storage tank was emptied of the sludge it contained.

\subsubsection{The Second Campaign (1962-1978)}

The A- and AX-farms were filled with waste from the Plutonium and Uranium Extraction (PUREX) processing facility during the 1950s and 1960s. At PUREX, plutonium, uranium, neptunium, and thorium were extracted from the process stream resulting from the dissolution of fuel elements. The remaining solution, which contained both long-lived and short-lived isotopes, was discharged to the tank farms. After approximately five years, the short-lived isotopes present in the tanks decayed, leaving mainly two isotopes; these were cesium (half life of ${ }^{137} \mathrm{Cs}=30.23+/-0.16$ years) and strontium (half-life of $90 \mathrm{Sr}=28.1$ years). (a) These components were the major heatproducing elements in the tanks. Strontium was found to be mainly present in the sludge layer that formed when the tanks were initially filled. The majority of the cesium present in the tanks was dissolved in the supernatant. As a result, both the sludge and the supernatant in the A- and AXfarms contained heat-producing isotopes.

Separating the cesium from the liquid waste was relatively straight forward; it involved transferring of the supernatant to B-plant and removing the cesium by ion exchange. However, extracting the strontium from the sludge required sluicing, which was the only developed sludgeretrieval technique available at the time. Test sluicing began in 1964, and actual sluicing operations began in A-farm in 1968.

The sluicing operations used during the 1960s and 1970s were nearly identical to those used in the 1950's. First, the supernatant was pumped from the tank to be sluiced to another tank for temporary storage. The retained supernatant was then pumped through the nozzle in the sluice tank and impinged on the sludge surface. The action of the liquid stream resuspended the solids, and a transfer pump returned the slurry to the accumulation tank. Liquid was recirculated through the sluicing nozzle until 2000 to 3000 gallons of sludge were retrieved. Sluicing was then halted and flocculant was added to the accumulation tank. Once the solids had settled, the supernatant layer above the concentrated slurry layer was returned to the sluice tank. Then, the concentrated slurry was transferred to the acidification tank for dissolution in nitric acid. The supernatant that had been pumped to the sluice tank was pumped back to the accumulation tank for use as the sluicing medium during the next sluicing cycle. Sluicing operations were halted in 1978.

\subsection{Mixer Pump}

Under the proposed campaign, jet mixer pumps will be placed into the double shell tanks to stir up (mobilize) the sludge and form a uniform slurry suitable for pumping to downstream processing facilities. These mixer pumps utilize powerful jets of tank fluid directed out of two nozzles pointed in diametrically opposed directions near the tank bottom. These fluid jets impinge upon the sludge bank and stir up the tank sludge. The amount of sludge mobilized by the mixer pump jet depends not only on the power of the jets, but also on the ability of the sludge to resist the jets.

The mixer pump mobilizes the settled sludge into the supernatant and creates a slurry suitable for transfer to the receiver tank or for in-tank washing. Each mixer pump takes in the slurry from the bottom of the tank and discharges the fluid horizontally through two opposing nozzles (located approximately 18-in. from the tank bottom). Simultaneously, the nozzle assembly oscillates approximately 180 degrees at a low rate (e.g., $<0.2 \mathrm{rpm})$, sweeping the jet past the sludge and

(a) CRC Handbook of Chemistry and Physics, 63rd edition, Section B, Pages 291 and 274. 
mobilizing more of the sludge with each pass. The pumps will be made of stainless steel to provide prolonged pump life and to facilitate mixer-pump cleaning and disposal. The number of mixer pumps required for each tank and the capacity of the pumps will be determined by a) the available riser size and the riser locations in the tank; b) the capacity of the mixer pump, which determines the effective cleaning radius (ECR); c) how much waste removal is required.

The capacity of the mixer pump can be stated in terms of nozzle diameter (D) and the nozzle discharge velocity $\left(\mathrm{U}_{\mathrm{O}}\right)$. The current plan is to purchase the highest capacity pumps that will fit into the existing riser sizes. The distance from a jet nozzle of the mixer pump to the most distant sludge it can mobilize is the key measure of mixing pump performance and is referred to as the ECR. The current methodology uses sludge shear strength and jet parameters to predict the ECR. Sludge dissolution is expected to result in enhanced sludge mobilization, which will increase the ECR. Density and viscosity as functions of the dilution rate may only have minor effects on the ECR; the density has a direct effect on the pump power requirements. Viscosity has only a minor effect on mixer-pump design.

The number of mixer pumps required depends on how much waste removal is needed. It is assumed that at least $90 \%$ but less than $100 \%$ of the waste will be retrieved from the DSTs. The horsepower requirements are set by the exit velocity $\left(U_{0}\right)$, nozzle diameter (D), and the waste properties, primarily density. Pump horsepower is only slightly affected by viscosity. The mixer pumps are expected to be between 100 and $500 \mathrm{hp}$.

\subsection{Scarifier End Effector (Water-Jet Cutting)}

End effectors will be deployed to retrieve waste remaining after sluicing and mixer pump operations. Salt cake waste will be retrieved using a scarifier equipped with a water-jet cutting tool. Sludge waste will be retrieved using a confined sluicing end effector. These two systems differ by their operating conditions: the water-jet tool uses a small volume of water at high pressures (about $50,000 \mathrm{psi}$ ) to mobilize waste, while the confined sluicing tool uses a higher volume of water at lower pressures (about 5,000 psi).

An air conveyance system will be used in conjunction with the water-jet tool for moving waste out of the SSTs to the above-ground retrieval facility. This system suspends solid particles or liquid in a high-velocity air stream and conveys it to a separator at the above-ground facility. This stream will handle solids, slurries, and viscous liquids.

Scarifying is a method of waste retrieval that limits the cleanup area, controls the water input, and monitors the waste output. This is accomplished by placing water jets under an enclosure and providing a continuous removal system. The equipment for scarifying consists of a high-pressure water supply, rotating water jets, a vacuum pickup, and a confinement dome. Water is dislodged by the jets and removed by the vacuum conveyance system. This method uses significantly less water than sluicing methods. In some applications, the water jets may be replaced with air jets to dislodge sludge and therefore add no water to the tank or waste.

The system would be mounted on a telescopic boom that enters the waste tank through a 1.1-m diameter riser. The pneumatic conveyance inlet would be mated to the scarifier shroud. The scarifier's gross position would be controlled by the telescoping boom. The scarifier system includes high-pressure jets (with supply lines and high-pressure intensifier), shroud and plenum to encase the jets and mate with the pneumatic conveyance components, and sensors to assess the waste type and the rate of dislodging. The conveyance system includes vacuum piping, a positive displacement blower, sensors (pressure drop, flowrate, and flow regime), a cyclone separator, a filter to remove any small particles or moisture not removed in the cyclone separator, and a high-efficiency particulate air (HEPA) filter system.

As part of an evaluation done by Westinghouse Hanford Company (WHC), air and water scarifiers were tested as potential tools for retrieving waste from SSTs. These scarifiers were tested on hard salt 
cake, soft salt cake, and sludge simulants. Air jets were found to be effective in cutting and dislodging soft salt cake and sludge, while only water jets were able to cut hard salt cake. With development, the scarifier was recommended as a tool for hard waste dislodging and final tank cleanup. This scarifier design did not seem well suited for soft salt cake or sludge retrieval. Data from these tests are applicable to the confined sluicing end effector. 


\subsection{Retrieval Processes and Technologies}

\subsection{Sluicing}

The mechanism of sluicing is the mobilization of waste by transfer of energy from a highvolume, high-velocity water jet to the waste bed. Although sluicing is an old practice (used over 100 years ago in the mining industry), it is a low-technology method and not much is known to correlate waste characterization with sluicing effectiveness. Therefore, models must be developed between the material properties of the waste and the performance of the sluicing system. After such models have been developed, waste characterization data are needed to predict the retrieval system's performance.

A preliminary model of the sluicing process has been developed in an effort to identify the most important waste and sluice jet properties (see Appendix A). This model was developed primarily to explain the sluicing of sludge wastes, but can possibly be extended to saltcake waste.

The retrieval of waste by sluicing has two important steps: to dislodge waste, and to maintain the waste in suspension. To dislodge the waste, the sluicing stream impacts the waste bank, and induces a mechanical disruption in the waste if the impact force is sufficient. The ability to suspend the waste particles in the slurry for transport requires the transfer of enough energy from the sluice stream to overcome the mechanical strength of the waste.

The process of mobilizing waste requires a significant pressure distribution in the sluicing stream. Summers $(\mathrm{a})$ provides data indicating that material removal rates are linearly tied to the impact pressure of the sluice jet, provided that some minimum threshold impact pressure is exceeded. Assuming this relationship applies to waste, the sluicing retrieval rate can be estimated by integrating over the area of maximum impact pressure, as well as over the region from the maximum to where to the jet pressure is zero:

$$
M=K\left(2 \pi \int_{0}^{\frac{D_{j}}{2}-\frac{H_{l i q}}{14}}\left(J-P_{t}\right) r d r+2 \pi \int_{\frac{D_{j}}{2}-\frac{H_{\text {liq }}}{14}}^{n}\left(\frac{-7 J}{H_{l i q}} r+\frac{J}{2}\left(\frac{7 D_{j}}{H_{l i q}}+1\right)-P_{t}\right) r d r\right)
$$

where $J, P[=] \mathrm{Pa}$

$H, D[=] \mathrm{m}$

The value of $K$ is found from a plot of retrieval rate $(M)$ versus maximum jet impact pressure $(J)$ (see Appendix A, page 6); $D_{j}$ is the diameter of the jet profile with the maximum jet impact pressure; $H_{\text {liq }}$ is the standing height of the liquid above the waste; and $r_{t}$ is the radial position within the jet beyond which the jet pressure is less than the threshold mobilization pressure $\left(P_{t}\right)$. The above expression can be integrated to give

$$
M=2 \pi K\left(\frac{\left(\mathrm{J}-\mathrm{P}_{t}\right)}{2}\left(\frac{D_{j}}{2}-\frac{H_{\text {liq }}}{14}\right)^{2}+\frac{-7 J}{3 H_{l i q}}\left(r_{t}^{3}-\left(\frac{D_{j}}{2}-\frac{H_{l i q}}{14}\right)^{3}\right)+\left(\frac{J}{4}\left(\frac{7 D_{j}}{H_{l i q}}+1\right)-\frac{P_{t}}{2}\right)\left(r_{t}^{2}-\left(\frac{D_{j}}{2}-\frac{H_{l i q}}{14}\right)^{2}\right)\right)
$$

Appendix A gives equations for $J$ and $D_{j}$ that can be substituted into the above equation to solve for rate of mobilization in terms of the process variables of initial jet impact pressure, nozzle design effects, nozzle diameter, standoff distance, and standing liquid thickness.

(a) Summers, D. 1993. Draft. Water-Jetting Technology. University of Missouri-Rolla, Rolla, Missouri. 
Because no testing has been performed to evaluate the accuracy of this sluicing model, the properties that control the value of $K$ have not been identified. It is expected, however, that $K$ takes into account the combined effects of salt dissolution; particle or grain size/shape distribution, which is related to porosity; and other effects. Without knowing the contributing properties to the constant $K$, it is difficult to say which properties are most important.

There is evidence, however, that shear strength, $\tau_{\mathrm{s}}$, may be related to the threshold mobilization pressure, $P_{t}$ (see page 7, Appendix A). It is suspected that $P_{t}$ varies linearly with $\tau_{s}$ according to the equation $P_{t}=10 \tau_{s}$. Neglecting variation in the constant $K$, this model predicts relatively constant sluicing retrieval rates with shear strengths from 0 to $5000 \mathrm{~Pa}$ for an assumed jet pressure of $1 \mathrm{MPa}$ (see Figure 3.1). Beyond $5000 \mathrm{~Pa}$, the measured value of shear strength becomes more important. As an example, for a shear strength of $2000 \mathrm{~Pa}, \mathrm{a} \pm$ $50 \%$ measurement error in shear strength results in only a 3\% error in retrieval rate; however, for a shear strength of $5000 \mathrm{~Pa}$, a $50 \%$ measurement error in the shear strength will cause an error of up to $38 \%$ in the retrieval rate.

Retrieval Rate vs. Shear Strength (Pa)

Initial Jet Pressure $=1 \mathrm{MPa}$, Stand-off Distance=3 m, D=2.54 cm, $\mathrm{H=5} \mathrm{cm}$

(Taken from MR Powell)

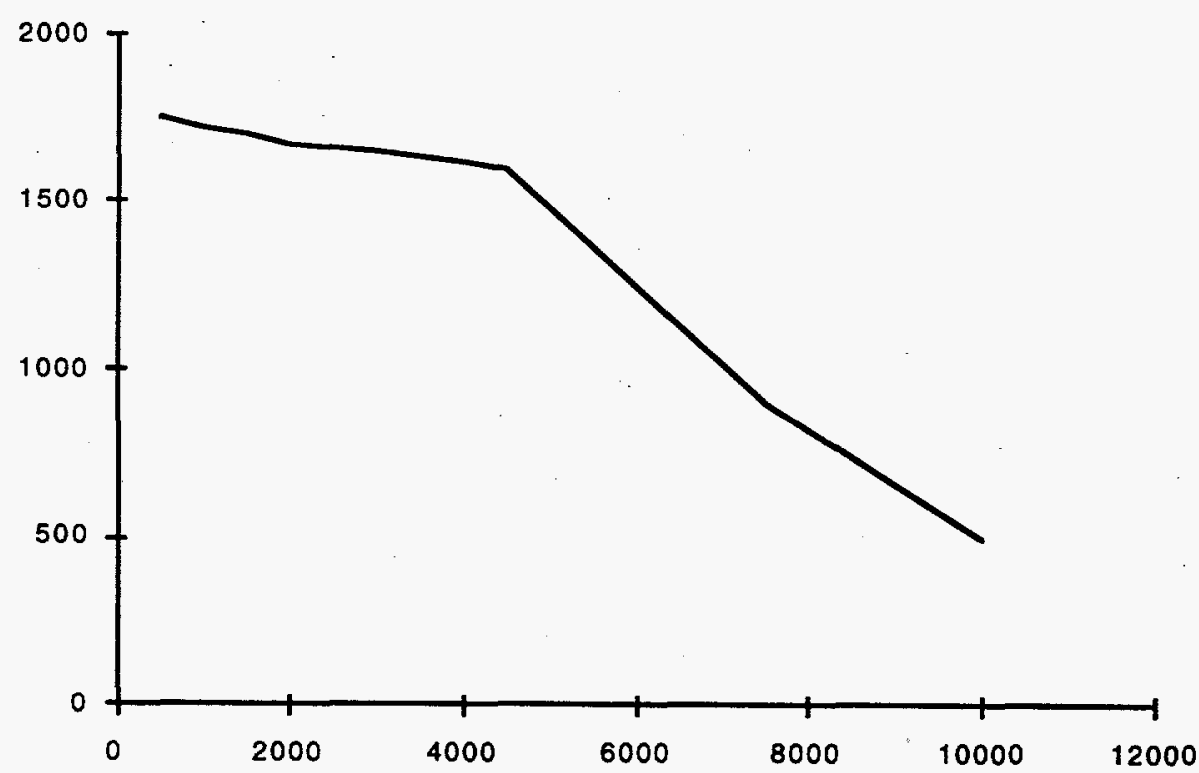

Figure 3.1. Retrieval Rate Versus Shear Strength $(\mathrm{Pa})$ Initial Jet Pressure $=1 \mathrm{MPa}$, Stand-Off Distance $=3 \mathrm{~m}, \mathrm{D}=2.54 \mathrm{~cm}, \mathrm{H}=5 \mathrm{~cm}$ (Taken from Appendix A)

\subsection{Mixer Pump}

The mixer pump jets mobilize sludge by a combination of erosion and bulk mobilization. As shearing fluid flow stresses are induced on a surface, erosion occurs when individual particles, or small particle aggregates, are worked loose from the surface and entrained in the moving fluid. The resistance of the sludge to erosion is principally a function of the sludge cohesion. When the mixer pump jets are powerful enough to break the sludge into relatively large (centimeter-sized) pieces, bulk mobilization occurs. Bulk mobilization results when the applied shearing stress exceeds the shear strength of the sludge. Sludge shear strength is thought to provide the most direct measure of bulk mobilization resistance. 
Sludge cohesion provides erosion resistance. Conceptually, cohesion is the strength of actual interparticle bonds consisting of physical and chemical forces. An attempt was made to correlate this property with the cleaning ability of a mixer pump (Powell et al. 1995a) by measuring the tensile strength of the material, which is a direct measurement of cohesion. However, measuring the tensile strength proved difficult. Shear strength measurement techniques are better developed and some success was achieved correlating mixer pump performance with shear strength. The data indicated, however, that only the portion of shear strength that is due to cohesion is useful for predicting mixer pump performance. Thus, if shear strength measurements are used, the shear strength data must be adjusted to account for the fact that a portion of the shear strength is not due to cohesion. Although a method has not been developed to predict the fraction of shear strength due to cohesion, it is expected that the 1/25-th scale mobilization correlation will likely under-predict the ECR in those cases where the shear strength is not actually due only to cohesion.

The correlation developed by Powell et al. of Pacific Northwest Laboratory (PNL) ${ }^{(a)}$ relates the ECR of a mixer pump to the shear strength of sludge:(b)

$$
\frac{E C R}{U_{0} D}=K \tau_{s, a d j}^{-n}
$$

where $E C R$ is the effective cleaning radius of the mixer pump,

$\tau_{s, \text { adj }}$ is the cohesive portion of the shear strength,

$U_{o} D$ is a measure of the mobilizing force of the jet,

and $K$ and $\mathrm{n}$ are empirical constants.

During sludge mobilization testing, Powell et al. used various mixtures of bentonite and kaolin clays as simulants. Bentonite clay has a specific surface area about $800 \mathrm{~m}^{2} / \mathrm{g}$; the mobilization of the bentonite-based simulants was found to be strongly dependent on the simulant shear strength. Kaolin clay has larger particles and a much lower specific surface area $\left(-10 \mathrm{~m}^{2} / \mathrm{g}\right)$; the mobilization resistance $\left(U_{0} D / E C R\right)$ of the kaolin simulants was mostly independent of shear strength. The conclusion drawn from the mobilization experiments was that simulants with specific surface areas greater than about $35 \mathrm{~m}^{2} / \mathrm{g}$ all behave similarly. That is, for all simulants with specific surface areas greater than $35 \mathrm{~m}^{2} / \mathrm{g}$, a single ' $\mathrm{n}$ ' and ' $\mathrm{K}$ ' will fit the mobilization data. Simulants with specific surface areas lower than $35 \mathrm{~m}^{2} / \mathrm{g}$ require different ' $n$ ' and ' $K$ ' values, depending on the actual value of the specific surface area.

These results apply specifically to sludges that derive their shear strength from interparticle attractive forces (e.g., van der Waals) and interparticle friction. Whether these results can be extended to include sludges with different mechanisms of shear strength development has not been determined. Examples of these alternative mechanisms include crystal growths between particles, which serve to bind the particles together, and the fusing of particles at their contact points.

Provided that a sludge is principally cohesive (i.e., specific surface area $>35 \mathrm{~m}^{2} / \mathrm{g}$ ), the sludge property that must be measured is the shear strength. If the specific surface area is less than $35 \mathrm{~m} / \mathrm{g}$, then some adjustment to the shear strength is required before the ECR correlation can be used. The nature of this adjustment has not yet been established. However, it is expected that sludges with a specific surface area $<35 \mathrm{~m}^{2} / \mathrm{g}$ will be easier to mobilize than the $>35 \mathrm{~m}^{2} / \mathrm{g}$ sludges.

(a) Pacific Northwest Laboratory is operated for the U.S. Department of Energy by Battelle Memorial Institute under Contract DE-AC06-76RLO 1830.

(b) This correlation was developed using $1 / 25$-scale tests. The validity of this work for full scale predictions has yet to be verified experimentally. 
Experiments have been performed that give different values for the constants $\mathrm{K}$ and $\mathrm{n}$. 1/12-scale testing(a) with simulants that have shear strengths from $4-17 \mathrm{kdynes} / \mathrm{cm}^{2}-12$ data points, 9 of which have shear strengths $\sim 10 \mathrm{kdynes} / \mathrm{cm}^{2}-$ gave values of $\mathrm{K}=17.3$ and $\mathrm{n}=0.67$. $1 / 25$-scale testing (Powell et al. 1995b) gave values of $K=2.3$ and $n=0.41$, but used simulants with a wider range of shear strength values $-2-100 \mathrm{kdynes} / \mathrm{cm}^{2}$. The constants based on $1 / 12$-scale testing give more conservative calculations of ECR than those from $1 / 25$-scale testing, but were determined from a limited amount of data over a more limited range of shear strength. More testing, using simulants with a wider range of shear strength, is required at 1/12-scale before either set of constants can be used with confidence.

Based on the propagation of error, the error of waste mobilized resulting from an error in measuring the sludge shear strength can be determined by the following correlation:

where

$$
\varepsilon_{v o l .}=100 \%\left(\frac{\left|\frac{d V}{d \tau}\right| \delta_{\tau}}{V}\right)
$$

$$
\begin{aligned}
& \delta_{\tau}=\varepsilon_{\tau} \tau \\
& V=\pi h\left(2.3 U_{o} D \tau_{s}^{-0.41}\right)^{2} \\
& \frac{d V}{d \tau}=-.82 \pi\left(2.3 U_{o} D\right)^{2} \tau_{s}^{-1.82}
\end{aligned}
$$

It can be found from this equation that if there is $10 \%$ error $\left(\varepsilon_{\tau}=0.10\right)$ arising from the measurement of shear strength, there will be approximately a $8.2 \%$ error in the amount of waste mobilized.

\subsection{Slurry Formation}

Slurry formation is the suspension of mobilized waste solids in a liquid stream prior to introduction to the conveyance line. There are three major design concerns involving slurry formation. These include the size of the particles being mobilized, keeping the waste in suspension before the conveyance line inlet, and ensuring that the waste agglomerates are small enough to be transported through the conveyance line.

Appendix A describes a mechanism for the breaking up of waste to a size characteristic of that caused by the applied shear of an impinging sluice jet. When the imposed shear field exceeds the material's shear strength, the material breaks into smaller agglomerates, and continues to do so as long as the mechanical shear is imposed until a characteristic size is achieved. Using assumptions described in Appendix A, the following hypothetical correlation between sluicing jet pressure $(J)$, shear strength $\left(\tau_{s}\right)$, standing liquid height $\left(H_{l i q}\right)$, and characteristic size $(a)$ can be derived:

$$
a=\frac{2 \tau_{s} H_{l i q}}{7 J}
$$

Equations relating characteristic size to material properties and operating conditions for other retrieval operations do not exist. During mixer pump sludge mobilization testing, however, it has

(a) Fow, C. L., P. A. Scott, G. A. Whyatt, and C. M. Ruecker. 1987. Pilot-Scale Retrieval Tests Using Simulated NCAW. 7W21-87-15, Letter Report for Westinghouse Hanford Company. Pacific Northwest Laboratory, Richland, Washington. 
been observed that large chunks of cohesive material remained on the bottom of the tank (Powell 1995a); this imposes a need to predict when such chunks may be encountered.

The size of particles collected by the conveyance system is dependent on the efficiency of waste collection by the retrieval pump. If the retrieval system only creates waste chunks larger than $1 \mathrm{~cm}$, the collection efficiency will not be very high because these pieces will settle very rapidly. If smaller particles, on the order of $<10 \mu \mathrm{m}$, are created, then nearly all are expected to be removed from the tank. This is supported by considering the settling rate of particles in a non-turbulent pool of water and the residence time of chunks in the tank. If the residence time of the chunks in the tank is less than the settling time for the chunks in a still pool of water, then it is reasonable to expect them to make it to the inlet of the conveyance line. Also, the fact that portions of the waste may be highly turbulent during retrieval operations implies that the settling time will be increased.

The final concern for the designer is to know if the waste chunks are smaller than the maximum aggregate size transportable by the conveyance system. If the particles, or chunks, are larger than the system can handle, it will be necessary to further process them in order to achieve a size that can be conveyed by the conveyance or transport line. One possible solution is to allow an additional amount of time for the waste to dissolve. This approach may not be appropriate if the time required is too great, or if the waste is insoluble, but would save the expense of additional development, equipment contamination, and personnel exposure. By measuring the amount of waste that dissolves in water as a function of time, the feasibility of this approach could be determined.

\subsection{Water-Jet Cutting(a)}

Water-jet cutting is a process by which a high-energy water jet strikes a surface and breaks it apart by crack formation. The efficiency of this process is defined by the power of the jet (shape and pressure profile) and the interaction of the jet with the target surface (crack formation). Waste dislodgment is currently being studied experimentally by the PNL Waste Dislodging \& Conveyance team (WD\&C), which includes Professor David Summers (University of Missouri-Rolla), in support of project W-340. Summers, in particular, studies the mechanism of mechanical failure by water-jet cutting. Equipment and mechanism theory development are also performed by Quest Integrated, Inc., of Seattle, Washington.

The controlling physical parameters in water jetting are likely to be grain or crystal size, as related to porosity, and the tensile strength of the saltcake. The failure of the target surface, therefore, is controlled by the grain size and the strength of the material at the crack tip but is equally controlled by the jet pressure profile. Other important properties are density, fracture toughness, and hardness.

Once the jet leaves the originating nozzle, the jet pressure is reduced as the water column rubs against the surrounding stationary air. This rapidly changes the pressure profile across the jet from an initially constant value to one where the pressure builds, from zero at the outside, to a peak in the center of a roughly bell-shaped distribution. The rate of change in this shape varies with the jet pressure and the jet diameter. Once the full shape is developed, the jet will begin to break into segments within a short distance; these segments will turn into droplets. Droplets rapidly break into smaller droplets and lose both velocity and cutting power with additional distance from the nozzle.

When the jet strikes the surface, the water will penetrate the surface cracks with an ease controlled by the jet fluid viscosity and relative surface tension. The depth of a typical crack is controlled by the grain size of the target material. The pressure required to increase the size of the crack will be a function of the crack length and the surrounding stress field. Pressure will be evenly distributed over the target surface under the jet, and thus there will be no failure (even though the pressure is at a maximum level). Material removal or erosion will occur only at the perimeter of the impact zone where the differential pressure across a grain is high. As the impact pressure is increased, however,

(a) Information concerning Water-jet cutting, and its application to waste retrieval, was obtained through communications with the members of the WD\&C simulant development and scarifier development team. 
circumferential cracks are generated around the impact zone. Because of the stepped nature of the surface at these cracks, the subsequent flow of fluid over the surface will initiate erosion at this location. As the target moves away from the nozzle, the pressure profile will become such that there is a differential across the entire radius, and at that time failure will occur across the entire jet width.

Failure of a smooth, homogeneous surface is initiated by the opening of surface fractures. These fractures will grow from existing smaller flaws located between grains and from those openings due to porosity. Significant surface tensile stresses are generated in the surface, which is sufficient to open cracks around the perimeter of the impact point. Water-jet cutting then occurs from the filling of these cracks and pressurization by the impact of the water jet.

In general, the material properties in order of importance are: 1) grain/crystal size: this controls crack growth and must be initiated for material removal to occur as related to porosity; 2) tensile strength: this controls the rate at which the failure progresses.

\subsection{Waste Dissolution}

Salt cake waste was formed from the accumulation of sodium salts as a result of reprocessing spent nuclear fuels from Hanford's nuclear reactors. Neutralization of nitric acid waste, which contained fission products, formed sodium nitrate, the principal salt. Other sodium salts were added during various processing steps. The most abundant salts are $\mathrm{NaNO}_{3}, \mathrm{NaNO}_{2}, \mathrm{NaOH}, \mathrm{NaAlO}_{2}$, $\mathrm{Na}_{2} \mathrm{SO}_{4}$, and $\mathrm{Na}_{2} \mathrm{CO}_{3}$. Compared with these salts, radioactive salts compose only a small fraction of the total volume.

Barney (1976) performed solubility experiments with the sodium salts in water. In each experiment, the aqueous phase was saturated with $\mathrm{NaNO}_{3}, \mathrm{NaNO}_{2}, \mathrm{NaAlO}_{2}, \mathrm{Na}_{2} \mathrm{SO}_{4}$, and $\mathrm{Na}_{2} \mathrm{CO}_{3}$; according to Barney, this closely simulated the waste conditions during the evaporation and storage processes for interstitial liquor mixtures of the salt cake. The concentration of sodium hydroxide was varied in each of the experiments; this was done because a wide range of this salt was found, and it is known to strongly influence the solubility of other salts.

During the retrieval and transport of Hanford waste, it is necessary to predict the identity of crystalline products. The precipitation of aluminum compounds, for example, must be avoided to prevent the formation of very small crystals that may agglomerate with other waste constituents to form aggregates that may hinder transport. Barney provides solubility curves giving conditions that should be maintained in order to keep aluminate and other salts in solution.

Figure 3.2 shows the solubilities of aluminum salts as a function of $\mathrm{NaOH}$ concentration and temperature. The graph shows that below a $\mathrm{NaOH}$ concentration of $\sim 2 \mathrm{M}, \mathrm{Al}(\mathrm{OH})_{3}$ precipitates at high $\mathrm{NaAlO}_{2}$ concentrations, while at higher $\mathrm{NaOH}$ concentrations, $\mathrm{NaAlO}_{2} \cdot 1.25 \mathrm{H}_{2} \mathrm{O}$ precipitates. The recommended operating condition of the transport line is at the $\mathrm{NaOH}$ concentration that allows maximum solubility of aluminate salts while the solubility of the other salts remains high.

The graphs of the other solubility curves (Figures 3.3 through 3.6) are provided for comparison to the aluminate solubility curve. Barney suggests that the increase in solubility of the other salts below a $\mathrm{NaOH}$ concentration of $\sim 2 \mathrm{M}$ may be a common ion effect due to the rapid decrease in solubility of $\mathrm{NaAlO}_{2}$ below this $\mathrm{NaOH}$ concentration. The solubility curves for the aluminate system do not indicate any temperature dependency between $20^{\circ}$ and $80^{\circ} \mathrm{C}$, and the increase in solubility with temperature for other salts was only noticed at higher $\mathrm{NaOH}$ concentrations.

The parameters that are critical to waste dissolution for salt cake materials are salt solubility and $\mathrm{NaOH}$ concentration. 


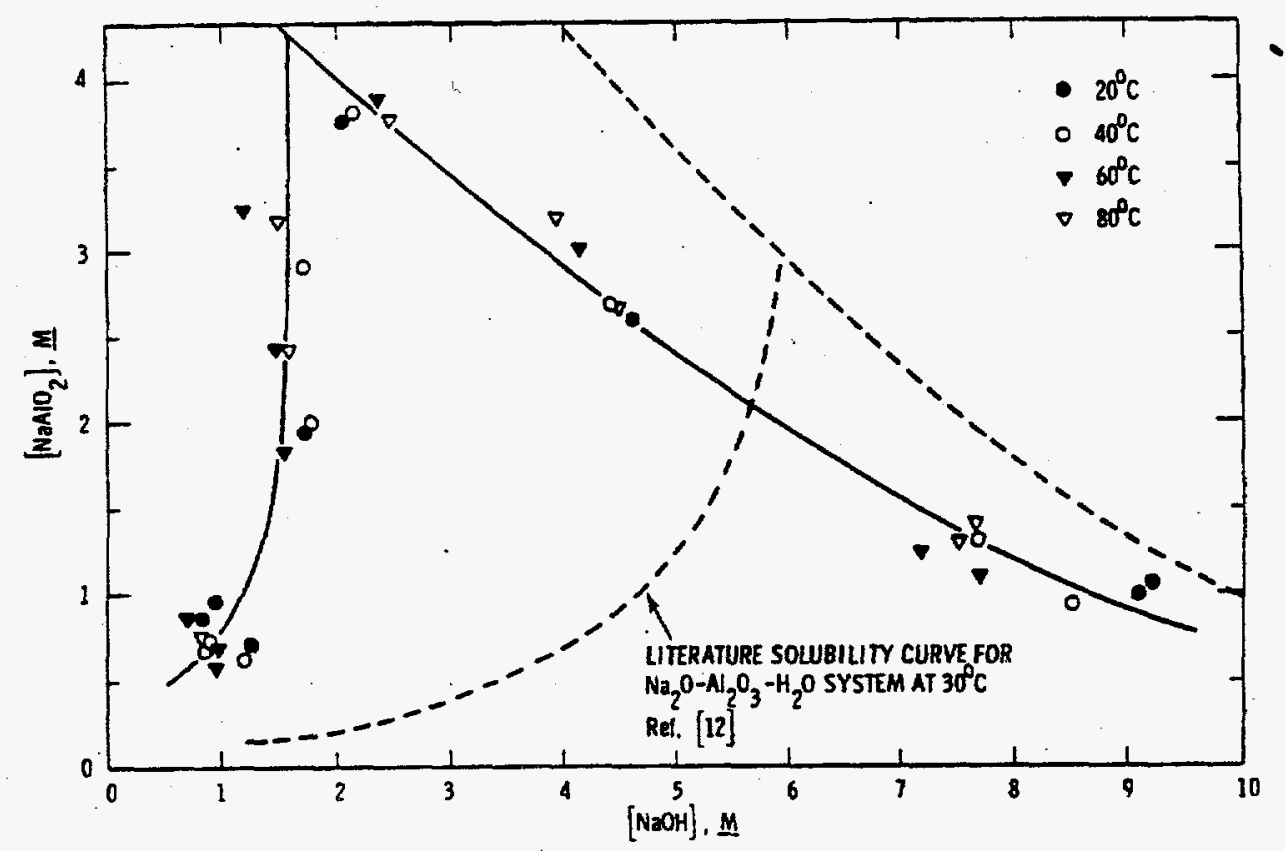

Figure 3.2. Solubility of $\mathrm{NaAlO}_{2}$ Relative to $\mathrm{NaOH}$ Concentration. Taken from Barney (1976) ARH-ST-133 Ref. [12] F. V. Vol'f and S. I. Kuznetsov, Ah. Prikl. Khim., 28; 597 (1955) Reference used to demonstrate difference in solubility due to presence of multiple salts ( reference curves are for $\mathrm{Na}_{2} \mathrm{O}-\mathrm{Al}_{2} \mathrm{O}_{3}-\mathrm{H}_{2} \mathrm{O}$ system).

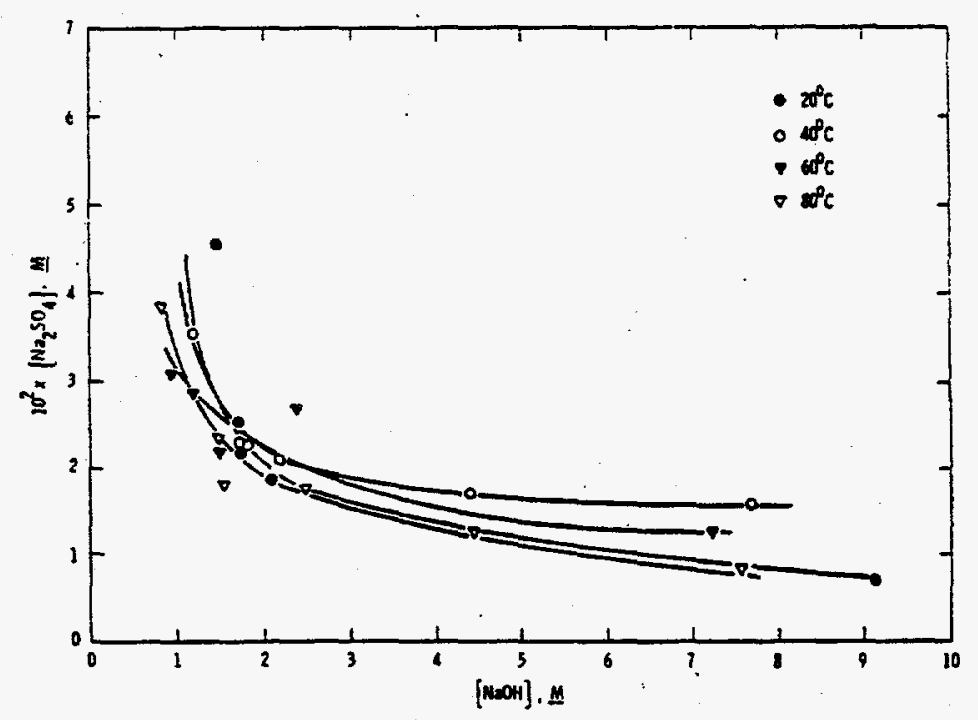

Figure 3.3. Solubility of $\mathrm{NaNO}_{2}$ Relative to $\mathrm{NaOH}$ Concentration Taken from Barney (1976) ARH-ST-133 


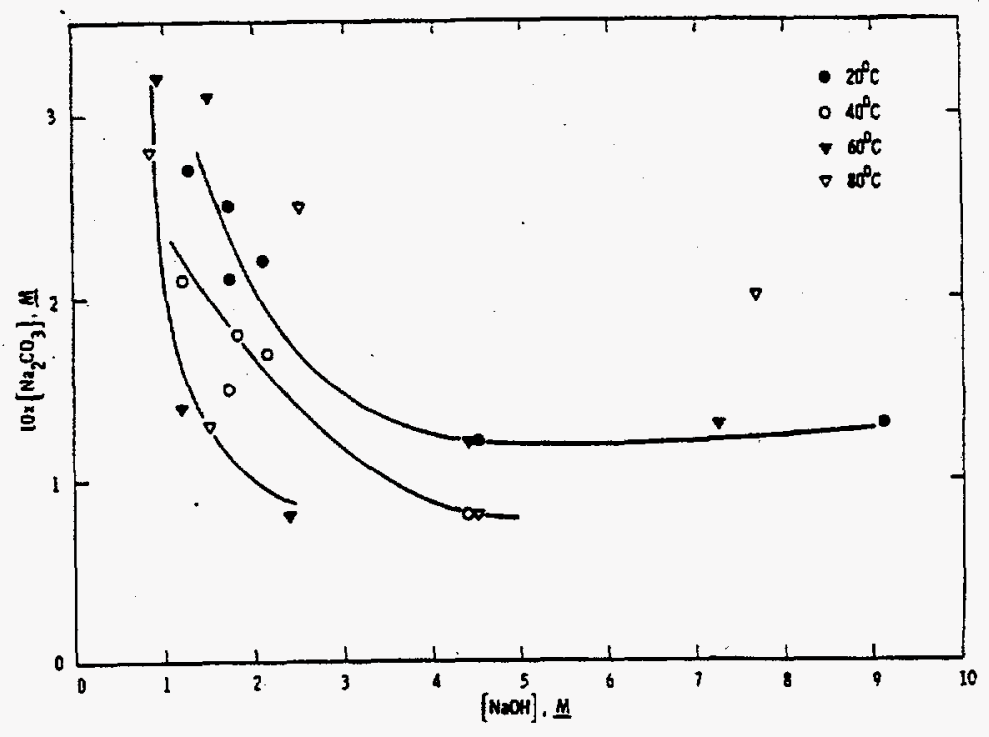

Figure 3.4. Solubility of $\mathrm{NaNO}_{3}$ Relative to $\mathrm{NaOH}$ Concentration Taken from Barney (1976) ARH-ST-133

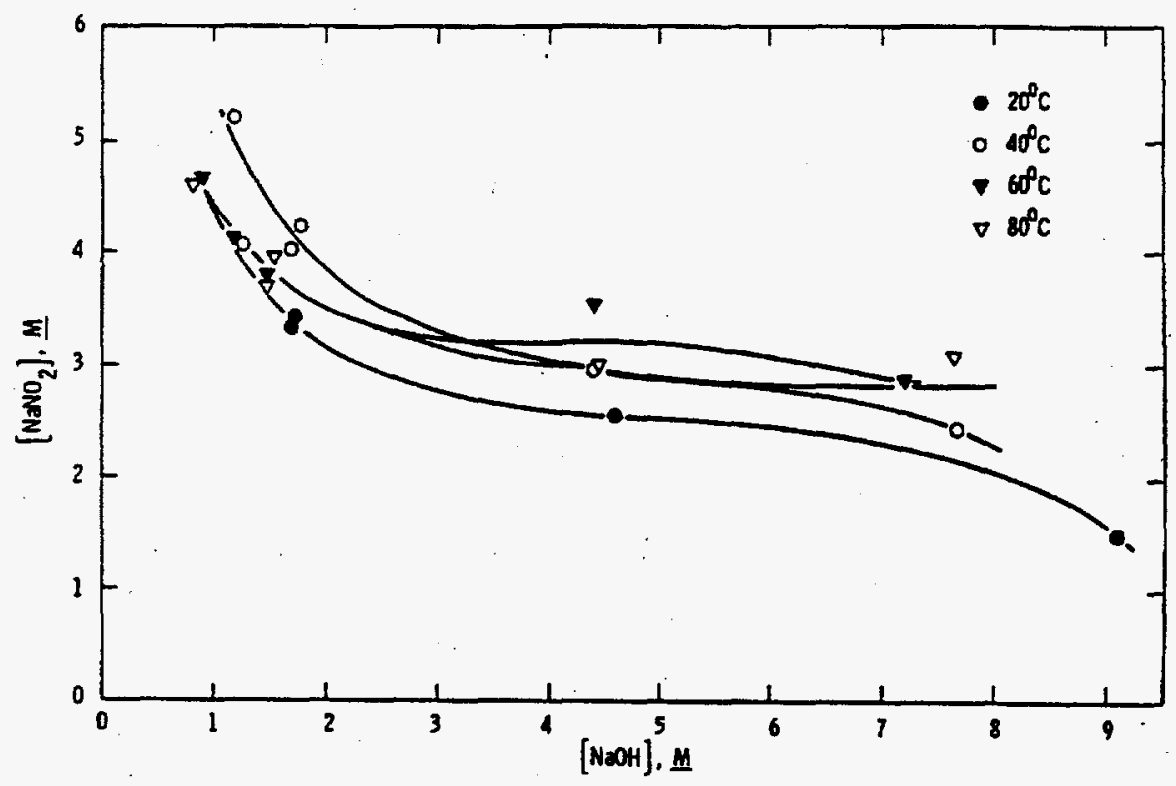

Figure 3.5. Solubility of $\mathrm{Na}_{2} \mathrm{SO}_{4}$ Relative to $\mathrm{NaOH}$ Concentration Taken from Barney (1976) ARH-ST-133 


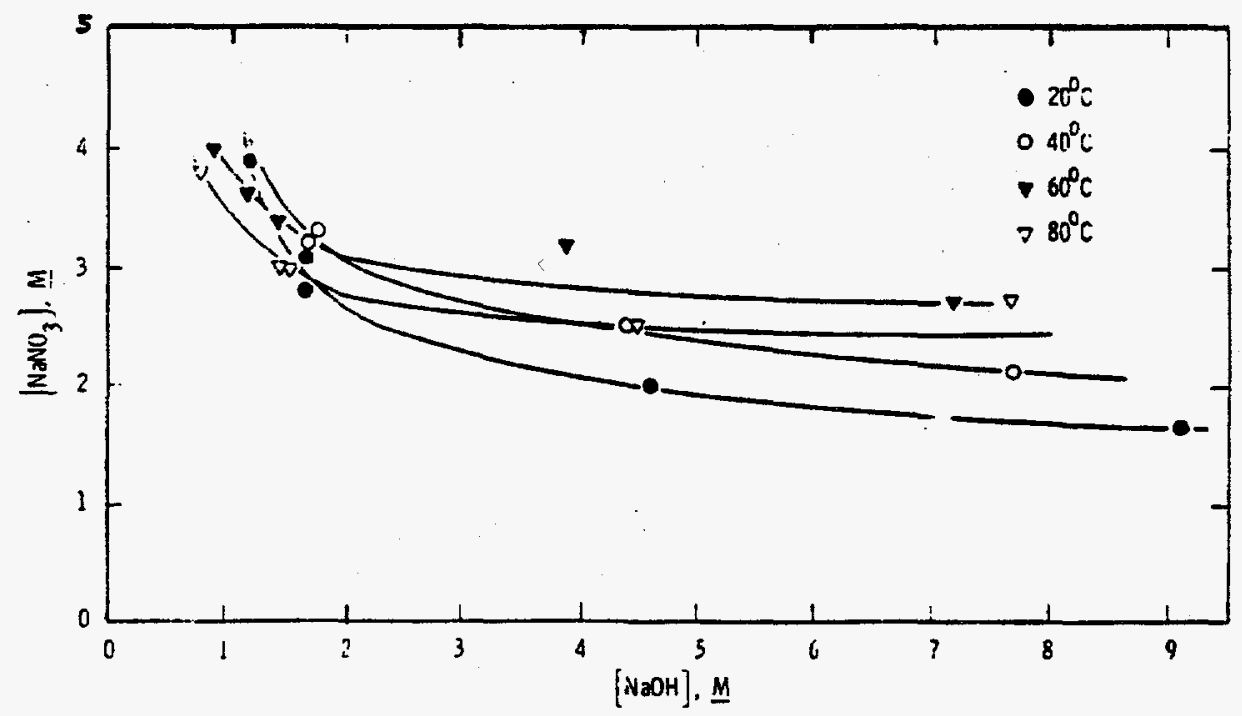

Figure 3.6. Solubility of $\mathrm{Na}_{2} \mathrm{CO}_{3}$ Relative to $\mathrm{NaOH}$ Concentration Taken from Barney (1976) ARH-ST-133

\subsection{Pneumatic Conveyance}

The process of pneumatically conveying waste out of a tank is currently under investigation by the Waste Dislodging \& Conveyance (WD\&C) activity. Suggested correlations have not been verified by testing. Erian's description of the pneumatic conveyance problem is attached as Appendix B.(a)

Pneumatic conveying of dry solid particles is an established technology; however, current correlations describing the conveyance of dry particles (Govier and Aziz 1977) do not apply to wet mobilized tank waste. The objective of the tank waste conveyance operation is to prevent the accumulation and adherence of sticky sludge materials on the conveyance line pipe wall. Erian has suggested that this problem may be overcome by injecting a lubricating film of water over the inner surface of the conveying line; effectively this would create an annular flow condition with fluid flow on the inner surface of the line, and gas-particulate flow through the core of the line. This high air superficial velocity in the core region will be sufficient to transport dispersed water droplets, atomized viscous liquid, sticky sludge particles, and solid particles. The existence of the lubricating film minimizes the chance of the sticky material adhering to the wall, thus allowing continuous transport of multi-form waste.

In the absence of comprehensive theory for annular fluid flow with the conveyance of solid particles, Erian suggests the following assumption for particle transport: particles shall be transported when the solid phase velocity exceeds the particle settling velocity. Erian provides the following particle-settling rate equations for different ranges of characteristic particle Reynolds numbers:

(a) Erian, F. F. March 6, 1995. "On the Design of Pneumatic Transport Pipelines." Attached as Appendix B of this document. 


$$
\begin{aligned}
& w=\frac{d^{2}\left(\rho_{s}-\rho_{l}\right) g}{18 \mu_{l}}, 0<\operatorname{Re}_{p}<2 \\
& w=\frac{0.153\left[g\left(\rho_{s}-\rho_{l}\right)\right]^{0.173} d^{1.143}}{\rho_{l}^{0.286} \mu_{l}^{0.428}}, 2 \leq \operatorname{Re}_{p}<500 \\
& w=1.74\left[\frac{g d\left(\rho_{s}-\rho_{l}\right)}{\rho_{l}}\right]^{0.5}, 500 \leq \operatorname{Re}_{p}<200,000
\end{aligned}
$$

where $w=$ settling rate

$\operatorname{Re}_{\mathrm{p}}=$ Particle Reynolds Number

$g=$ gravitational acceleration

$d=$ average particle diameter

$\rho_{s}=$ solids density

$\rho l=$ liquid density

$\mu l=$ liquid viscosity

The solids velocity can be approximated as the difference between the solid waste retrieval rate (per cross-sectional area of the conveyance line) and the particle settling rate by assuming that the waste is retrieved as it is mobilized (i.e., there is no accumulation of waste after mobilization), and by assuming a vertical direction of flow:

$$
V_{s}=\frac{M_{s}}{C S A_{\text {pipe }}}-w
$$

where $V_{s}$ is the solids velocity,

$M_{s}$ is the solids retrieval rate in units of volume per unit time,

$C S A_{\text {pipe }}$ is the cross sectional area of the conveyance line,

and $w$ is the settling rate of the solid particles.

Although the above equation determines whether the waste will be conveyed, it is necessary to determine if the value of $V_{s}$ is feasible with the limited pressure drop in the conveyance line. To do this, Erian proposes an approach that combines the requirements of dry pneumatic conveyance with two-phase annular dispersed flow. This approach is suggested because it will describe the required pressure drop to sustain conveyance of dry solids and annular gas-liquid flow. This approach requires separately calculating the pressure drop for pneumatic conveyance of dry solids and annular dispersed flow. Erian gives the following equation for pneumatic conveyance of dry solids:

$$
-\left(\frac{d P}{d L}\right)_{\substack{P . C . \\ \text { of solids }}}=\frac{f_{g} \rho_{g} V_{g}^{2}}{2 D}+\frac{1}{2}\left(\frac{f_{g}}{D}\right)\left(\frac{f_{s}}{f_{g}}\right)\left(\frac{F_{s}}{A}\right)\left(V_{g}-V_{w} \sqrt{\alpha}\right)+\frac{F_{s} g \Delta H}{A V_{s} \Delta L}+\frac{\alpha F_{s} g}{A\left(V_{g}-V_{w} \sqrt{\alpha}\right)}
$$

where $P=$ local pressure $\left(\mathrm{lb}_{\mathrm{f}} / \mathrm{ft}^{2}\right)$

$L=$ length along the pipe (ft)

$f_{g}=$ friction factor for the gas phase

$f_{s}=$ friction factor for the solids phase

$D=$ pipe diameter $(\mathrm{ft})$

$F_{s}=$ solids mass flow rate $\left(\mathrm{lb}_{\mathrm{m}} / \mathrm{s}\right)$

$A=$ pipe cross sectional area $\left(\mathrm{ft}^{2}\right)$

$g=$ gravitational acceleration $\left(32.2 \mathrm{ft} / \mathrm{s}^{2}\right)$ 


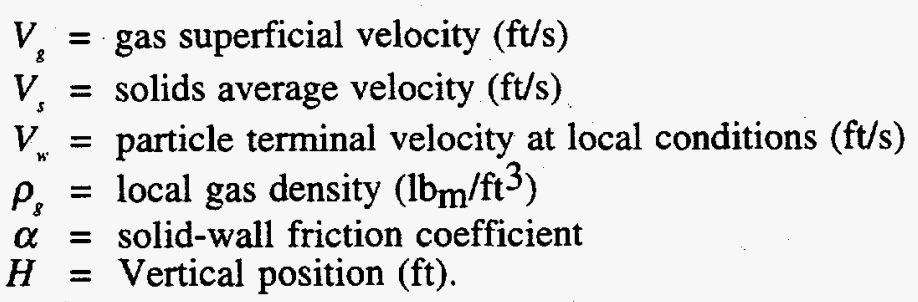

In order to use this equation to calculate the pressure drop, it is necessary to determine the gas velocity. Since the pressure drop for annular dispersed flow is highly dependent on gas phase velocity, it is reasonable to set the gas phase velocity above the minimum velocity required to sustain annular dispersed flow. Erian gives the following equation for the minimum gas phase velocity required to maintain annular dispersed flow:

$$
U_{g, \text { Min. }}=\left(\frac{4 K}{3 C_{D}}\right)^{1 / 4} \frac{\left[\sigma g\left(\rho_{l}-\rho_{g}\right)\right]^{1 / 4}}{\rho_{g}^{1 / 2}}
$$

with $K=30$ and $C_{d}=0.44$ as suggested by Turner (reference 4, Appendix B) where $\sigma$ is the surface tension of the liquid phase. It should be noted that this is the minimum gas phase velocity. The operating velocity should be maintained above this value; however, the available pressure drop is limited, and should be reserved to convey waste. At this point, the designer should calculate the pressure drop for pneumatic conveyance: if it is greater than the available pressure drop, the waste cannot be conveyed, and it is then necessary either to reduce the waste retrieval rate, or to further process the waste in-tank to reduce the waste-settling rate.

The remainder of the conveyance problem is to determine the pressure drop required to maintain annular dispersed flow. The purpose of combining pneumatic solids conveyance with annular dispersed flow is to coat the conveyance line with a film of water to prevent waste from clogging the line during operation. There are two constraints on the amount of water added to the conveyance line: the upper constraint is that the amount of liquid must be sufficiently small so as not to allow churn flow (as described by Erian in Appendix B), and the lower is that the amount of liquid be sufficient to prevent waste from adhering to the pipe wall. It should be noted, however, that the larger the superficial liquid flowrate, the larger the pressure drop for annular dispersed flow will be. Since the allowable pressure drop is limited to less than one atmosphere, experimentation is required to develop a correlation between the minimum liquid velocity and the allowable pressure drop. Levy (1966) determined the pressure drop in two-phase gas-liquid flow in a vertical pipe:

$$
-\frac{d p}{d L}=\left[\frac{g\left(V_{1} r_{1}+V_{g} r_{g}\right)}{V_{1}+V_{g}}\right]+\frac{0.43}{2 D^{12}}\left(\frac{\sigma}{73}\right)^{0.4}+\left[\left(V_{1}+V_{8}\right)\left(V_{8} r_{8}+V_{1} r_{1}\right)\right]^{0.75}
$$

where $V=$ the velocity of the phase $(\mathrm{g}=$ gas, $1=$ liquid $)$

$\sigma=$ the surface tension of the liquid (dyne-cm), and other variables are as defined above.

When the pressure drop is calculated with this equation, it should be added to the pressure drop required for pneumatic conveyance of dry solids. Since the pressure drop is limited, the following rule applies:

$$
\left(-\left.\frac{d p}{d L}\right|_{\text {P.C. }}\right)+\left(-\left.\frac{d p}{d L}\right|_{A . D .}\right)=\left(-\left.\frac{d p}{d L}\right|_{\text {Toral }}\right) \leq 1 \text { atm }
$$

If the pressure drop due to annular dispersed flow causes the calculated total pressure drop to rise above 1 atmosphere, it will be necessary to reduce both pressure drop requirements by either changing the waste retrieval rate and waste settling rate to reduce the pressure drop for pneumatic conveyance of solids, or by reducing the liquid flow rate for annular dispersed flow. 
The above algorithm requires the following characterization: densities of all phases, the surface tension of the liquid, the intrinsic viscosity of the gas in the stream, and the particle size distribution to calculate settling rates.

\subsection{Slurry Transport}

The critical design concerns for the slurry transport operations of Hanford waste are related to chemical and physical properties. The chemical properties of a slurry affect the build-up of scale, and also particle agglomeration, gelation, and crystallization. Physical properties affect the particle settling, which may result in forming a stationary bed in the pipeline. Correlations that relate slurry chemistry to flow parameters have not been developed. Observations based on non-reacting slurries have resulted in the formulation of the critical velocity. This parameter is the minimum velocity that must be maintained to prevent a stationary bed of waste from forming. Although this correlation provides a starting point, slurry chemistry must be incorporated to obtain a full understanding of reacting systems.

The phenomena associated with the chemical properties of a slurry include crystallization, gelation, and the build-up of scale on the walls of the transport piping. Precipitation of aluminate was discussed in Section 3.5, where it was stated that the concentration of $\mathrm{NaOH}$ must be controlled to balance the precipitation of aluminate with other hydrolysis products. McKay et al. (a) cites the effects of solution $\mathrm{pH}$, temperature, and concentration of soluble species on the precipitation of hydrolysis products. As an additional solid phase is formed in the slurry pipeline, the slurry's viscosity changes, which affects the flow conditions, and could change the flow pattern from turbulent to laminar; this would allow larger particles to settle and form a stationary bed.

Gelation is also a chemical concern to the designer. Most waste particles are expected to be smaller than $1 \mu \mathrm{m}$ in diameter, which distinguishes them as colloids. In dilute non-ionic suspensions, colloids will not interact, but as solution conditions change and hydrolysis products are formed, the particles can interact to form aggregates, which can alter the fluid rheology. A simple representation of how a gel forms is that as the solution chemistry changes, colloids form aggregates that begin to collide to form a matrix of connected colloidal particles. When a gel forms, the viscosity of the slurry may rise by a factor of $>200$, and is manifest by an elastic response to stress. The increase in slurry viscosity and the substance's elasticity may seriously inhibit the pump's performance; therefore, slurry conditions conducive to gel formation must be avoided. Past experience indicates that these types of chemical changes can be very rapid.

The formation of scale on the pipe walls is also a chemical concern. As supersaturated solutions of dissolved species nucleate, a scale forms on the pipe wall. This process depends on the attraction between the pipe surface and the nucleated species, as well as the solution's saturation level. The effect on the slurry transport pipeline is to reduce the effective cross-section; effectively, this burdens the pump, and may cause the transition of flow from turbulent to laminar.

The physical properties of the slurry affect the formation of stationary beds in the pipeline. Densities, viscosities, particle size distribution, and solids loading have an effect on bed formation. This phenomenon has been studied by Erian, (b) and is documented in Appendix C.

The critical velocity according to Erian is:

(a) McKay, R. L., C. J. Call, and E. A. Daymo. 1994. Methodology for Defining the Appropriate Tank Waste Properties for Transport. DSTRTP-CY94-031, Pacific Northwest Laboratory, Richland, Washington.

(b) Erian, F. F. March 1995. "On the Design of Long-Distance Slurry Pipelines." Attached as Appendix $\mathrm{C}$ of this document. 


$$
\begin{gathered}
U_{c}=80.75 w_{m}\left(\frac{\rho_{l}}{\bar{\rho}}\right)\left(\frac{\eta}{\mu_{l}}\right)^{0.14} \\
w_{m}=w \exp \left(-5.9 C_{\nu}\right)
\end{gathered}
$$

where $w_{m}$ is the hindered particle-settling rate for the median size particle (Govier and Aziz 1977), $\rho_{l}$ is the carrier liquid density, $\bar{\rho}$ is the average slurry density, $\mu_{l}$ is the carrier liquid viscosity, $w$ is the unhindered settling rate, $C_{v}$ is the volume fraction, and $\eta$ is the apparent viscosity of the slurry. Erian explains the critical velocity as the slurry velocity at which a stationary bed starts to form; below this velocity, particles begin to settle on the bottom of the pipe and form a stationary bed.

The different flow regimes are related to the solids concentration as distributed in a crosssection of slurry flow. At high slurry velocities, homogeneous flow is encountered as highintensity turbulence distributes particles uniformly over the pipe's cross-section. When the mixture velocity is reduced, a concentration profile appears along the vertical diameter where the bottom of the pipe is more concentrated than the top. Further reduction in mixture velocity leads to slurry flow at the critical velocity; below this velocity, a stationary bed forms on the bottom of the pipe.

Calculation of the critical velocity depends on the particle and slurry properties. Erian offers different equations for particle-settling rates; selection is based on the particle Reynolds number. Particle size, particle-settling rate, liquid density, and liquid viscosity are intrinsic to this parameter, and can be measured analytically. Since tank waste is not composed of uniform particles, it is necessary to define the particle size distribution and the effective particle size relative to shape effects. Erian reports that this may be done by determining the effective particle diameter, which can be attained through experimentation at conditions of equal drag coefficients for the different Reynolds number ranges.

The slurry properties important to the critical velocity calculation include the average slurry density, the carrier liquid density and viscosity, and the slurry viscosity. The average slurry density can be calculated with known quantities:

$$
\bar{\rho}=\bar{C} \rho_{s}+(1-\bar{C}) \rho_{l}
$$

where $\bar{C}$ is the average solids volume concentration. To model the slurry viscosity, Erian suggests using the Bingham-plastic model at a solids volume concentration greater than $20 \%$. The viscosity of lower solids concentration slurries may be modeled using the KriegerDougherty model.(a)

$$
\begin{aligned}
& \eta=\mu_{i} \exp \left[\frac{2.7 \bar{C}}{1-S \bar{C}}\right] \quad \text { Bingham-plastic Model } \\
& \eta=\mu_{i}\left[1-\frac{\bar{C}}{\overline{C_{\max }}}\right]^{-x_{i}\left(\overline{C_{m}}\right.} \quad \text { Krieger }- \text { Dougherty Model }
\end{aligned}
$$

where $\bar{C}$ is the volume concentration of particles, $\overline{C_{\max }}$ is the maximum solids loading, $S$ is an experimental parameter, and $K$ is a constant called the shape factor, which is related to how

(a) Call, C. J. 1994. "DST Slurry Simulant Development Phase I. Test Results." Letter Report. Pacific Northwest Laboratory, Richland, Washington. 
easy it is to transport the waste through the solution. These models are preliminary; others are under development in the W-211 project.

The uncertainty of the minimum-velocity equation is given by the propagation of uncertainty:

$$
\varepsilon_{U_{o}}=\sqrt{\varepsilon_{w_{p}}^{2}+\varepsilon_{\rho}^{2}+\left(0.14 \varepsilon_{\eta}\right)^{2}+\left(0.14 \varepsilon_{\mu}\right)^{2}}
$$

where the uncertainties of the settling rate and average slurry density are found by evaluating their partial differential equations relative to their independent variables:

$$
\begin{gathered}
\varepsilon_{w_{s}}=100 \% \frac{\sqrt{\left(\frac{\partial w_{p}}{\partial d} \delta_{d}\right)^{2}+\left(\frac{\partial w_{p}}{\partial \rho_{s}} \delta_{\rho_{1}}\right)^{2}+\left(\frac{\partial w_{p}}{\partial \rho_{l}} \delta_{\rho_{i}}\right)^{2}}}{w_{p}} \\
\varepsilon_{\bar{\rho}}=100 \% \frac{\sqrt{\left(\frac{\partial \bar{\rho}}{\partial \rho_{s}} \delta_{\rho_{s}}\right)^{2}+\left(\frac{\partial \bar{\rho}}{\partial \rho_{i}} \delta_{\rho_{i}}\right)^{2}}}{\bar{\rho}}
\end{gathered}
$$

Slurry transport is affected by chemical and physical phenomena. The properties important to precipitation, gelation, and scale formation include solution $\mathrm{pH}$, temperature, and soluble species concentration. Bed formation is affected by densities, viscosities, particle size distribution, solids loading, and settling rate. Since the chemical phenomena affect the physical behavior of the stream, it is expected that they will be the controlling factors of slurry transport performance.

The purposes of the preceding sections are to describe the mechanisms that are important to the retrieval of tank waste and to establish a basis for requesting characterization data by providing equations that will use those data. The intended use of these equations is to demonstrate a need for data and its required accuracy. The validity of these equations has not been established with fullscale testing, which should be done to provide a basis for equipment design. 


\subsection{References}

Barney, G. S. 1976. Vapor-Liquid-Solid Phase Equilibrium of Radioactive Sodium Salt Wastes at Hanford. ARH-ST-133, Atlantic Richfield Hanford Company, Richland, Washington.

Govier, G. R. and Aziz, K . 1977. The Flow of Complex Mixtures in Pipes. Robert E. Krieger Publishing Company, Malabar, Florida.

Levy, S. 1966. "Prediction of Two-Phase Annular Flow with Liquid Entrainment." International Journal of Heat and Mass Transfer. 9:171-188.

Powell, M. R., G. R. Golcar, C. R. Hymas, and R. L. McKay. 1995a. Fiscal Year 1993 1/25-Scale Sludge Mobilization Testing. PNL-10464, Pacific Northwest Laboratory, Richland, Washington.

Powell, M. R., C. M. Gates, M. A. Sprecher, and N. J. Morter. 1995b. Fiscal Year 1994 1/25-Scale Sludge Mobilization Testing. PNL-10482, Pacific Northwest Laboratory, Richland, Washington.

Summers, D. A., R. D. Fossey, M. D. Mann, and J. G. Blaine. 1994. Hazardous Waste Dislodging and Conveyance: The Confined Sluicing Method. PNL-10074, Pacific Northwest Laboratory, Richland, Washington.

Weast, R. C., and M. J. Astle, eds. 1983. CRC Handbook of Chemistry and Physics. 63rd edition. Chemical Rubber Publishing Company, Boca Raton, Florida. 


\subsection{Bibliography}

Bamberger, J. A., B. M. Wise, W. C. Miller. 1992. Retrieval Technology Development for Hanford Double-Shell Tanks. PNL-SA-20710, Pacific Northwest Laboratory, Richland, Washington.

Bamberger, J. A., J. M. Bates, J. K. Keska, M. R., N. J. Lombardo. 1993. Strategy to Develop and Test a Multi-Function Scarifier End Effector with an Integral Conveyance System for Waste Tank Remediation. PNL-8477, Pacific Northwest Laboratory, Richland, Washington.

Bamberger, J. A., M. A. McKinnon, D. A. Alberts, D. E. Steele, C. T. Crowe. 1994. Development of a Multi-Functional Scarifier Dislodger with an Integral Pneumatic Conveyance Retrieval System for Single-Shell Tank Remediation. PNL-8901, Pacific Northwest Laboratory, Richland, Washington.

Benson, S. W. 1982. The Foundations of Chemical Kinetics Chapter 15, Sections 3-5, R. E. Krieger, Melbourne, Florida.

Bhatia, P. K. 1993. Retrieval Technologies Characterization Data Needs. WHC-SD-WM-RD-039, Rev. 0, EDT \#129211, Westinghouse Hanford Company, Richland, Washington.

Cheremisinoff, N. P. ed., 1986. "Slurry Flow Technology." Encyclopedia of Fluid Mechanics. Vol. 5, Chapters 2-3, Gulf Publishing, Houston, Texas.

Golcar, G. R., C. M. Gates, A. S. Rizzo, and C. J. Call. 1994. Waste Dislodging and Conveyance FY94 Simulant Development Technology Progress Report Draft. Draft Report, Pacific Northwest Laboratory, Richland, Washington.

House, W. A. 1989. "The Kinetics of Crystallization of Solids from Aqueous Solution." Comprehensive Chemical Kinetics Vol. 28, Chapter 3, Elsevier Science Publishing Co., New York.

Krieg, S. A. 1990. Single-Shell Tank Waste Retrieval Study. WHC-EP-0352, Westinghouse Hanford Company, Richland, Washington.

Rodenhizer, P. G. 1987. Hanford Waste Tank Sluicing History. WHC-SD-WM-TI-302, Westinghouse Hanford Company, Richland, Washington.

Summers, D. 1993. "Water-jetting Technology." Draft Report, University of Missouri-Rolla, Rolla, Missouri.

Taylor, J. R. 1982. An Introduction to Error Analysis. University Science Books, Mill Valley, California.

Thielges, J. R. 1992. Waste Retrieval End Effector Evaluation; Project W139 WHC-SD-WI39-ES004, Rev. 0, Westinghouse Hanford Company, Richland, Washington.

Whyatt, G. A., C. L. Fow, M. R. Powell, and P. A. Scott. 1988. "FY 1988 Bench-Scale Sludge Mobilization Testing." Letter Report, Pacific Northwest Laboratory, Richland, Washington. 
Appendix A

Development of a Semi-Empirical Model for Waste Tank Sluicing 


\title{
Appendix A
}

\section{Development of a Semi-Empirical Model for Waste Tank Sluicing}

\author{
by \\ Mike R. Powell \\ March 10, 1995
}

Comprehensive models that describe the sluicing of radioactive waste have not yet been developed. Presented below is a rough framework from which model development can proceed. Sluicing models will be useful for interpreting the results of scaled testing as well as predicting behavior at full-scale in the absence of specific full-scale operational experience. The discussion that follows focuses primarily on the sluicing of sludge-type wastes because sludge simulants will be used exclusively during the initial pilot-scale testing. The model can be extended so that it applies to saltcake wastes provided that salt dissolution and saltcake fracture effects are incorporated.

The sluicing of radioactive waste sludge can be conceptually separated into three sequential steps. First, the sluicing jet issues from the in-tank nozzle to produce a coherent stream of fluid that impacts the sludge/slurry after traveling through the tank vapor space. Second, the jet impacts the waste and, if the impact force is sufficient, induces a mechanical disruption in the sludge. If pieces of the sludge are removed from the bulk, they may be as small as individual sludge particles or chunks up to several centimeters in dimension (depending upon the force of the jet and the mechanical/rheological properties of the sludge). Finally, the third step in the sequence involves the shearing and transport of the dislodged pieces of sludge to form a slurry that is pumped out of the tank by the retrieval pump.

To model the sluicing process, each of these three steps will be considered separately. The performance of the sluicing process is measured most directly by the waste retrieval rate, which is determined by the sum of all three steps. It is proposed that the following relationship be used for model development:

$$
S_{p}=M(L(J)) \cdot S(L(J))
$$

where $\quad S_{p}=$ sluicing system performance, $\mathrm{kg} / \mathrm{s}$ waste retrieved

$M=$ function describing response of bulk sludge to impinging sluice jet

$S \quad=$ function describing slurrying action of sluice jet on dislodged pieces of sludge

$J=$ function describing the properties of the jet prior to contacting the waste slurry

$L=$ function that describes effect of standing slurry liquid above sludge on the jet

As written, this equation is not useful for making predictions. Its only use is to show conceptually how the three steps outlined above are related to the sluicing effectiveness. The jet is produced at the jet nozzle and travels through the tank vapor space until it impacts the waste slurry. This process is described by the function " $J$." Changes in the fluid's exit-velocity profile (determined by nozzle design and entrance conditions), sluice fluid flow, nozzle diameter, fluid rheology, standoff distance, and the tank's vapor space conditions all enter into determining the function " $J$."

The function " $L$ " acts on the value given by " $J$ " to account for the effect the layer of standing liquid above the sludge has on the sluicing jet. If, for example, there is no liquid layer present such that the jet can impact directly upon the sludge surface, then the value given by $L(J)$ is equal to the value of $J$. Since the standing liquid layer is most likely to reduce the effectiveness of the sluice stream, it would be reasonable to expect that $L(J)$ ranges in value from 0 to $J$.

The functions $M$ and $S$ describe the action of the jet reaching the sludge surface on the bulk sludge and the resulting pieces of sludge. $M$ is determined by the mechanical and rheological properties of the sludge as well as the dislodging potential of the impinging sluice stream, which is 
given by $L(J)$. The sludge properties thought to determine $M$ are addressed below. $S$ accounts for the slurrying action of the jet upon the dislodged pieces of sludge material. The local shear rates within the region of jet impact as well as any tendency of the waste to imbibe water and disperse are included in $S$.

Candidate relationships for $M, S, J$, and $L$ are developed below. It must be stressed that these are preliminary relationships developed based on data obtained to support similar, but different, processes (e.g., sluice mining for gold). These proposed correlations will need to be supported and refined by test data developed using waste simulants and from data gathered during previous Hanford tank sluicing campaigns.

\section{Function J: Sluice Jet Travel Through Tank Vapor Space}

The behavior of water-in-air fluid jets has received considerable attention from various industries. High-pressure water-in-air jets are used in materials processing to cut complex shapes at high traverse rates and in the mining industry for the cutting of rock. Lower-pressure jets are used for sluice mining of clays, coal, and gold as well as by fire protection personnel. It is the lower-pressure jets that are most relevant to the Hanford sluicing process, but much of the research into high-pressure jet behavior can also be applied to the lower-pressure case.

Nozzle design can greatly affect the rate at which a sluicing jet will break up and lose its effectiveness. The stream issuing from a poor nozzle will rapidly break apart into a mist of droplets, which is generally ineffective for the mobilization of sludge-like materials. By contrast, a welldesigned nozzle can result in a coherent jet stream that extends beyond 100 nozzle diameters downstream before losing significant jet velocity due to breakup. It seems likely that sluicing performance is maximized by utilizing a nozzle that produces the most coherent jet stream (i.e., one that resists breaking up). Therefore, the effect of a nozzle design flaw is to decrease the actual jet performance from that expected from an ideal jet. As a first approximation, the effect of nozzle design will be taken into account using a scalar multiplier, $\mathrm{C}_{\mathrm{N}}$, which ranges in value from 0 to 1 . At $\mathrm{C}_{\mathrm{N}}=1$, the nozzle produces an ideal fluid jet stream (e.g., the most coherent jet achievable). More poorly designed nozzles will have lower values for $\mathrm{C}_{\mathrm{N}}$. Due to the extensive amount of research that has previously been done to improve jet nozzles, it is expected that the Hanford sluicing nozzles will have a $\mathrm{C}_{\mathrm{N}}$ of approximately 1.0 .

As the sluicing stream travels through the tank's vapor space towards the sludge, momentum is lost to the surrounding air due to shear at the surface of the jet. This momentum loss, in conjunction with surface-tension effects, eventually breaks up the jet into droplets, which very rapidly lose their momentum. This effect has been studied by researchers in the waterjet and mining industries. Summers (1994) presents data from other investigators that indicate a very rapid loss of water-in-air jet momentum occurs at downstream distances of approximately 100 nozzle diameters. This implies that the jet produced by a $2.5 \mathrm{~cm}$ nozzle will break up at a distance of about 2.5 meters.

At distances beyond 100 diameters, the jet pressure, which is proportional to the fluid density times the square of the bulk velocity, will decay roughly in inverse proportion to the downstream distance. Summers (1994) gives the following relationship between initial jet pressure and downstream jet pressure:

$$
P_{k t}=240 P_{\text {int }}-\left(\frac{x}{D}\right)^{-1.19}
$$

where

$$
\begin{array}{ll}
P_{\text {jet }} & =\text { Downstream jet impact pressure } \\
P_{\text {init }} & =\text { Jet impact pressure at nozzle exit } \\
x & =\text { downstream distance } \\
D & =\text { nozzle diameter }(x / D>100) .
\end{array}
$$

Summers (1994) also provides data that show the retrieval rate of clay undergoing sluice mining 
is linearly related to the jet's maximum impact pressure once the impact pressure exceeds some threshold level. Based on this, it is appears that the jet pressure may be the jet property that will most conveniently correlate to the sluicing retrieval rate.

It is proposed that the function $J$, which describes the flight of the sluice stream through the tank's vapor space, be given by

$$
J=240 C_{N} P_{\text {init }}\left(\frac{x}{D}\right)^{-119} \quad x / D>100
$$

This equation is valid only for downstream distances greater than about 100 nozzle diameters. Smaller distances will need to be addressed using a correlation that has not yet been identified. Given the currently planned sluicing system designs, most of the operation will be conducted using distances greater than 100 diameters. As shown above, $J$ has units of pressure $(\mathrm{Pa})$.

This equation will serve as a baseline from which improved relationships will be derived based on testing. It is implied in this equation that the performance of the sluicing system will degrade with increasing distance to the sludge. Summers (1994) presents some sluice mining data that support this, but other research ${ }^{(a)}$ implies that sluicing may be better than the equation for $J$ would indicate at distances of approximately 300 diameters.

\section{Function L: Inhibition of Jet by Standing Fluid Layer:}

During portions of the sluicing operation it is likely that pools of sluice liquid will accumulate. When the sluice stream is directed at the sludge beneath these pools, the jet effectiveness is reduced by the loss of jet momentum to the fluid covering the sludge. The jet reaching the sludge surface then imparts a reduced pressure force. This results in a reduced rate of sludge mobilization.

When the sluice stream enters a layer of liquid, its behavior transitions from that of a water-in-air jet to a submerged jet. The rate of decay of a jet's impact pressure is much more rapid for a submerged jet than for a water-in-air jet. The stagnation pressure decay for submerged radial wall jets is given by Rajaratnam (1976) as

$$
P_{s}=\frac{50}{(H / D)^{2}} P_{\text {init }}
$$

where $H$ is the standoff distance between the submerged jet's origin and the planar target. This relationship applies only for standoff distances greater than about 7 nozzle diameters. In the zone between 0 and 7 nozzle diameters, the stagnation pressure is relatively constant and equal to the initial jet pressure. The distribution of the jet energy, however, changes in this region. As the jet travels through the first 7 diameters, it loses momentum to the surrounding fluid primarily through shear along the cylindrical surface of the jet. At a distance of about 7 diameters, however, turbulent eddies penetrate into the core of the jet and decrease the maximum fluid velocity within the jet. Jet pressure loss in the region beyond 7 diameters is dominated by the action of the turbulent eddies.

Given that a reasonable sluicing nozzle diameter is about $2.5 \mathrm{~cm}$, it seems likely that the region of submerged jet behavior that is of interest for sluicing is in the 0-to-7-diameter range. Further literature review is required to determine whether correlations for this zone have already been generated. As a starting basis it is proposed that the maximum impact pressure between 0 and 7 diameters be assumed to be constant. The area over which this maximum acts, however, should

(a) Platt, E. A., and R. B. Carr. 1975. "Science and Technology: Fluid Jets: Enhanced Cutting in the Far Zone at Lower Pressures." Energy and Technology Review. Lawrence Livermore Lab. UCRL-52000-75-11. Nov. 1975. 
decrease from a maximum at 0 diameters to near zero at 7 diameters. This region of maximum pressure acts through a conical volume with its base at the nozzle exit and apex near 7 diameters downstream. The pressure distribution outside this conical region will be assumed to decay radially via an assumed function.

To account for the presence of the liquid layer that may interfere with the sluice stream, the following relationship is proposed. It has been assumed that the pressure decays linearly with radial distance beyond the conical region of constant jet pressure. The rate of linear decay is assumed to be such that at 7 diameters downstream the pressure decays from the maximum at the centerline to zero at a radial distance of 1 jet diameter. Efforts will be made to improve these assumptions through the use of correlations that may be available in the literature. The pressure distribution that results from these assumptions is:

$$
\begin{gathered}
L(r)=J \quad \text { for } r<_{-} \frac{D_{j}}{2}-\frac{H_{\text {liq }}}{14} \\
L(r)=\left(\frac{-7 J}{H_{\text {liq }}}\right) r+\frac{J}{2}\left(\frac{7 D_{j}}{H_{\text {liq }}}+1\right) \text { for } \frac{D_{j}}{2}-\frac{H_{\text {liq }}}{14}<r<\frac{D_{j}}{2}+\frac{H_{\text {liq }}}{14}
\end{gathered}
$$

where

$$
\begin{aligned}
& H_{l i q}=\text { thickness of slurry layer covering the sludge } \\
& J \quad=\text { pressure of sluicing jet just prior to contacting the slurry layer } \\
& r \quad=\text { radial distance outward from jet centerline } \\
& D_{j} \quad=\text { diameter of sluicing jet just prior to contacting the slurry layer }
\end{aligned}
$$

The value of $D_{j}$ is given by empirical relationships provided by Summers (1994). For the sluicing nozzle standoff distances of primary interest (e.g., $x / D>125$ ), the jet diameter is given by:

$$
D_{\mathrm{j}}=\left(0.021 \frac{x}{D}-0.27\right) D
$$

where $D$ refers to the nozzle diameter.

The equations given above provide a rough estimate of the pressure distribution applied to the sludge by the sluice stream. This pressure distribution will be utilized by the next function to be developed, which is the sludge mobilization response function $(M)$. It should be noted that the equations above do not account for the entrainment of air by the sluice stream as it enters the slurry layer. Air entrainment would be expected to improve the effectiveness of the jet by reducing momentum transfer between the jet fluid and the slurry layer. The importance of this effect is not known at this time.

\section{Function M: Mobilization of Sludge by Impinging Fluid Stream}

The sluice stream will impact the sludge surface with the pressure distribution given by the function $L(r)$ shown above. Summers (1994) provides data that show the relationship between material recovery rates and jet pressure for sluice mining operations. Below some material-dependent threshold impact pressure $\left(P_{t}\right)$, the sluice jet gives negligible erosion rates. Beyond $P_{t}$, however, increases in impact pressure result in proportional increases in material recovery rates as shown in Figure A.1, below. 


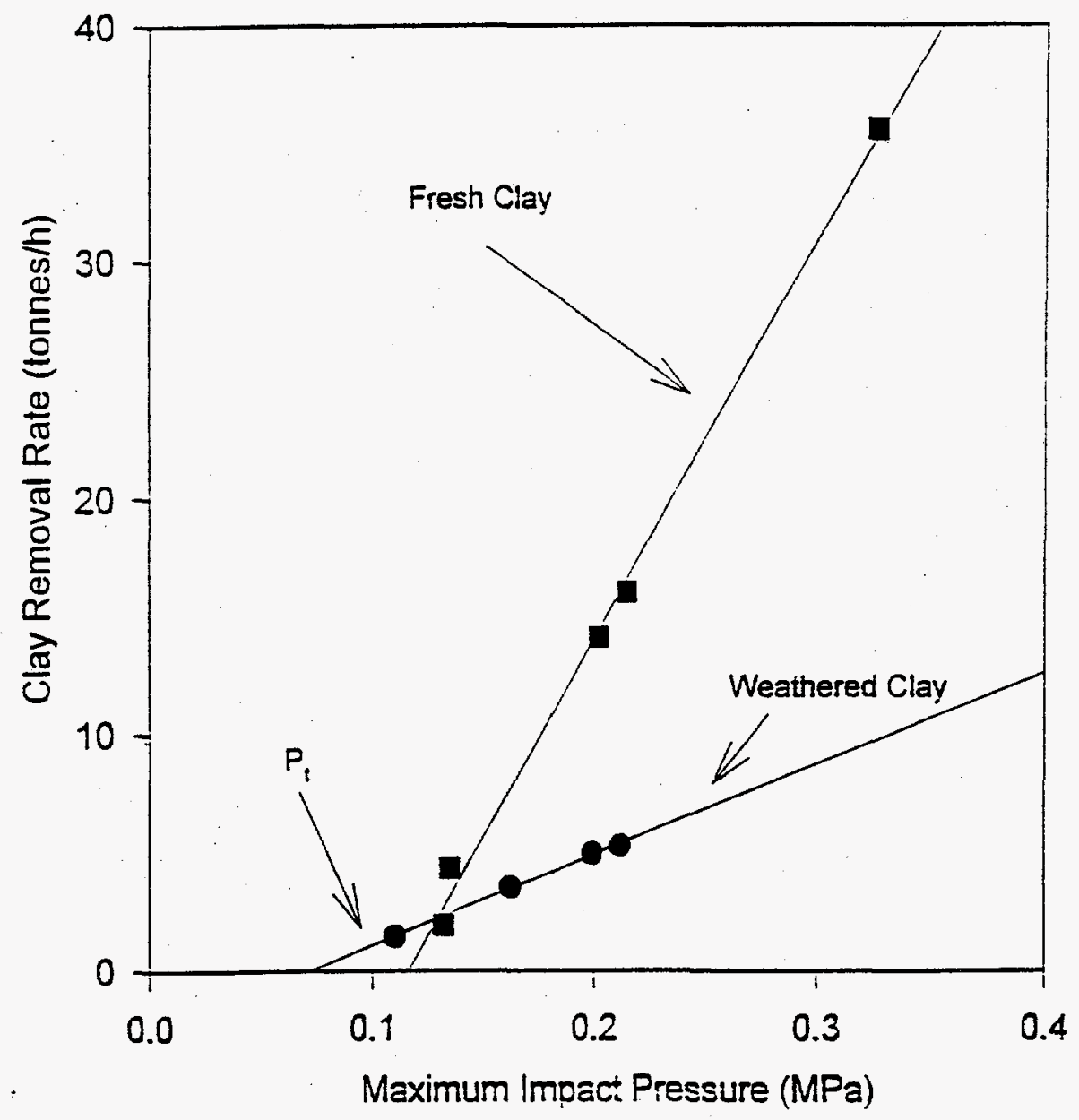

Figure A.1. Data from Davies and Jackson (1981) as Reported in Summers (1994) for the Hydraulic Mining of China Clay 
Applying this linear relationship between impact pressure and removal rate to waste tank sluicing, the rate of waste mobilization will be given by an equation of the form:

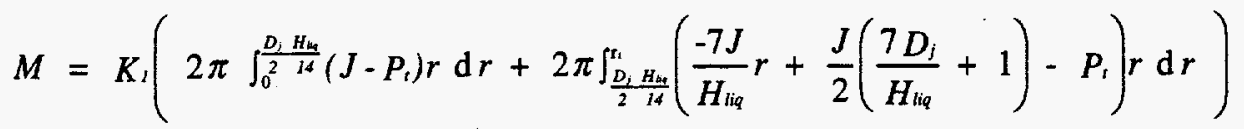

which is integrated to give

$$
M=2 \pi K_{t}\left[\frac{\left(J-P_{t}\right)}{2}\left(\frac{D_{j}}{2}-\frac{H_{\text {liq }}}{14}\right)^{2}+\frac{-7 J}{3 H_{\text {liq }}}\left(\mathrm{r}_{1}^{3}-\left(\frac{D_{j}}{2}-\frac{H_{\text {liq }}}{14}\right)^{3}\right)+\left(\frac{J}{4}\left(\frac{7 D_{j}}{H_{\text {liq }}}+1\right)-\frac{P_{t}}{2}\right)\left(r_{1}^{2}-\left(\frac{D_{j}}{2}-\frac{H_{\text {liq }}}{14}\right)^{2}\right)\right](\mathrm{A}
$$

where $K_{l}$ is an empirical constant given by slope of removal rate versus pressure line (see Figure A.1) and $r_{t}$ is radial position within the jet beyond which the jet pressure is less than the threshold mobilization pressure $\left(P_{t}\right)$ and is given by:

$$
r_{t}=\frac{-H_{\text {liq }}}{7 J}\left[P_{t}-\frac{J}{2}\left(\frac{7 D_{j}}{H_{\text {iqq }}}+1\right)\right]
$$

Equations given earlier for $J$ and $D_{j}$ can be substituted into the above equations to solve for the waste mobilization rate $(M)$ in terms of the recognizable process variables of initial jet pressure $\left(P_{\text {init }}\right)$, nozzle design effects $\left(C_{N}\right)$, nozzle diameter $(D)$, standoff distance $(x)$, and standing liquid thickness $\left(H_{l i q}\right)$. It remains to provide an estimate of the threshold mobilization pressure $\left(P_{t}\right)$ and the mobilization rate constant $\left(K_{1}\right)$ in terms of more easily measured waste physical properties.

Unique relationships between $P_{t}$ and general physical properties like density, void fraction, and shear strength do not exist. As a first approximation, however, it is suggested that work performed by Whyatt et al. ${ }^{(a)}$ be incorporated into the sluicing model. Whyatt utilized a modified penetrometer to determine the penetration resistance of a variety of clay-based sludge simulants. The penetration resistance was found to correlate linearly with vane shear strength for these materials. The penetration resistance was found to be approximately 10 times the vane shear strength. It is clear that mobilization will occur if the sluicing jet applies pressure to the waste surface that is in excess of the waste's penetration resistance. Mobilization might occur at lower impact pressures, but it is not presently known how much lower these pressures might be. For the purposes of this model, the threshold mobilization pressure will be estimated from the vane shear strength $\left(\tau_{s}\right)$ using the equation

$$
P_{t}=10\left(\tau_{s}\right)
$$

The mobilization rate constant, $K_{1}$, is obtained from the slope of the line generated in a plot of mobilization rate $(\mathrm{kg} / \mathrm{s})$ versus jet impact pressure $(\mathrm{Pa})$. No correlations have yet been identified that allow the prediction of $K_{1}$ based on other measurements. It may be possible to establish the expected range of $K_{l}$ using simulant-based tests. Using this approach it becomes important to understand the mechanisms by which the waste obtains its mobilization resistance. Tests should utilize simulants that possess these same mechanisms.

\section{Function S: Slurry Action of the Jet on the Dislodged Sludge}

The remaining aspect of the sluicing model to be developed captures the effect of the sluice jet

(a) Whyatt, G. A., C. L. Fow, T. D. Powell, and P. A. Scott. FY 1988 Bench-Scale Sludge Mobilization Testing. A Letter Report for Westinghouse Hanford Company. Prepared by Pacific Northwest Laboratory, Richland, Washington. September 1988. 
on the dislodged waste. The tendency of the dislodged pieces of waste to be broken up into progressively smaller pieces and eventually form a slurry is described by the function $S$. The energy of the impinging sluice jet creates stresses on the dislodged waste. These stresses are resisted by the mechanical strength of the waste. That this effect can be important in determining the performance of a sluicing system has been demonstrated by commercial sluicing operations in which cohesive clay was found to be difficult to sluice. The chunks of dislodged clay were not subsequently broken up and transported by the sluice water. This necessitated a change in operating procedure wherein the clay was dislodged by closely adjacent passes of the sluice jet to prevent the formation of large chunks (Summers 1994).

The interactions between the sluice jet, the liquid height, the liquid rheology, and the characteristics of the dislodged waste are very complex. An attempt is made below to model these interactions. Several simplifying assumptions are required and the validity of these assumptions is not presently known. This model should be applied cautiously and improved upon using experimental data gathered during pilot-scale sluicing tests.

Consider a 5-cm-sized chunk (roughly cubical) of dislodged waste. When the sluice jet is directed at or near this piece of waste, the jet may induce mechanical failure in the chunk, thereby resulting in two or more smaller pieces. The attrition of the progressively smaller pieces will continue until a characteristic size is reached. This characteristic size is determined by the strength with which the particles resist the jet and by the magnitude of the shear field imposed on the particles by the jet. The strength of the waste pieces that is most relevant is the shear strength. The imposed shear field is related to the radial pressure gradient within the jet.

It was assumed for the development of the function $L(r)$ that the jet pressure decayed from a maximum to zero linearly over a distance determined by the thickness of the standing liquid layer above the waste surface. The pressure gradient, then, at a point mid-way between the waste surface and the liquid surface is given by

$$
\frac{\mathrm{d}(L(r))}{\mathrm{d} r}=\frac{-14 J}{H_{l i q}}
$$

The mid-way point is selected rather arbitrarily to represent an average of the very high pressure gradient at the point where the jet enters the standing liquid and the relatively low gradient near the waste surface.

If this average pressure gradient is applied to one face of a cubical piece of waste, one half of the cube will be subjected to a higher average force than the other side. If this difference in forces is larger than the product of the waste's shear strength and the shear failure area, then the cube will be split into two smaller pieces. It can be shown that the pieces will be made progressively smaller until the difference in forces is no longer sufficient to overcome the waste's shear strength. At this point the approximate size of the remaining waste pieces $(a)$ is given by

$$
a=\frac{2 \tau_{\mathrm{s}} H_{\text {liq }}}{7 \mathrm{~J}}
$$

It is assumed in this equation that the jet very rapidly breaks down the dislodged pieces of waste to form a slurry consisting primarily of particles of dimension $a$. To improve this relationship, a reasonable residence time distribution could be used along with an accounting for the fact that a larger diameter jet will subject a greater volume of waste to the shearing stresses. 
Determining the ultimate size of the remaining waste pieces is directly relevant to the determination of the efficiency of waste collection by the retrieval pump. If the jet is only sufficient to create $1-\mathrm{cm}$ and larger chunks of waste, then the collection efficiency will be very low because these pieces will settle very rapidly once the jet is directed somewhere else. On the other hand, if the jet can create $0.01-\mathrm{mm}(10-\mu \mathrm{m})$ particles, then it is expected that nearly all of these particles will be transported by the flowing sluice liquid to the intake of the retrieval pump. Between these extremes the waste collection efficiency will vary depending primarily upon the waste particle sizes generated by the jet, the distance from the slurried waste to the retrieval pump, and the flow of the sluice liquid towards the retrieval pump.

It is proposed that the effect of waste slurry formation on the sluicing system performance (function $S$ ) be modeled by relating the efficiency of dislodged waste collection to the particle size formed $(a)$. The value of $S$ is assumed to range from 0.0 , for the case where none of the dislodged waste is recovered by the retrieval pump, to 1.0 , where all of the dislodged waste is recovered. As a first approximation, it will be assumed that if the generated particles settle at rates of less than 0.5 $\mathrm{cm} / \mathrm{s}$, then all particles will reach the retrieval pump intake (i.e., $S=1.0$ ). This settling rate corresponds to waste particles on the order of $100 \mu \mathrm{m}$ in size. The settling velocity of spheres increases with the square of the sphere diameter (in general). Using this relationship for the generally non-spherical pieces of dislodged waste and assuming that the waste collection efficiency decreases linearly with increasing settling velocity gives the following equation for $S$ :

$$
S=\frac{10^{-8} \mathrm{~m}^{2}}{a^{2}}=\frac{\left(1.23 \times 10^{-7} \mathrm{~m}^{2}\right) J^{2}}{\tau_{s}^{2} H_{\text {fiq }}^{2}} \text { for } a \geq 100 \mu \mathrm{m}
$$

When $a$ is less than $100 \mu \mathrm{m}$, then $S$ is equal to 1.0 .

\section{Implications of Sluicing System Performance Model}

The model developed above can be used to predict the nature of the interactions between the various process variables. This is the primary value of any physical process model. If this model (or some future, improved model) can be verified using data collected during pilot-scale and full-scale sluicing operations, then we will have a very powerful tool that can be used to identify potential improvements in the performance of sluicing system design. If, for example, the model predicts that the waste retrieval rate is constrained primarily by the resettling of particles before they make it to the retrieval pump, then it will be worthwhile to investigate ways to remedy this problem-like installing multiple retrieval pumps or directing the sluice jets such that the waste is dislodged in progressive, concentric rings surrounding the retrieval pump intake.

The model as presently developed has not been tested against experimental data. Further, the number of simplifying assumptions employed make it likely that changes to the model will be required for it to agree with experiments. Thus, the model presented above is not useful for making design changes to the baseline sluicing system. However, this model is valuable in that it allows the qualitative identification of which process variables are likely to control the performance of sluicing. Identifying these variables is an essential part of developing a test plan for pilot-scale testing. This is especially true for larger-scale testing where cost prohibits exhaustive testing of all process variable permutations.

Given below are predictions of sluicing system performance based on the model developed above. These predictions are subject to alteration as the process model is refined, both through expanded literature surveys and utilization of experimental data. In general, the plots show expected relationships (e.g., increasing retrieval rate with increasing nozzle diameter). In some cases, however, the results are less obvious. The effect of shear strength, for example, is relatively minor until about $5000 \mathrm{~Pa}$ is exceeded, at which point retrieval rate rapidly diminishes with increasing shear strength. In other cases, like that of the effect of standoff distance, it is expected that some of the predicted behavior is an unintended artifact of the assumed pressure decay rates. It is not expected that retrieval rate would be lower for low standoff distances (nozzle close to the waste) as is shown in the 
plot. This is believed to be an artifact of the assumed $7 \mathrm{D}_{j}$ jet penetration depth. Given a welldeveloped model, plots like those shown below could be constructed and used to guide design and operation of the sluicing system.

The results of the developed sluicing model point to several key process variables that determine performance. First, increasing jet pressure and jet nozzle diameter both markedly improve the waste retrieval rate. Since there is a definite tradeoff between pump expense for high pressure and the desire to keep the volumetric flow of sluice fluid low, it is not clear whether it would be better to maximize retrieval rate by increasing the pressure or the nozzle diameter or by some intermediate combination of both. Through the use of experimental data in conjunction with an accurate process model, it should be possible to determine the optimum nozzle size and pressure for waste sluicing based upon a given set of waste properties.

If a sluice fluid flow rate is assumed, it is possible to optimize nozzle diameter using the model with respect to the energy efficiency of the waste mobilization and slurrying. For an assumed flow rate of $360 \mathrm{gpm}$, the nozzle size predicted to use the least amount of energy per unit mass of waste retrieved is about 0.9 inches. These data are shown in Figure A.7 below. It is important to stress that the 0.9-inch optimum size prediction is not expected to be accurate based upon this relatively crude model (at least unless the model can be verified using experimental data). The discussion of the 0.9 -inch optimum has been included solely to illustrate the usefulness of a well-developed process model for sluicing system design.

The model outlined above will be used to make the preliminary selection of test variables for the initial set of pilot-scale tests to be conducted in the 1/4-scale facility by PNL. Figures A.2 through A.7 indicate that the most important variables are likely to be nozzle diameter and pressure, standoff distance, and the thickness of any standing liquid layer above the waste. Sludge shear strength does not appear to be a controlling variable provided that it is less than about $5 \mathrm{kPa}$. The true range of sludge shear strengths that exist throughout the Hanford SSTs is not currently known but is expected to range from about 1 to $10 \mathrm{kPa}$.

Designing pilot-scale tests requires some knowledge of how the process being tested scales up. The model developed above will be used to support the design of the first round of 1/4-scale sluicing tests. Based on the model, the 1/4-scale tests should be conducted using geometrically scaled nozzle diameter, standoff distance, and standing liquid thickness. That is, each of these dimensions should be one-quarter of their expected full-scale counterparts. The sluicing jet nozzle pressure, nozzle design, and sludge simulant shear strength should all be kept close to their prototypic values. A welldesigned nozzle operated at about 150 psig and a sludge simulant with a $\tau_{s}$ of about $5000 \mathrm{~Pa}$ should satisfy this requirement for preliminary testing. Since the estimated waste retrieval rate is based upon the impact area of the sluice jet, the rate of waste simulant retrieval observed at $1 / 4$-scale is predicted to be about $1 / 16$ th that observed at full-scale. All waste retrieval rate data collected at $1 / 4$-scale should be multiplied by 16 to make full-scale estimates.

Linear geometric scaling of the nozzle size, standoff distance, etc. is predicted by the model because most of the empirical and assumed relationships between jet pressure decay and mobilization rates are linear with respect to nozzle size and standoff distance. If these relationships are found to be non-linear, a modification of this scaling methodology may be needed. 


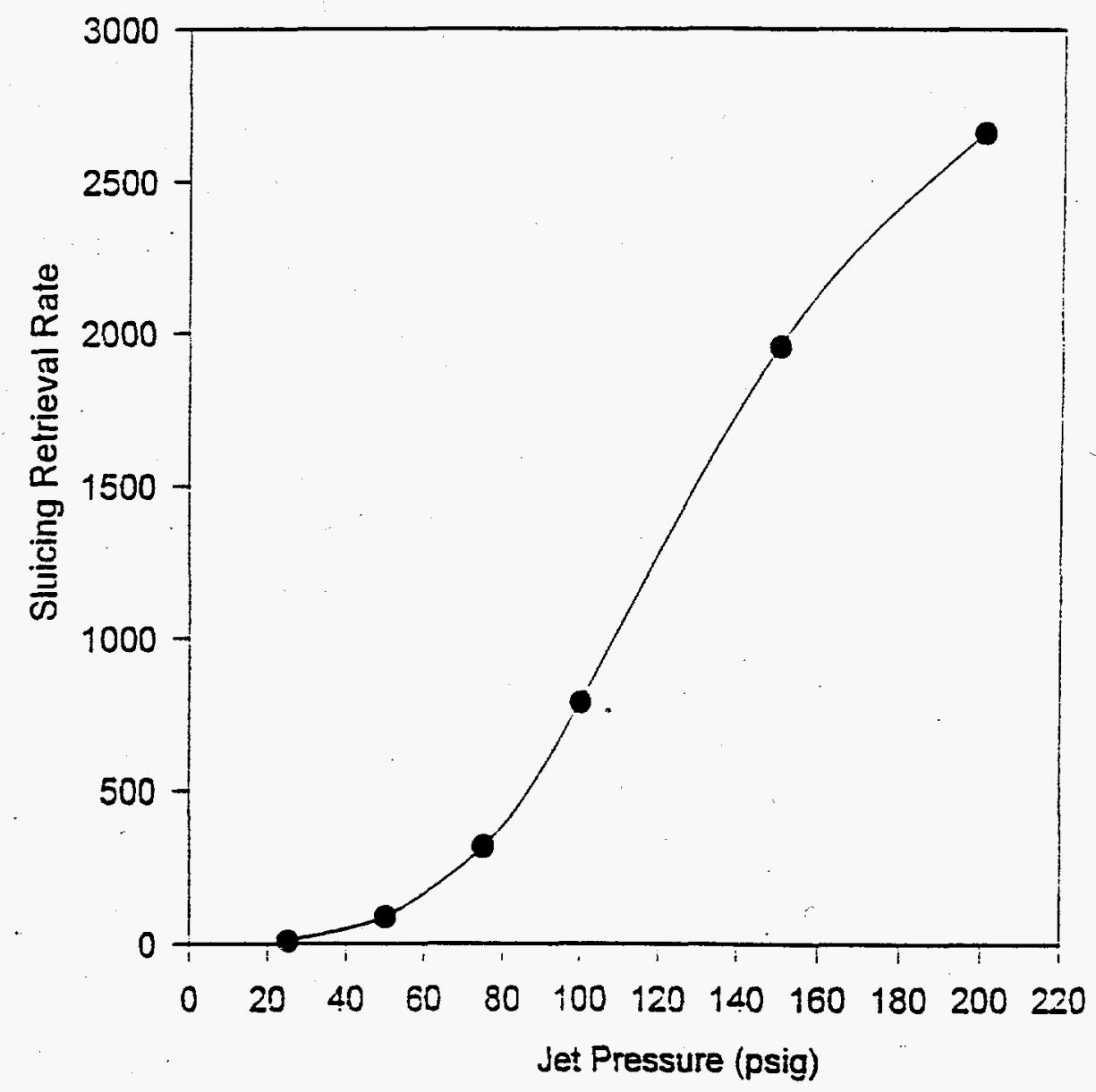

Figure A.2. Effect of Pressure on Retrieval Rate. $x=3 \mathrm{~m}, D=.0254 \mathrm{~m}, H_{\text {liq }}=.05 \mathrm{~m}, \tau_{s}=5000 \mathrm{~Pa}$ 


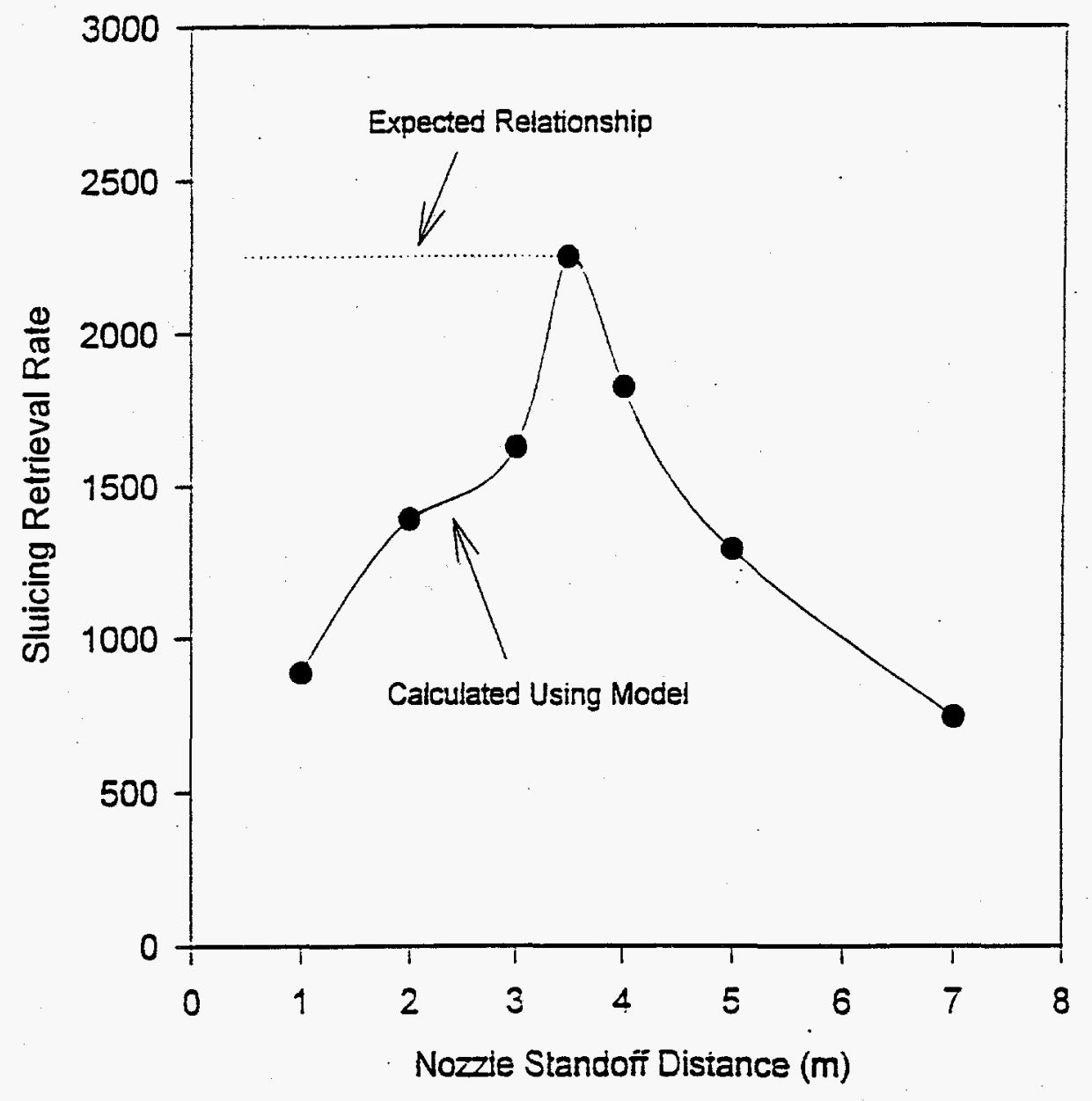

Figure A.3. Effect of Standoff Distance on Retrieval Rate. $P_{\text {init }}=150 \mathrm{psi}, D=.0254 \mathrm{~m}$, $H_{\text {liq }}=.05 \mathrm{~m}, \tau_{s}=5000 \mathrm{~Pa}$ 


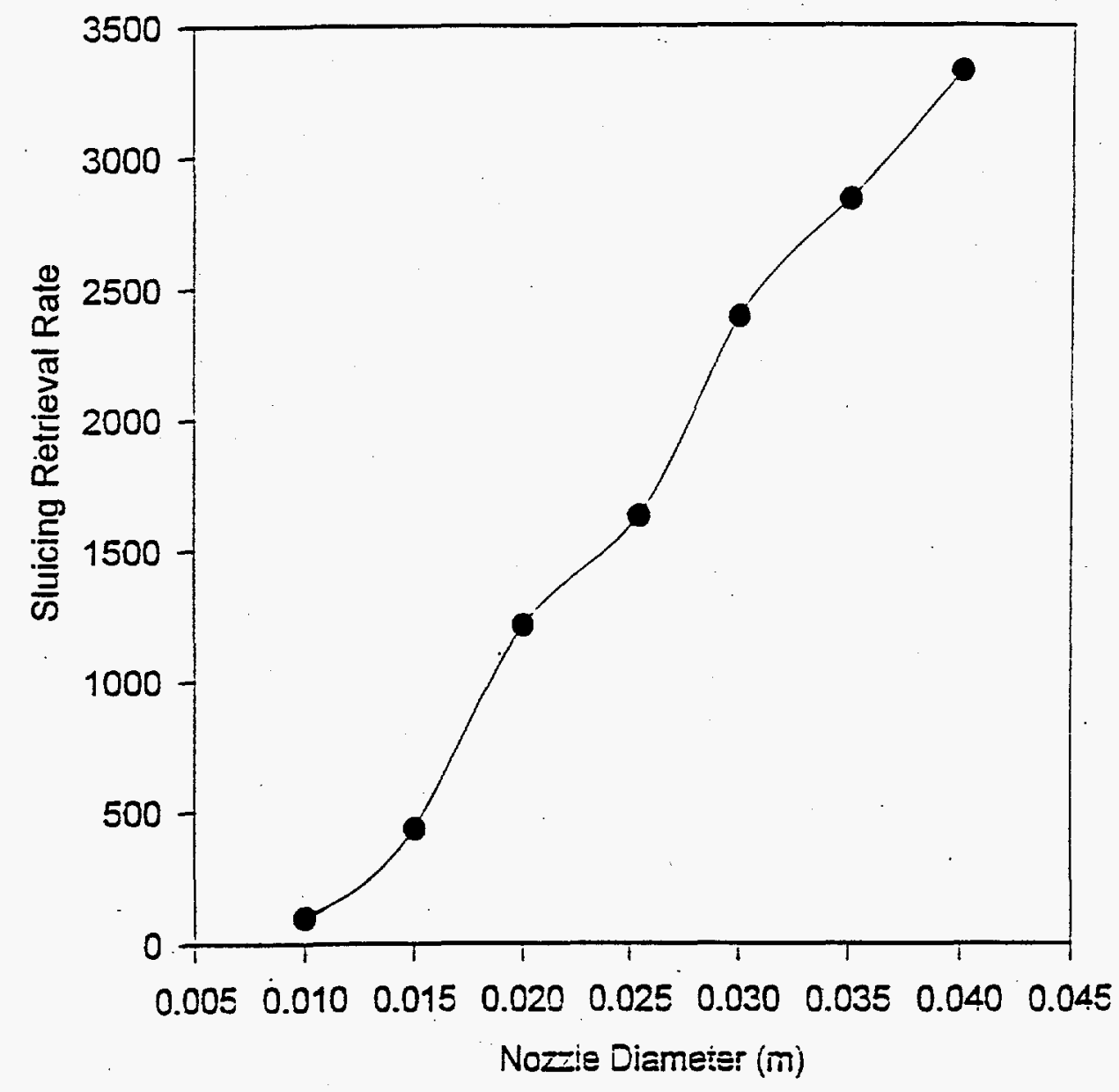

Figure A.4. Effect of Nozzle Diameter on Retrieval Rate. $P_{\text {init }}=150 \mathrm{psi}, x=3 \mathrm{~m}, H_{l i q}=.05 \mathrm{~m}$, $\tau_{s}=5000 \mathrm{~Pa}$ 


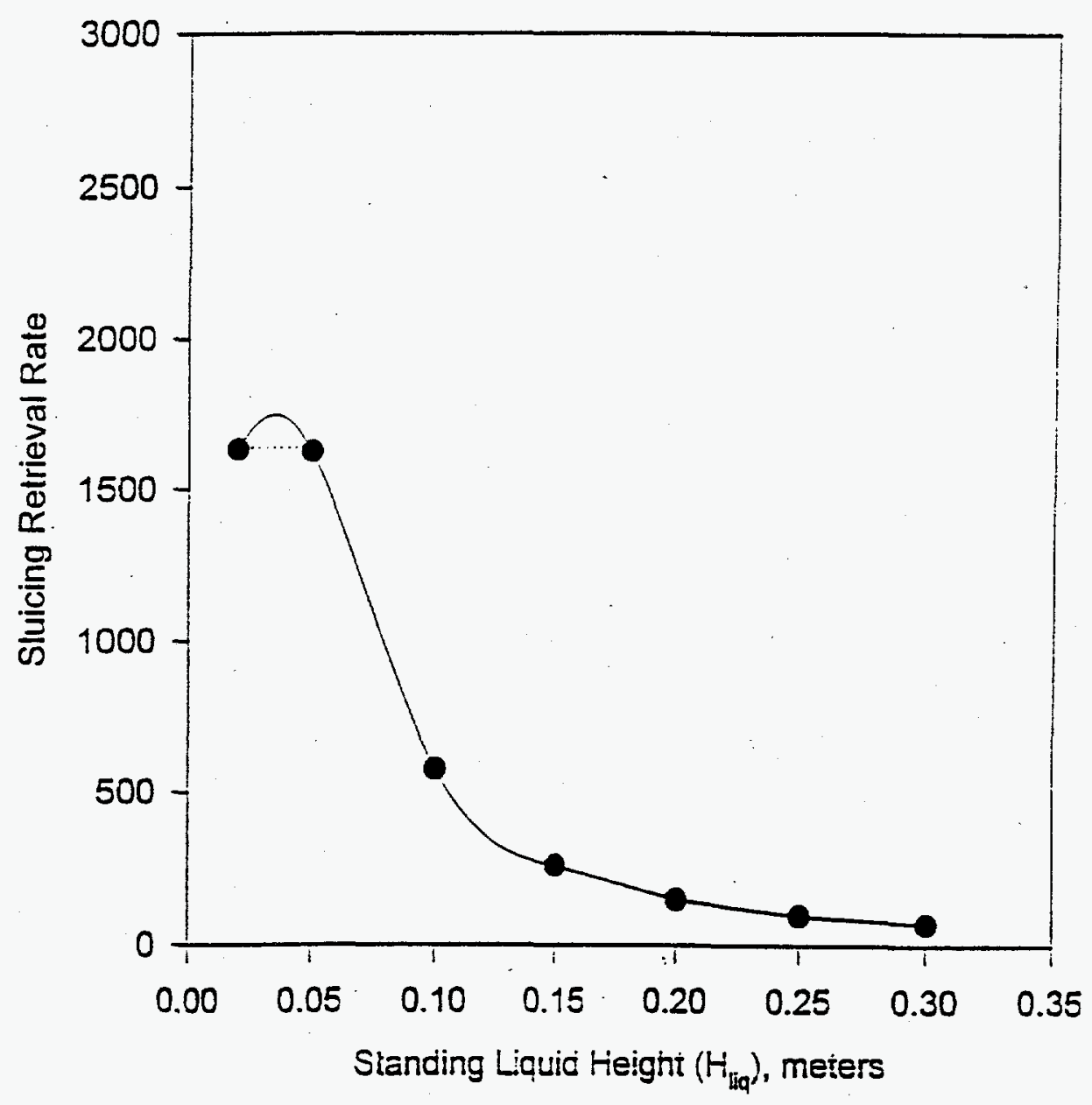

Figure A.5. Effect of $H_{\text {lig }}$ on Retrieval Rate. $P_{\text {init }}=150 \mathrm{psi}, x=3 \mathrm{~m}, D=.0254 \mathrm{~m}, \tau_{s}=5000 \mathrm{~Pa}$ (Note that hump between first two points is an artifact of the interpolation). 


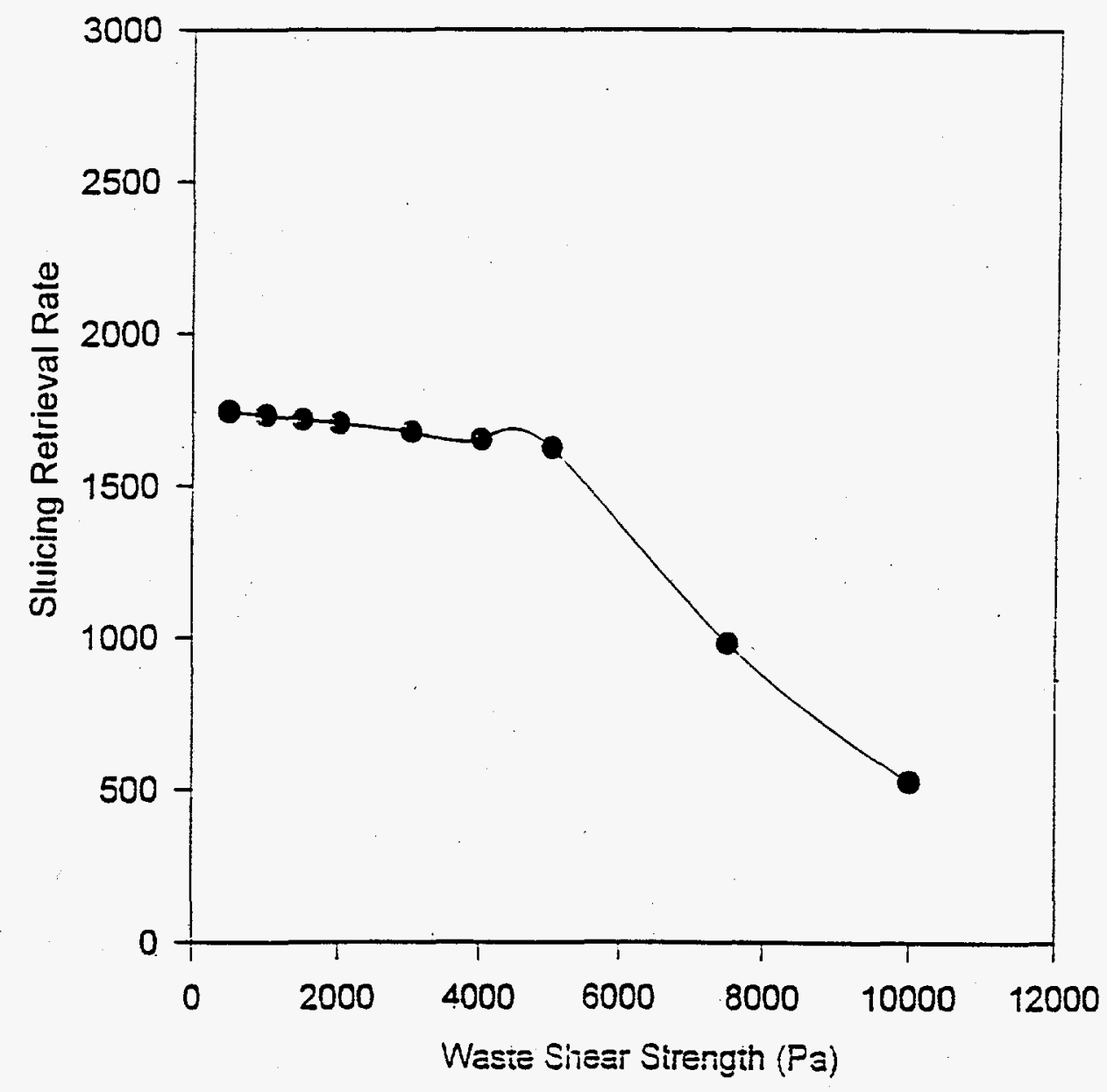

Figure A.6. Effect of Shear Strength on Retrieval Rate. Pinit $=150 \mathrm{psi}, x=3 \mathrm{~m}, D=.0254 \mathrm{~m}, H_{l i q}$ $=0.05 \mathrm{~m}$ 




Figure A.7. Determination of Optimum Nozzle Diameter for $360 \mathrm{gpm}$ total sluice flow (model prediction) 


\section{References}

Davies, T. W., and M. K. Jackson. "Optimum Conditions for the Hydraulic Mining of China Clay." Paper 3.4 Proc 1st US Water Jet Symposium, April 1981, Golden, Colorado.

Rajaratnum, N. 1976. Developments in Water Science 5: Turbulent Jets. Elsevier Scientific Publishing Company, Amsterdam, The Netherlands.

Summers, David A. 1994. Waterjetting Technology. 
Appendix B

On the Design of Pneumatic Transport Pipelines 


\section{Appendix B}

\section{On the Design of Pneumatic Transport Pipelines}

by

Fadel F. Erian

March 6, 1995

In the following presentation a procedure is given for establishing the power and operational requirements to transport a specified amount of solid particles in an air stream through a pipeline. Only the pipeline component of the transport system is considered here. Other essential parts, such as the solids feed system at intake and the gas-solid separation system at discharge, are not included here. In general, such systems must be designed to interface properly with both upstream and downstream process components. The following assumptions are made:

1. The solids are coarse particles that have a narrow size distribution and can be sufficiently characterized by an average particle size.

2. The particle size is much smaller than the pipe diameter and is of the order of the turbulence integral scale.

3. Transport is in the dilute phase regime, where particle-particle interactions are negligible and the concentration by volume does not exceed $\bar{C}=0.04$.

4. The physical properties of both the carrier gas and the solid particles are known.

5. The solid particles' overall shape, settling velocities and material properties are also known.

6. The pipe contains both horizontal and vertical runs connected with appropriately oriented bends. Pressure drops due to bends are significant and shall be accounted for.

The flow of gas-solid mixtures in pipelines can be described by a variety of models:

*Continuum Models - treat the mixture as a homogeneous fluid with uniform physical properties that are a combination of both the gas and solid properties. These models are suited for very small solid particles such as fine sand and powders.

*Particle Mechanics models - follow the motion of a multitude of particles (Lagrangian mechanics), each with its own independent path. Average properties that are useful for engineering design purposes are obtained by ensemble averaging over a sufficient number of particles both at the inlet and outlet of the piping system. This approach is best used when transporting mostly large particles that may interact with each other and with the pipe wall.

*Bulk Effects Model (phenomenological) - describes the influence of a gas stream on a representative group of relatively coarse particles, and, the impact of that group of particles on the behavior of the gas stream. This model is the easiest to develop, verify experimentally, and to use in engineering design. Because of its semi-empirical nature it is suitable for a wide range of particle sizes, which may overlap with the upper size range of the continuum regime, and the lower size range, which follows the particle mechanics models.

In this report a formulation of a phenomenological bulk effect model is presented. It permits the calculation of the overall pressure drop through a piping system that transports a dry gas-solid mixture between two prescribed points. The model represent the basis of the calculation procedures followed by the computer program PNEUPE, which has recently been licensed for BMI personnel 
use by the Shell Development Company, Houston, Texas. The program was developed originally to design short and intermediate distance pneumatic transport pipelines to carry commodities such as pulverized coal, small gravel particles, cement powder, bentonite, and other solids used in forming drilling fluids. Applications for these transport systems existed in refineries, chemical plants, and on offshore platforms in inaccessible regions such as in the Arctic Ocean.

One major advantage, derived from the licensing agreement, is that we have been able to acquire the source code of the pneumatic conveying program. Any of the model components, adjustable constants, and empirical correlations that are imbedded in the program can be replaced with improved formulations, new adjustable constants, and new correlations that correspond to our own solids materials, and are derived from our own experimental work. It is believed that the calculation scheme used in this program is more versatile and represents an excellent alternative to existing commercial packages that perform similar calculations.

\section{Pneumatic Transport of Dry Gas-Solid Mixtures}

The computer program PNEUPE has been developed for the calculation of pressure drop across pipelines transporting gas-solid mixtures. In straight horizontal pipe sections, PNEUPE considers airwall friction, the effect of solids on air-wall friction, and solids-wall friction. When the pipe is vertical, a term representing the elevation head is included. The model employs friction-factor type calculations. It lacks the ability to calculate its own fundamental constants from fundamental fluiddynamical considerations. Hence, it is subject to considerable improvement. The user has override options on the various adjustable constants including the friction factors, which allow the adjustment of model calculation results to fit particular sets of data. For this purpose, among other information, the program input requires data on particle terminal settling velocity or effective particle diameter, solids-wall coefficient of friction, and solids-effect-on-air/wall friction. The last has a zero default value since it is in general difficult to separate the individual effects of solids-wall friction and the solids-effect-on-air/wall friction. This default value can be changed when appropriate data have been obtained.

In bends, PNEUPE requires the consideration of solids' approach velocity, deceleration toward a limiting "spiral" velocity, reacceleration from the bend's exit velocity to the downstream velocity, and the air-solids friction loss in the bend. The different components of the overall pressure drop in bends are shown in equation B.1.

The pressure drop in a straight vertical section of pipe is obtained by integrating the following first order equation along the pipe length:

$$
\begin{gathered}
\frac{d P}{d L}=-\frac{1}{2} f_{g} \frac{\rho_{g} V_{g}^{2}}{D}-\frac{1}{2}\left(\frac{f_{g}}{D}\right)\left(\frac{f_{s}}{f_{g}}\right)\left(\frac{F_{s}}{A}\right)\left(V_{g}-V_{w} \sqrt{\alpha}\right)-\frac{F_{s} g H}{A V_{s}}-\frac{\alpha F_{s} g}{A\left(V_{g}-V_{w} \sqrt{\alpha}\right)} \\
I I \quad I I I \quad I V
\end{gathered}
$$

where $\mathrm{I}=$ Air-Wall Friction.

II $=$ Solids Effect on Air Friction.

III = Elevation Head.

IV $=$ Solids-Wall Friction.

For a horizontal pipe, the elevation head, III, is zero. In the above equation,

$$
\begin{aligned}
& \frac{f_{s}}{f_{g}} \text { is a friction factor ratio such that } 0 \leq \frac{f_{s}}{f_{g}} \leq 1, \\
& \left(V_{g}-V_{w} \sqrt{\alpha}\right) \text { is the local solids slip velocity, } \mathrm{ft} / \mathrm{sec}
\end{aligned}
$$


where $P=$ local pressure, in $1 \mathrm{bf}_{\mathrm{f}} / \mathrm{ft}^{2}$

$L=$ length along the pipe

$f_{g}=$ friction factor for the gas phase

$f_{S}=$ friction factor for the solid phase

$D=$ pipe diameter

$F_{S}=$ solids mass flow rate in $\mathrm{lb}_{\mathrm{m}} / \mathrm{sec}$

$A=$ pipe cross-sectional area, $\mathrm{ft}^{2}$

$g=$ gravitational acceleration, $\mathrm{ft} / \mathrm{sec}^{2}$

$V_{g}=$ gas superficial velocity, $\mathrm{ft} / \mathrm{sec}$

$V_{S}=$ solids average velocity, $\mathrm{ft} / \mathrm{sec}$

$V_{w}=$ particle terminal velocity at local conditions, $\mathrm{ft} / \mathrm{sec}$

$\rho_{g}=$ local gas density, $\mathrm{lb}_{\mathrm{m}} / \mathrm{ft}^{3}$

$\alpha=$ solid-wall friction coefficient

In vertical pipe sections the pressure drop due to solids friction on the wall is considered negligible since the gravitational force component normal to the wall is zero. The elevation head is calculated according to the solids' inventory inside the pipe.

The treatment of the pressure drop in bends involves the following steps:

1. Calculation of the solids' approach velocities, $V_{s}$,

for horizontal approach

$$
V_{s}=V_{g}-V_{t} \sqrt{\frac{\alpha \rho_{o}}{\rho_{g}}},
$$

for vertical downflow

$$
V_{s}=V_{g}+V_{t} \sqrt{\frac{\rho_{o}}{\rho_{g}}},
$$

for vertical upflow

$$
V_{s}=V_{g}-V_{t} \sqrt{\frac{\rho_{o}}{\rho_{g}}}
$$

In the above expressions, $V_{t}$ is the particle terminal velocity at standard conditions, $p_{o}$ and $\rho_{o}$, such that

$$
V_{w}=V_{t} \sqrt{\frac{\rho_{o}}{\rho_{g}}},
$$

2. Calculation of the steady solids velocity in an infinite spiral of radius $\mathrm{R}, V_{s p}$,

$$
V_{s p}=\frac{V_{g}}{(1+\sqrt{\eta})}
$$

where

$$
\eta=\frac{4}{3} \frac{d_{p} \mu \rho_{s}}{R C_{D} \rho_{g}}
$$

3. Calculation of the deceleration of particles around the bend, 


$$
V_{s}-V_{e}=\left(V_{s}-V_{s p}\right) \exp \left(-\beta_{b} \varepsilon\right)
$$

where $\varepsilon$ is the effective bend angle in radians, assumed $=70 \infty=1.22$ radians, and, $\beta_{b}$ is the effective coefficient of friction $=0.4$, and $V_{e}$ is the solids velocity at the bend's exit. Therefore,

$$
V_{s}-V_{e} \approx 0.6\left(V_{s}-V_{s p}\right)
$$

4. Calculation of the pressure drop due to the air drag on the particles is given by Ikemori and Munakata, \{2\}:

$$
\Delta P=-C_{s b} \frac{F_{s}}{A} \frac{\pi}{2} \frac{V_{s}\left(V_{g}-0.5\left(V_{a p}+V_{e}\right)\right)}{V_{g}}
$$

where the correction factor $C_{s b}=0.4$ to 0.9 , and will be taken here to be $\approx 0.6 . V_{a p}$ is the solids approach velocity and is equivalent to $V_{s}$.

The equation of Ikemori was derived and evaluated for horizontal bends and will require some adjustment for vertical-to-horizontal and horizontal-to-vertical bends. The solids velocities after reacceleration, $V_{s e}$, can be written as in [1]:

for horizontal approach

$$
V_{s e}=V_{g}-V_{t} \sqrt{\frac{\alpha \rho_{o}}{\rho_{g}}},
$$

for vertical downflow

$$
V_{s e}=V_{g}+V_{t} \sqrt{\frac{\rho_{o}}{\rho_{g}}},
$$

for vertical upflow

$$
V_{s e}=V_{g}-V_{t} \sqrt{\frac{\rho_{o}}{\rho_{g}}},
$$

5. Calculation of the pressure drop due to reacceleration of the particles:

when

$$
\begin{aligned}
& V_{s e} \leq V_{g} \text { and } V_{e} \leq V_{g} \\
& \Delta P=-\frac{\left(V_{s e}-V_{e}\right) F_{s}}{A},
\end{aligned}
$$

when

$$
V_{s e}>V_{g} \text { and } V_{e}>V_{g}
$$

$$
\Delta P=+\frac{\left(V_{s e}-V_{e}\right) F_{s}}{A},
$$

when

$$
V_{s e}>V_{g} \text { and } V_{e} \leq V_{g}
$$


when

$$
\Delta P=-\frac{\left(V_{s e}-V_{g}-V_{g}+V_{e}\right) F_{s}}{A},
$$

$$
\begin{gathered}
V_{s e} \leq V_{g} \text { and } V_{e}>V_{g} \\
\Delta P=+\frac{\left(V_{s e}-V_{g}-V_{g}+V_{e}\right) F_{s}}{A},
\end{gathered}
$$

6. Air friction pressure drop in bends is calculated by an equivalent straight pipe of length $2 R$.

The calculation procedures for the pressure drop involve the integration of the differential model given at the beginning of this section over the length of straight pipe sections. The pressure drop across a pipe bend is represented by equations already in integrated form as shown above.

Vacuum systems can be calculated by trial and error assuming various discharge (vacuum) pressures until the atmospheric inlet pressure is reached by the computations. Finally, the initial static pressure for starting the integration process, $P_{i}$, is equal to the static pressure at the "pick up" point where solids are introduced into the pipe, $P_{p u}$, less the acceleration pressure drop. This pressure drop represents the amount of mechanical energy absorbed by the solid particles as they accelerate from zero velocity at the point of introduction into the pipe to their final steady velocity, $V_{s}$. This is a one time reduction in the available static pressure, and we shall assume that the solids are introduced into a straight section of the piping system. The effective initial pressure is given by:

$$
P_{i}=P_{p u}-\frac{F_{s} V_{s}}{A}
$$

The computer program PNEUPE performs all the above calculations given a solids loading and an average gas velocity at the solids pick-up point. Additional input information will be described after the program has been readied for operation.

\section{Pneumatic Transport of Wet Gas-Solid Mixtures}

Transporting wet solids pneumatically is a much more complex process. When, in addition to the wet solids, viscous liquids and sticky sludge particles are also being transported with the wet solids, an approach different from conventional pneumatic conveyance must be developed.

During some recent experiments, pneumatic transport of sticky, sludgy materials upward through a vertical pipe was attempted. The flow became intermittent and unstable and no significant transport took place. The sticky, sludgy material started to accumulate and, eventually, a ball-shaped agglomerate of the material was formed. which bridged the pipe, and, due to the ensuing pressure buildup, the ball-shaped obstacle started moving upward aided by the lubrication of the local pipe wall by the viscous liquids included in the waste material.

The author of this report advanced the concept of creating and maintaining a lubricating film over the inner surface of the conveying pipe. It is thought likely, in the presence of this lubricating, film, even that sticky and sludgy material will move upward in the core region of this annular-type flow, even if thrown against the pipe wall. In the following sections we shall present models to predict minimum gas speeds required to insure the existence of the annular flow pattern in the upward flow of a gas-liquid mixture. Furthermore, a model for estimating the pressure drop in this two-phase flow pattern will be described. 


\section{A. Transition to Annular Dispersed Flow in a Vertical Pipe}

When gas-liquid mixtures flow in a conduit, the two phases distribute themselves in a variety of patterns [1]. The particular pattern one observes depends on the gas and liquid flow rates, physical properties, and the size and inclination of the conduit. One of the central tasks in this field is to predict which flow pattern will exist under any set of operating conditions. Figure B.1, shows the flow patterns that may exist in an upward gas-liquid flow in a vertical pipe. As indicated earlier, we hope to maintain a thin liquid film on the inside of the conveying pipe to act as a lubricant that will facilitate the upward transport of sludgy and sticky materials.

In order to predict the conditions under which transition between flow patterns will take place, it is important to understand the physical mechanisms by which such transitions occur. In this way, the influences of the superficial velocities (flow rates), physical properties, and pipe size can be accounted for naturally in the resulting physically based models. The model equations for transition can be expected to apply generally, without the need for scale-up rules, but they have to be verified experimentally to ensure that they include all the pertinent physical phenomena.

Transition to annular flow from the churn flow pattern occurs at high gas-flow rate, as shown in Figure B.1. The liquid film flows upwards adjacent to the wall, and gas flows in the center carrying entrained liquid droplets. The upward flow of the liquid film against gravity results from the forces exerted by the fast moving gas core. This film has a wavy interface, and the waves tend to shatter and enter the gas core as entrained droplets. Thus, the liquid moves upwards, due to interfacial shear and to form drag on both the wave crests at the film surface and on the entrained droplets. Somewhere downstream of where the droplets were shorn off the wavy film surface they rejoin the film due to random impacting generated by the turbulence in the high-velocity gas core. This process creates what could be considered a steady annular dispersed flow with part of the liquid transported in the film and the remaining part as droplets entrained in the gas core.


Figure B.1. 
Experience in gas lift operations in the petroleum industry suggests that annular flow cannot exist unless the gas velocity in the gas core is sufficient to lift the entrained droplets. When the gas velocity rate is insufficient, the droplets fall back, accumulate, and form a bridge, and churn flow is recovered.

The minimum gas velocity required to suspend a droplet is determined from the balance between the gravity and drag forces acting on it,

$$
\frac{1}{2} C_{d}\left(\pi d^{2} / 4\right) \rho_{G} U_{G}^{2}=\left(\pi d^{3} / 6\right) g\left(\rho_{L}-\rho_{G}\right)
$$

which gives,

$$
U_{G}=\frac{2}{\sqrt{3}}\left[\frac{g\left(\rho_{L}-\rho_{G}\right) d}{\rho_{G} C_{d}}\right]^{1 / 2}
$$

The drop size, $d$, is determined by the balance between the impact force of the gas that tends to shatter the drop and surface tension forces that hold the drop together. Hinze, $\{2\}$, showed that the maximum stable drop size will be

$$
d=\frac{K \sigma}{\rho_{G} U_{G}^{2}},
$$

where $K$ is the critical Weber number and takes a value between 20 and 30 for drops that are gradually accelerated. Combining the above two equations we get,

$$
U_{G}=\left(\frac{4 K}{3 C_{d}}\right)^{1 / 4} \frac{\left[\sigma g\left(\rho_{L}-\rho_{G}\right)\right]^{1 / 4}}{\rho_{G}^{1 / 2}}
$$

As suggested by Turner et al., $\{4\}$, values of $K=30$ and $C_{d}=0.44$ are recommended.

A main characteristic of annular flow is that the film thickness is quite low even for relatively high liquid flow rates. As a result, the actual gas velocity, $U_{G}$, can be replaced by the superficial velocity, $U_{S G}$, and the final transition boundary is given by

$$
\frac{U_{S G} \rho_{G}^{1 / 2}}{\left[\sigma g\left(\rho_{L}-\rho_{G}\right)\right]^{1 / 4}}=3.1
$$

The superficial gas velocity given by the above equation will predict the minimum value below which stable annular flow will not exist. This simple criterion shows the transition to the annular pattern is independent of liquid flow rate and pipe diameter.

\section{B. Annular Dispersed Flow in a Vertical Pipe}

In the previous section we were able to establish a lower limit for the upward superficial gas velocity above which annular dispersed flow will exist in a vertical tube. Gas velocities larger than this lower limit will always produce this flow pattern.

It is necessary to know the pressure drop that will result from the annular dispersed flow. When that pressure drop is added to the pressure drop due to the pneumatic conveying of the dry solid particles, they should not exceed the available pressure to this vacuum system, which can not exceed 1 
atmosphere. For this purpose we shall follow the two-fluid model of Oliemans et al. $\{5\}$. In this model the liquid in the thin film at the wall is regarded as one phase and the gas plus droplets in the core as the other phase. The model is based on the following assumptions: flow.

1. There is a steady-state, one dimensional, concurrent, upward, and fully-developed two-phase

2. There is no mass transfer between the phases.

3. The acceleration terms in the momentum equations are ignored.

4. The flow is Axisymmetric.

5. The physical properties of both the gas and the liquid are constant.

6. The liquid and gas mass flow rates $W_{L}$ and $W_{G}$, or the superficial velocities, $V_{S L}$ and $V_{S G}$, are given.

7. The liquid droplets in the core travel at the gas speed (no slip).

Applying momentum balances to the pipe core and to the whole pipe contents we obtain,

$$
-\frac{\partial p}{\partial z}=\rho_{C} g+\frac{\tau_{i} P_{i}}{A_{C}}
$$

and

$$
-\frac{\partial p}{\partial z}=\left(\alpha_{F} \rho_{L}+\alpha_{c} \rho_{C}\right) g+\frac{\tau_{W F} P_{F}}{A}
$$

Eliminating the pressure gradient term from both equations we get

$$
\frac{\tau_{W F} P_{F}}{A}-\frac{\tau_{i} P_{i}}{A_{C}}+\alpha_{F} \Delta \rho g=0,
$$

with

$$
\alpha_{F}=\frac{A_{F}}{A}, \quad \alpha_{C}=\frac{A_{C}}{A}, \quad \alpha_{F}+\alpha_{C}=1, \quad \text { and, } \quad \Delta \rho=\rho_{L}-\rho_{C}
$$

Subscripts F, C, i, and W refer to the Film, the core, the interface, and the wall, respectively.

Additional equations representing the wall shear, the interfacial shear, interfacial velocity, interfacial roughness, liquid holdup, and the physical properties of the two fluids are derived or given. They form, along with expressions for the liquid division as given by Hewitt and Govan, $\{6\}$, a closed set of equations that can be solved numerically to yield the pressure drop due to this annular flow pattern.

\section{Recommendations}

Model formulation for the transition to the Annular Dispersed flow pattem is complete but needs to be tested experimentally. The pressure drop expected during upward vertical two-phase flow of a gas-liquid mixture has to be determined from the solution of the two-fluid model mentioned above. This model too should be verified experimentally. The final step is to perform special proof-ofconcept experiments to demonstrate the validity of the original concept that sticky, sludgy material can be reliably transported with a lubricant film attached to the pipe wall. During the performance of 
these experiments, data on the overall pressure drop can be obtained and used to verify pressure drop predictions.

\section{References}

(1) Taitel, Y., D. Barnea, and A. E. Dukler. 1980. "Modeling Flow Pattern Transition for Steady Upward Gas-Liquid Flow in Vertical Tubes," AIChE Journal, 26, 345.

\{2\} Ikemori, K., and H. Munakata. 1974. "A New Method of Expressing Pressure Drop in Horizontal Pipe Bends in Pneumatic Transport of Solids," Paper A3 - Proceedings of Pneumotransport 2. BHRA Fluid Engineering, Cranfield, UK.

\{3\} Hinze, J. O. 1955. "Fundamentals of the Hydrodynamic Mechanism of Splitting in Dispersion Processes," AIChE Journal, 1, 289.

\{4\} Turner, R. G., M. G. Hubbard, and A. E. Dukler. 1969. "Analysis and Prediction of Minimum Flow Rate for the Continuous Removal of Liquid from Gas Wells," J. Petroleum Tech., 21, 1475.

(5\} Oliemans, R. V. O., B. F. M. Pots, and N. Trompe. 1986. "Modeling of Annular Dispersed Two-Phase Flow in Vertical Pipes," Int. J. Multiphase Flow, V. 12, No. 5, pp. 711-732.

16\} Hewitt, G. F., A. H. and Govan. 1990. "Phenomenological Modeling of Non-Equilibrium Flows with Phase Change, "Int. J. Heat Mass Transfer, V. 33, No. 2, pp. 229-242. 
Appendix C

On the Design of Long-Distance Slurry Pipelines 


\title{
Appendix C
}

\section{On the Design of Long-Distance Slurry Pipelines}

\author{
by \\ Fadel F. Erian \\ March 1, 1995
}

In the following presentation a procedure is given for establishing the pipeline size, power requirements, and average mixture velocity needed to transport a specified amount of solid particles in slurry form. Other essential parts such as the slurry preparation, conditioning and feed system at intake, and, the solid-liquid separation system at discharge are not included here. In general such systems must be designed to interface properly with both upstream and downstream process components. The following assumptions are made:

1. Transport is over long distances in a nearly horizontal pipe. The flow is assumed turbulent and fully developed over most of the pipeline length.

2. Small overall upward or downward inclinations; \pm 10 degrees from the horizontal, are permitted.

3. Additional pressure drops due to bends, valves, etc. are negligible compared with the overall frictional pressure drop along the pipe length.

4. The physical properties of the carrier liquid and the solid particles are known; the solid particles vary in size between, approximately, $1 \mu \mathrm{m}$ to $1000 \mu \mathrm{m}$; and their general shape and size distribution are also given.

5. The slurry mixture follows a Bingham-plastic rheological model.

6. No chemical reactions or changes in the slurry chemical composition take place during transport.

The following procedures describe briefly the computational scheme followed in the slurry computer program that recently been licensed for BMI personnel use by the Shell Development Company, Houston, Texas. The program was developed originally to design long-distance coal slurry pipelines. and its reliability has been tested extensively with a variety of slurries (unfortunately, we do not have access to the test results). One major advantage, derived from the licensing agreement, is that we have been able to acquire the source code of the slurry program. Any of the correlations, especially those describing the slurry rheology, which are imbedded in the program, can be replaced with rheological models derived from slurried simulants used in PNL's own applications. Furthermore, the program performs calculations for slurries containing a wide range of particle sizes that may have differing densities. It is believed that the calculational scheme used in this program is more versatile and represents an excellent alternative to existing commercial packages that perform similar calculations.

For simplicity and clarity, the computational procedures are described in the following sections for a slurry with solid particles having only one size, $d_{p}$, and one density, $\rho_{s}$. In all cases the physical properties of the carrier liquid, mainly its density, $\rho l$, and its viscosity, $\mu l$, are known. 


\section{Particle Properties:}

The solid particles in the slurry are described by means of their density, size, and shape. The computer code calculates the velocity with which a single spherical particle settles in an infinite amount of the carrier liquid. The following equations produce the settling velocity for various conditions:

$$
\begin{gathered}
w=\frac{d^{2}\left(\rho_{s}-\rho_{1}\right) g}{18 \mu_{1}}, 0<\operatorname{Re}_{p}<2 \\
w=\frac{0.153\left[g\left(\rho_{s}-\rho_{1}\right)\right]^{0.714} d^{1.143}}{\rho_{1}^{0.286} \mu_{1}^{0.428}}, 2 \leq \operatorname{Re}_{p}<500 \\
w=1.74\left[\frac{g d\left(\rho_{s}-\rho_{1}\right)}{\rho_{1}}\right]^{0.5}, 500 \leq \operatorname{Re}_{p}<200,000
\end{gathered}
$$

where, $\operatorname{Re}_{\mathrm{p}}$, the particle Reynolds number, is defined as

$$
\operatorname{Re}_{p}=\frac{w d \rho_{1}}{\mu_{1}}
$$

To determine the settling velocity of non-spherical, irregular particles whose size is represented by a length scale, $d$, a shape factor, $S_{f}$, is employed to obtain an effective particle diameter, $d_{e f f}$, such that

$$
\mathrm{d}_{\mathrm{eff}}=\mathrm{S}_{\mathrm{f}} \cdot \mathrm{d}
$$

The shape factor, $S_{f}$, is obtained experimentally at conditions of equal drag coefficients for the different Reynolds number ranges shown above. For most common minerals with comparable minimum and maximum length scales, the shape factor usually varies between 0.75 and 0.95 . A shape factor of 1.0 corresponds to a perfectly spherical particle. To calculate the settling velocity for an irregular particle from the above expressions, deff should be used in place of $d$.

As will be shown the settling velocity, $w$, will be used later for the calculation of the solids concentration profiles along the horizontal pipe's vertical diameter.

\section{Slurry Properties:}

\section{A. Densities and Concentrations}

The average concentration of solids by volume, $\bar{C}$, or by weight, $C_{w}$, are usually established from operational considerations. For instance, slurry rheology is always described as a function of $\bar{C}$, while in the calculation of the solids throughput $C_{w}$ is often employed. An upper operational limit on the slurry's "apparent viscosity" will determine the maximum allowable solids concentration by volume, $\bar{C}$. A required solids throughput will determine the needed solids concentration by weight, $C_{w}$. Both $\bar{C}$ and $C_{w}$ can be defined in terms of the average slurry density, 
$\bar{\rho}$, the density of the carrier liquid, $\rho_{\mathbf{l}}$, and the material density of the solid particles, $\rho_{\mathrm{s}}$. The slurry density is given by the following expression when only one particle size with a single density is used:

$$
\bar{\rho}=\bar{C} \rho_{s}+(1-\bar{C}) \rho_{\mathbf{I}}
$$

A more general expression is used in the computer code gives the average slurry density when a particle size distribution having particles with different densities exists. The following expressions relate densities to concentrations:

$$
\begin{gathered}
\bar{C}=\frac{\bar{\rho}-\rho_{1}}{\rho_{s}-\rho_{1}} \\
C_{w}=\frac{\bar{\rho}^{-1}-\rho_{1}^{-1}}{\rho_{s}^{-1}-\rho_{1}^{-1}}
\end{gathered}
$$

The concentrations are related as follows:

$$
C_{w}=\frac{\rho_{s}}{\bar{\rho}} \bar{C}
$$

Either $\bar{C}$ or $C_{w}$ should be specified a priority. The slurry program requires as an input a value for $\bar{C}$.

\section{B. Slurry Rheology}

The rheological properties of solid/liquid suspensions are dependent on the average solids concentration. Experience suggests that in most slurries that are chemically inert, suspensions are essentially Newtonian at concentrations $\bar{C}<0.2$. They tend to become non-Newtonian at higher concentrations. The behavior of concentrated slurries can be described by the Bingham Plastic model, which involves an apparent viscosity, $\eta$, and a yield stress, $\tau_{y}$, such that

$$
\tau=\tau_{y}+\eta \dot{\gamma}
$$

where $\tau$ and $\dot{\gamma}$ are the shear stress and the shear rate of strain, respectively. In the computer code, the following general expressions have been developed for the apparent viscosity, $\eta$, and the yield stress, $\tau_{y}$, from extensive experimentation:

$$
\begin{gathered}
\eta=\mu_{1} \exp \left[\frac{2.7 \bar{C}}{1-S \bar{C}}\right] \\
\tau_{y}=\exp \left[\frac{5.4 \bar{C}^{2}(S-1.54)}{(1-S \bar{C})(1-1.54 \bar{C})}\right]\left[\exp \left(\frac{4.3 \bar{C}}{1-\bar{C}}\right)-1\right]
\end{gathered}
$$

In the above expressions $\eta_{\text {and }} \mu_{1}$ must have the same units, and $\tau_{y}$ is in dynes $/ \mathrm{cm}^{2}$. The measured yield stresses for the tested slurries were relatively small and their impact on the overall 
friction losses in turbulent pipe flow is considered negligible. In the above equations the parameter $S$ is strongly influenced by the particle shape and size distribution. For a particular solid/liquid slurry the magnitude of these effects can best be determined by performing a few viscosity measurements with a fine-particle slurry. For instance, if we have a solid-particle size distribution with a mean size d50, we choose a finer subset of that distribution with a mean size $d_{0}$, such that $d_{0}<d_{50}$ and with $d_{0}$ in the neighborhood of $25 \mu \mathrm{m}$. By employing the above equation for $\eta$ to fit the data from these measurements, a reference parameter $S_{o}$ which corresponds to $d_{o}$ is obtained.

This pair of reference values, $d_{o}$ and $S_{o}$, is found to be sufficient to calculate $S$ and the rheological properties of any other slurry (of the same materials) with a given wide-particle size distribution and with mean size $d 50$. In the computer code $d_{o}$ and $S_{o}$ are input parameters, and $S$ is computed as follows:

$$
\begin{gathered}
S=S_{o}\left[1.0-0.17 \ln \left(\frac{d_{50}}{d_{o}}\right)\right], \text { if } \frac{d_{50}}{d_{o}} \leq 3.0 \\
S=0.81 S_{o}, \text { if } \frac{d_{50}}{d_{o}}>3.0
\end{gathered}
$$

In the limiting case when $d_{50}=d_{0}$, we get $S=S_{0}$. To avoid the need to make measurements, reasonably accurate estimates of the two reference values $d_{0}$ and $S_{0}$ can be obtained by using the following values:

a. $S_{0}=1.80$ with $d_{0}=25 \mu \mathrm{m}$, for irregular particles.

b. $S_{0}=1.30$ with $d_{0}=25 \mu \mathrm{m}$, for spherical particles.

The same value of $\mathrm{S}$ computed from the above expressions is used in calculating both the slurry's apparent viscosity, $\eta$, and its yield stress, $\tau_{y}$. Two options are offered in the computer code: the first is to calculate both the apparent viscosity and the yield stress according to the above method, and the second is to calculate the apparent viscosity but take the yield stress to be zero.

\section{Solids Concentration Distribution}

\section{A. Background Information}

A significant difference between the present computations and other calculation methods is its ability to account for flow heterogeneity, which results from partial particle settling and the existence of a particle size distribution along the vertical diameter of the transporting pipe. In most other calculation methods, friction factor correlations are developed for a basic homogeneous slurry mixture. The contribution of flow heterogeneity to the overall pressure drop can be significant, as seen in the following qualitative description of the various flow classifications encountered during slurry transport.

Referring to Figure C.1, line AA' represents homogeneous flow at high mean slurry velocity. The particles are uniformly distributed over the pipe's cross-section due to high turbulence intensity. At lower mean velocities, line $A B$, vertical concentration profiles of the solid particles begin to appear, and the slurry concentration at the pipe's bottom is larger than that at its top. This is the heterogeneous flow condition, and, although the flow is still turbulent, the pressure drop is larger than that for a hypothetical homogeneous slurry at the same mean velocity. At yet smaller mean velocities, a sliding bed condition begins to develop, line $B C$, at which condition the mean flow is unable to provide sufficient energy to maintain all the particles in suspension. Particles in the sliding bed tend to be slow-moving and lagging behind those faster moving particles in the upper fluid layers. A minimum pressure gradient is observed at the lower limit of this regime, and the mean 


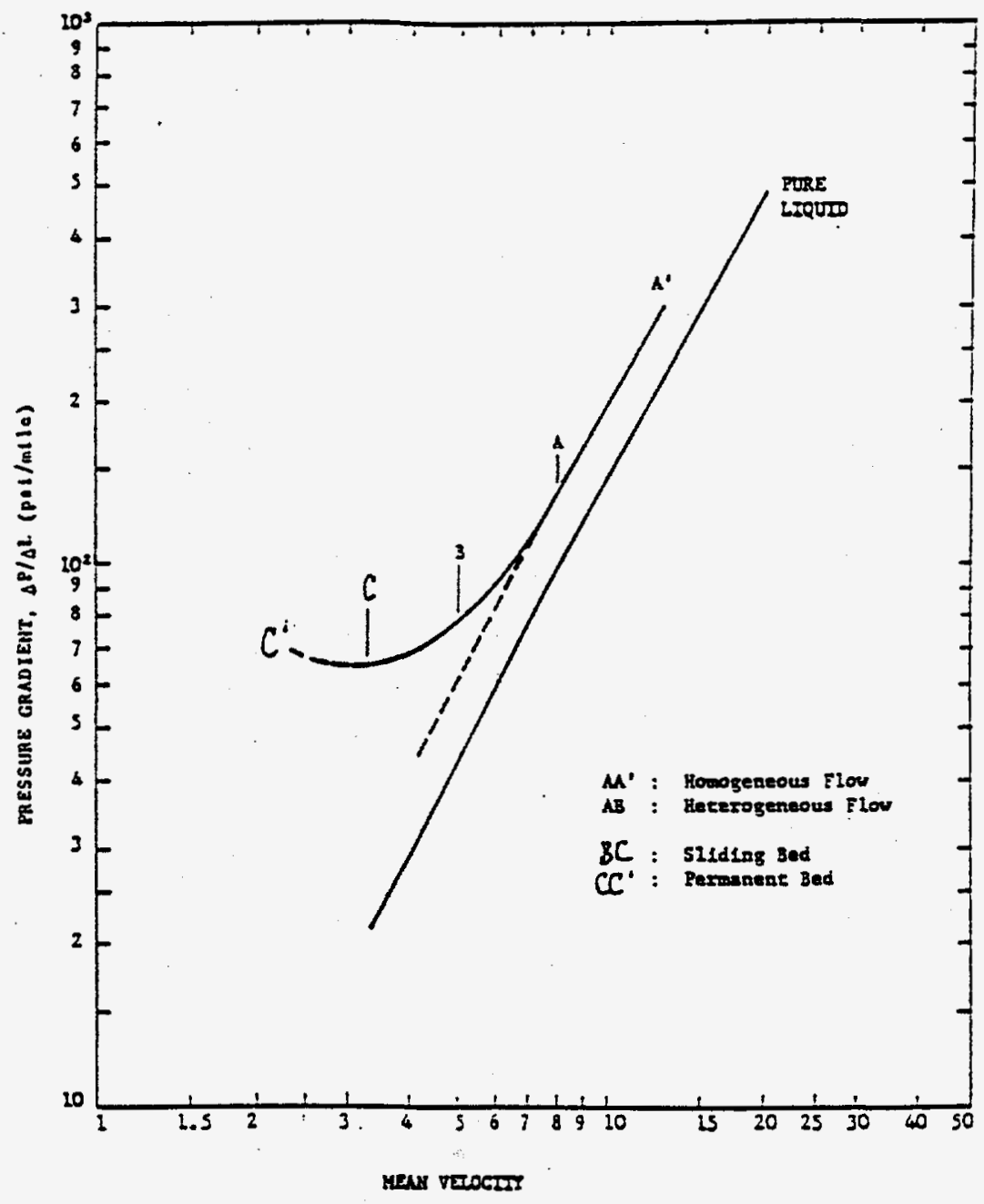

Figure C.1. Typical Variation of Friction Losses with Mean Velocity in Pipe Flow of Concentrated Suspensions 
velocity corresponding to this limit point is called the critical velocity. A further decrease in mean velocity leads to a permanent bed formation, line CC', at the bottom of the pipeline. Operation of a long-distance slurry pipeline under these conditions or even at slightly above the critical velocity is undesirable because of potential instabilities.

Most practical slurry pipeline transport takes place in the heterogeneous flow regime. Some of the main advantages are reasonable power consumption, reduced pipeline erosion, and particle attrition.

Clearly, the pressure drop in the heterogeneous flow regime cannot be accurately described by a simple friction factor correlation as in the homogeneous regime. In the computer code used here, the calculation of the pressure drop under heterogeneous flow conditions is somewhat complicated and is based on a modified version of the Wasp-Durand correlation $\{1\}$. According to this model the total pressure drop is divided into two parts; one part is due to the homogeneous component of the flow field, and a second part is dependent on its heterogeneity, as follows:

$$
\left.\frac{\Delta P}{\Delta L}\right|_{\text {total }}=\left.\frac{\Delta P}{\Delta L}\right|_{\text {hom }}+\left.\frac{\Delta P}{\Delta L}\right|_{\text {het }}
$$

The homogeneous part corresponds to the pressure drop due to a slurry mixture of uniform concentration while the heterogeneous part corresponds to the pressure drop due to a slurry mixture of non-uniform concentration.

The above information is presented to explain the importance of obtaining the solids concentration profile. It is this concentration distribution that determines the degree of heterogeneity of the slurry mixture, which in turn determines the heterogeneous component of the total pressure drop.

\section{B. Solids Concentration Distribution}

Hunt $\{2,3\}$ developed a general set of equations describing solids distribution in a horizontal turbulent stream. He derived a general diffusion equation in which the effect of particle size distribution is taken into account. The following simplified form of this equation is obtained under the assumption that the diffusivity of solids is nearly equal to that of the fluid and that the concentration varies only in the direction of gravity. The equation for a single-size particle is given by:

$$
\varepsilon \frac{d C}{d y}+(1-C) C w=0
$$

where $C=C(y)$ is the local volume concentration of the solid particles, $\mathrm{y}$ is the vertical direction along the gravitational field, $w$ the settling velocity of a single particle size, and $\varepsilon$ is the turbulent eddy diffusivity. The solution to the above equation gives the following concentration distribution:

$$
C(y)=\left[1+\frac{\exp (K y)}{\bar{V}}\right]^{-1}
$$

where $\bar{V}=\bar{C} /(1-\bar{C})$, and $\mathrm{K}=\mathrm{w} / \mathrm{C}_{1} \mathrm{u}^{*}$ with $\mathrm{C}_{1}=0.5$, a constant, and $\mathrm{u}^{*}$ is the frictional velocity, which is dependent on the pressure drop according to the following expression:

$$
u^{*}=\sqrt{\frac{\tau_{w}}{\bar{\rho}}}=\sqrt{\frac{\Delta P R}{\Delta L 2 \bar{\rho}}}
$$


In the above expression $\tau_{w}$ is the wall shear stress and $\mathrm{R}$ the pipe radius. A typical concentration distribution along a pipe's vertical diameter is shown in Figure C.2. It is customary to associate a homogeneous component of the overall pressure drop with a corresponding homogeneous component of the local concentration distribution, and, a heterogeneous component of the pressure drop with a measure of the non-uniformity of the concentration distribution, $C_{\text {het }}$. Referring to Figure C.2, these two components of the solids concentration are defined as follows in the present calculation procedures:

$$
\begin{aligned}
& C_{\text {het }}=|\bar{C}-C(1)| \\
& C_{\text {bow }}=\bar{C}-C_{\text {het }}
\end{aligned}
$$

where $C(1)$ is the concentration at the top of the pipe where the dimensionless radius, $y / R$, is equal to 1. This analysis describes the situation when a single particle size with uniform density is present. In the computer code more complex solutions are associated with a given particle size distribution and with non-uniform densities. For each particle size with a given density, a unique concentration profile is produced. From this profile the value of the mean concentration is produced by simple integration. Using the local concentration value at the top of the pipe for this case, a corresponding measure of the concentration heterogeneity pertinent to this particle size and density is obtained. The overall values of $C_{\text {hom }}$ and $C_{\text {het }}$ are obtained by direct summation over all the particle sizes and densities. The calculation of the overall pressure drop is described in the next section.

\section{Calculation of the Overall Pressure Drop}

\section{A. The Homogeneous Pressure Drop, $\left.\frac{\Delta P}{\Delta L}\right|_{\text {hom }}$}

In order to calculate the homogeneous pressure drop $\Delta P / \Delta L$ hom, one of the following two correlations can be used. The first is the Newtonian correlation and is the most reliable, especially in cases where the yield stress of the flowing slurry, $\tau_{y}$, is equal to zero. The second is the nonNewtonian correlation, which is not as reliable.

The Newtonian Correlation A value of the friction factor, $\mathrm{f}$, is first obtained using the Colebrook equation:

$$
\frac{1}{\sqrt{f}}=-2.0 \log _{10}\left[\frac{\varepsilon}{3.7 D}+\frac{2.51}{\operatorname{Re} \sqrt{f}}\right]
$$

where $\varepsilon$ is the pipe roughness, $\mathrm{D}$ the pipe diameter, and the Reynolds number, $\mathrm{Re}$, is calculated using the mean slurry density, $\bar{\rho}$, and the mean slurry viscosity, $\eta$. The homogeneous pressure gradient can then be obtained from:

$$
\frac{\Delta P}{\Delta L} \grave{U}_{\text {hom }}=\frac{f}{\Phi} \frac{2 \bar{\rho} \bar{U}^{2}}{D}
$$




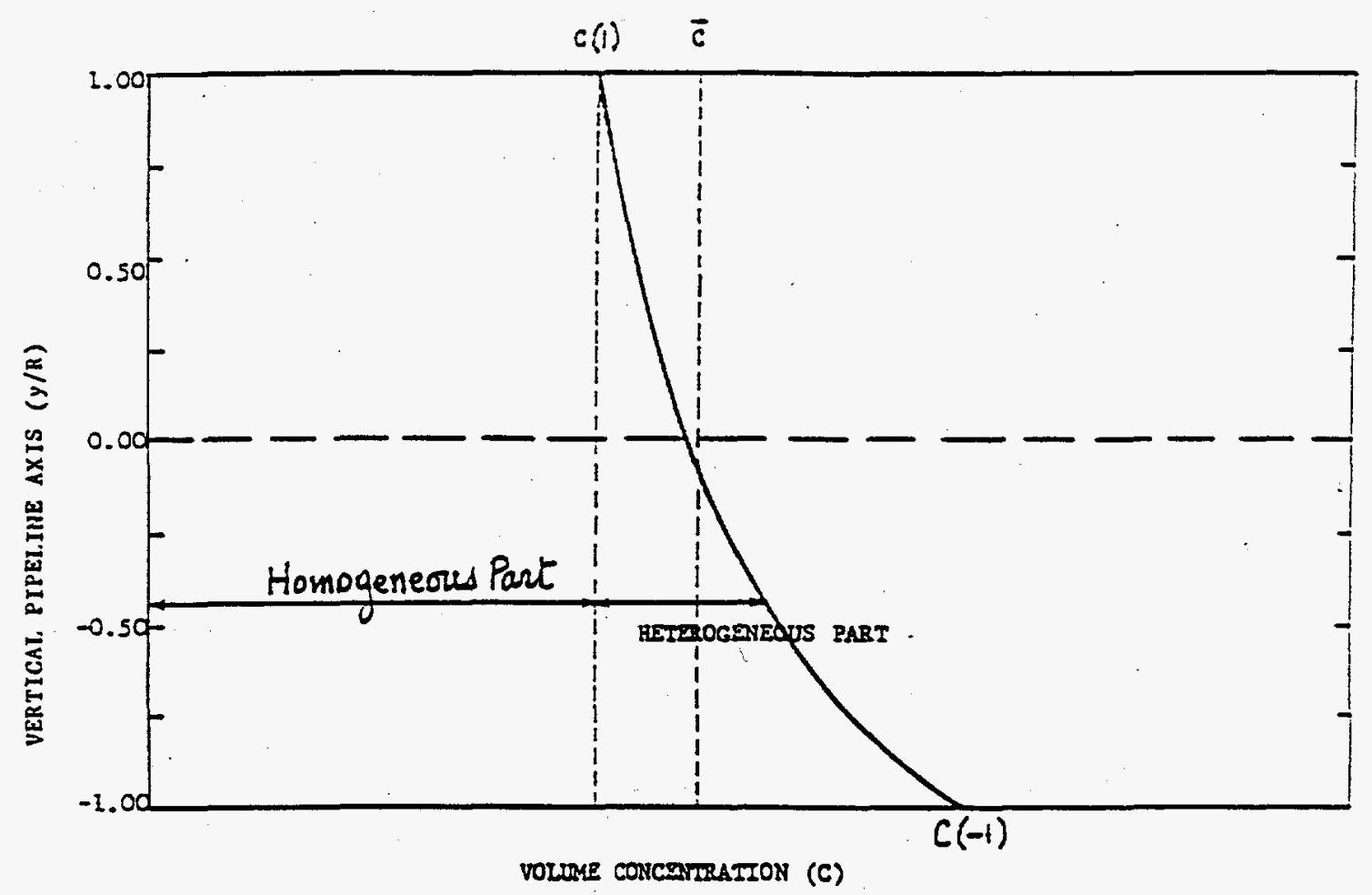

Figure C.2. Terms Describing Heterogeneous Distribution of Solids 
where $\bar{U}$ is the mean slurry velocity, and the empirical correction factor $\Phi$ is defined as follows,

$$
\Phi \equiv\left[\frac{\eta}{\mu_{1}}\right]^{0.12} \exp \left[140 \cdot \frac{d_{50}}{D} \cdot \bar{C}\right]
$$

The first term, viscosity ratio, represents the influence of particles on the turbulent friction factors, and the second term represents the effect of the particle size on the friction factor.

The Non-Newtonian Correlations When the yield stress is nonzero, two correlations are used to determine the friction factor. If the Reynolds number is smaller than the transition Reynolds number, $\mathrm{Re}_{t}$, The Buckingham equation is applicable. It is given by

$$
\frac{1}{\operatorname{Re}}=\frac{f}{16}-\frac{1}{6} \frac{H e}{\operatorname{Re}^{2}}+\frac{1}{3} \frac{H e^{4}}{f^{3} \operatorname{Re}^{8}}
$$

where $H e$ is the Hedström number, which is defined as follows:

$$
H e=\frac{\tau_{y} D^{2} \bar{\rho}}{\eta^{2}}
$$

The solution to the Buckingham equation for the laminar friction factor, $f$, is carried out in the computer code.

Hanks and Dadia $\{4\}$, developed a semi-empirical model for Bingham-plastic fluids that accounts for the effect of the Hedström number in the turbulent flow regime. Their correlation has been incorporated into the computer code, which allows the calculation of the turbulent friction factor for a Bingham-plastic fluid with a finite yield stress. Finally, transition between the laminar and turbulent flow regimes is defined by the transition Reynolds number, $\mathrm{Re}_{t}$, which has been defined by Hanks $\{5\}$, as follows:

$$
\operatorname{Re}_{t}=\frac{H e}{8 a}\left[1-\frac{4}{3} a+\frac{1}{3} a^{4}\right]
$$

with the constant $a$ being the positive real root of the following cubic equation,

$$
\frac{H e}{16800}=\frac{a}{(1-a)^{3}}
$$

The correlation of turbulent friction losses explained by Hanks and Dadia 44 is usually available in the form of a chart from which numerical values can be extracted as done in the present case.

\section{B. The Heterogeneous Pressure Drop, $\left.\frac{\Delta P}{\Delta L}\right|_{\text {het }}$}

The heterogeneous component of the overall pressure drop is calculated based on the empirical correlation of Durand and Condolios $\{6\}$, which was modified later by Wasp $\{1\}$. It is given by:

$$
\left.\frac{\Delta P}{\Delta L}\right|_{\text {het }}=\left.81 \cdot \frac{\Delta P}{\Delta L}\right|_{\text {hom }} \cdot C_{\text {het }}\left[\frac{g D}{\bar{U}^{2}} \frac{\rho_{s}-\bar{\rho}}{\bar{\rho}} \cdot \frac{1}{\sqrt{C_{d}}}\right]^{1.5}
$$


It is important to note that the drag coefficient, $C_{d}$ is calculated based on the density and viscosity of the homogeneous slurry properties and not based on those of the clear liquid. The total pressure drop can now be calculated by adding the homogeneous and the heterogeneous components.

\section{Critical Velocity}

The critical velocity, $\bar{U}_{c}$, is defined as the velocity corresponding to the minimum pressure gradient and tends to increase with increasing concentration, if the flow is turbulent. An empirical correlation to predict the critical velocity is given below:

$$
\bar{U}_{c}=80.75 w_{m}\left(\frac{\rho_{1}}{\bar{\rho}}\right)\left(\frac{\eta}{\mu_{1}}\right)^{0.14}
$$

Operating velocities should be higher than the critical velocity in order to maintain a stable and reliable slurry transport. The recommendation is to define a factor of safety, $F$, such that,

$$
U_{\min }=F \cdot \bar{U}_{c}
$$

A value for $F$ that has been used frequently is 1.375 .

\section{Pressure Drop in Inclined Pipes}

At small-to-moderate solids concentration, the influence of slight pipe inclination, $\pm 10^{\circ}$, on the concentration profiles are negligible. The total pressure drop in an inclined pipe can then be calculated as follows:

$$
\Delta P_{\text {total }}=\Delta P_{\text {friction }} \pm \bar{\rho} g \Delta h
$$

where the + and - signs correspond to uphill and downhill elevations, $\Delta h$, respectively. The pressure drop due to friction losses, $\Delta P_{\text {friction }}$, is the sum of $\Delta P / \Delta L_{\text {hom }}$ and $\Delta P / \Delta L_{\text {het }}$.

\section{Recommendations}

The availability of the source code of this computer program makes it possible to improve, modify, and add to its computing power. It may be possible, for instance, to incorporate more realistic rheological models if the Bingham Plastic model proves to be unsatisfactory. Furthermore, it may be desirable to include the effects of some simple chemical reactions, changes in the chemical composition of the slurry along the transport route, and the addition or extraction of heat. 


\section{References}

1) Wasp, E. J. et al., "Cross Country Coal Pipeline Hydraulics," Pipe Line News, V. 35, No. 7, pp 20-28, July 1963.

2) Hunt, J. N., Proc. Royal Soc., A 224, p 322, 1954.

3 H Hunt, J. N., Quart. J. Mech. and Applied Math., V. 22, Prt. 2, p 235, 1969.

4) Hanks, R. W., and Dadia, B. H., "Theoretical Analysis of the Turbulent Flow of Non-Newtonian Slurries in Pipes," A.I.Ch.E. Journal, V. 17, No. 3, pp 554-557, 1971.

5\} Hanks, R. W., "The Laminar-Turbulent Transition for Fluids with a Yield Stress," A.I.Ch.E. Journal, V. 9, No. 3, pp 306-309, 1963.

6\} Durand, R., and Condolios, E., "The Hydraulic Transport of Coal and Solid Material in Pipes," Proceedings of Colloquium on the Hydraulic Transport of Coal; held by the National Coal Board in London, Paper IV, November 5-6, 1952. 
Appendix D

Sample Calculations 


\section{Appendix D}

\section{Sample Calculations}

\section{Critical Velocity Equation}

$$
\mathrm{U}_{\mathrm{c}}=80.75 \mathrm{~W}\left(\frac{\rho_{\ell}}{\bar{\rho}}\right)\left(\frac{\eta}{\mu}\right)^{0.14} \pm \delta \mathrm{u}_{\mathrm{e}}
$$

for developed turbulent flow:

$$
\begin{gathered}
\mathrm{W}_{\mathrm{p}}=1.74\left[\frac{\operatorname{gd}\left(\rho_{\mathrm{s}}-\rho_{\ell}\right)}{\rho_{\ell}}\right]^{0.5} \\
\mathrm{~W}=\mathrm{XW}_{\mathrm{p}}
\end{gathered}
$$

where $X=\exp \left\{-5.9 C_{v}\right\}$ which accounts for the hindered setting effect of a concentrated solution. ${ }^{(a)}$

$$
\bar{\rho}=\mathrm{C}_{\mathrm{v}} \rho_{\mathrm{s}}+\left(1-\mathrm{C}_{\mathrm{v}}\right) \rho_{\ell}
$$

The uncertainty of $U_{c}$ is found by observing the law for the propagation of uncertainty:

$$
\mathrm{E}_{\mathrm{u}_{\mathrm{c}}}=\left(\mathrm{E}_{\mathrm{w}}^{2}+\mathrm{E}_{\bar{p}}^{2}+\mathrm{E}_{\rho_{\ell}}^{2}+\left(0.14 \mathrm{E}_{\eta}\right)^{2}+\left(0.14 \mathrm{E}_{\mu}\right)^{2}\right)^{1 / 2}
$$

where $\mathrm{E}$ is expressed as a percentage.

Assume measurement uncertainties of $10 \%$ :

$$
\mathrm{E}_{\mathrm{d}}=10 \%, \mathrm{E}_{\rho_{\mathrm{s}}}=10 \%, \mathrm{E}_{\rho_{\ell}}=10 \%, \mathrm{E}_{\mu}=10 \%, \mathrm{E}_{\eta}=10 \%
$$

(a) This empirical expression for hindered settling is taken from Govier and Aziz, page 18, The Flow of Complex Mixtures in Pipes, Krieger Publishing Co., Malabu, FL. 
Determine $\mathrm{E}_{\mathrm{w}_{\mathrm{p}}}$

$$
\begin{gathered}
\mathrm{W}_{\mathrm{p}}=\mathrm{f}\left(\mathrm{d}, \rho_{\mathrm{s}}, \rho_{\ell}\right) \\
\delta_{\mathrm{w}_{\mathrm{p}}}=\left[\left[\frac{\partial \mathrm{w}_{\mathrm{p}}}{\partial \mathrm{d}} \delta_{\mathrm{d}}\right]^{2}+\left[\frac{\partial \mathrm{w}_{\mathrm{p}}}{e \ell_{\mathrm{s}}} \delta \rho_{\mathrm{s}}\right]^{2}+\left[\frac{\partial \mathrm{w}_{\mathrm{p}}}{\partial e_{\ell}} \delta \rho_{\ell}\right]^{2}\right]^{1 / 2} \\
\delta_{\mathrm{w}_{\mathrm{p}}}=\mathrm{E}_{\mathrm{w}_{\mathrm{p}}} \mathrm{W}_{\mathrm{p}} \Rightarrow \mathrm{E}_{\mathrm{w}_{\mathrm{p}}}=\frac{\delta_{\mathrm{w}_{\mathrm{p}}}}{\mathrm{W}_{\mathrm{p}}}
\end{gathered}
$$

To calculate $\delta \mathrm{w}_{\mathrm{p}}$, must evaluate $\partial \mathrm{w}_{\mathrm{p}}$ :

$$
\begin{aligned}
& \mathrm{w}_{\mathrm{p}}=1.74\left[\frac{\operatorname{gd}\left(\rho_{\mathrm{s}}-\rho_{\ell}\right)}{\rho_{\ell}}\right]^{1 / 2}=1.74\left(\frac{\mathrm{g}\left(\rho_{\mathrm{s}}-\rho_{\ell}\right)}{\rho_{\ell}}\right)^{1 / 2} \mathrm{~d}^{1 / 2} \\
& \frac{\partial \mathrm{w}_{\mathrm{p}}}{\partial \mathrm{d}}=\frac{1.74}{2}\left[\frac{\mathrm{g}\left(\rho_{\mathrm{s}}-\rho_{\ell}\right)}{\mathrm{d} \rho_{\ell}}\right]^{1 / 2}=\frac{1.74}{2}\left(\frac{\mathrm{g} \rho_{\mathrm{s}}}{\mathrm{d} \rho_{\ell}}-\frac{\mathrm{g}}{\mathrm{d}}\right)^{1 / 2} \\
& \mathrm{w}_{\rho}=1.74\left(\frac{\mathrm{gd}}{\rho_{\ell}}\right)^{1 / 2}\left(\rho_{\mathrm{s}}-\rho_{\ell}\right)^{1 / 2} \\
& \frac{\partial \mathrm{w}_{\mathrm{p}}}{\partial \rho_{\mathrm{s}}}=1.74\left[\frac{\mathrm{gd}}{\rho_{\ell}}\right]^{1 / 2}(1 / 2)\left(\rho_{\mathrm{s}}-\rho_{\ell}\right)^{-1 / 2}=\frac{1.74}{2}\left[\frac{\mathrm{gd}}{\rho_{\ell}\left(\rho_{\mathrm{s}}-\rho_{\ell}\right)}\right]^{1 / 2} \\
& w_{p}=1.74\left[\frac{\operatorname{gd} \rho_{s}}{\rho_{\ell}}-g d\right]^{1 / 2}
\end{aligned}
$$




$$
\begin{aligned}
& \frac{\partial w_{p}}{\partial \rho_{\ell}}=\frac{1.74}{2}\left[\frac{\operatorname{gd} \rho_{s}}{\rho_{\ell}}-g d\right]^{-1 / 2}\left(\frac{-g d \rho_{s}}{\rho_{\ell}^{2}}\right) \\
& =\frac{-1.74}{2}\left[\frac{\rho_{\ell}}{\operatorname{gd}\left(\rho_{\mathrm{s}}-\rho_{\ell}\right)}\right]_{1 / 2}^{1 / 2}\left[\frac{\mathrm{g}^{2} \mathrm{~d}^{2} \rho_{\mathrm{s}}^{2}}{\rho_{\ell}^{4}}\right]^{1 / 2} \\
& =\frac{-1.74}{2}\left[\frac{\operatorname{gd} \rho_{\mathrm{s}}^{2}}{\rho_{\ell}^{3}\left(\rho_{\mathrm{s}}-\rho_{\ell}\right)}\right]^{1 / 2} \\
& \dot{\mathrm{E}}_{\mathrm{w}_{\rho}}=\frac{\left[\left[\frac{1.74}{2}\left[\frac{\mathrm{g} \rho_{\mathrm{s}}}{\mathrm{d} \rho_{\ell}}-\frac{\mathrm{g}}{\mathrm{d}}\right]^{1 / 2} \delta_{\mathrm{d}}\right]^{2}+\left[\frac{1.74}{2}\left[\frac{\mathrm{gd}}{\rho_{\ell}\left(\rho_{\mathrm{s}}-\rho_{\ell}\right)}\right]^{1 / 2} \delta \rho_{\mathrm{s}}\right]^{2}+\left[\frac{-1.74}{2}\left[\frac{\mathrm{gd} \rho_{\mathrm{s}}^{2}}{\rho_{\ell}^{3}\left(\rho_{\mathrm{s}}-\rho_{\ell}\right)}\right]^{1 / 2} \delta \rho_{\ell}\right]^{2}\right]^{1 / 2}}{\mathrm{w}_{\mathrm{p}}}
\end{aligned}
$$

Determine $\mathrm{E}_{\bar{\rho}}$

$$
\begin{gathered}
\bar{\rho}=\mathrm{f}\left(\rho_{\mathrm{s}}, \rho_{\ell}\right) \quad \delta \bar{\rho}=\left[\left[\frac{\partial \bar{\rho}}{\partial \rho_{\mathrm{s}}} \delta \rho_{\mathrm{s}}\right]^{2}+\left[\frac{\partial \bar{\rho}}{\partial \rho_{\ell}} \delta \rho_{\ell}\right]^{2}\right]^{1 / 2} \\
\delta_{\bar{\rho}}=\mathrm{E}_{\bar{\rho}} \bar{\rho} \Rightarrow \mathrm{E} \bar{\rho}=\frac{\delta_{\bar{\rho}}}{\bar{\rho}} \\
\bar{\rho}=\mathrm{C}_{\mathrm{v}} \rho_{\mathrm{s}}+\left(1-\mathrm{C}_{\mathrm{v}}\right) \rho_{\ell} \Rightarrow \frac{\partial \bar{\rho}}{\partial \rho_{\mathrm{s}}}=\mathrm{C}_{\mathrm{v}} ; \frac{\partial \bar{\rho}}{\partial \rho_{\ell}}=1-\mathrm{C}_{\mathrm{v}} \\
\mathrm{E}_{\bar{\rho}}=\frac{\left.\left[\left(\mathrm{Cv} \delta_{\rho_{\mathrm{s}}}\right)^{2}+\left(1-\mathrm{C}_{\mathrm{v}}\right) \delta_{\rho_{\ell}}\right)^{2}\right]^{1 / 2}}{\bar{\rho}}
\end{gathered}
$$

assign values: $\mathrm{d}=100 \mu \mathrm{m}=1.0 \times 10^{-2} \mathrm{~cm}, \mathrm{C}_{\mathrm{v}}=0.30, \rho_{\mathrm{s}}=2.5 \mathrm{~g} / \mathrm{cm}^{3}$

$$
\rho_{\ell}=1.0 \mathrm{~g} / \mathrm{cm}^{3}, \mu=1.0 \mathrm{cP}, \eta=15 \mathrm{cP}, \mathrm{g}=980.66 \mathrm{~cm} / \mathrm{s}^{2}
$$

calculate $\delta$ 's: $\delta_{\mathrm{x}}=\mathrm{E}_{\mathrm{x}} \mathrm{X}$

D. 3 


$$
\begin{aligned}
& \delta_{\mathrm{d}}=(0.10)\left(1 \times 10^{-2}\right)=1 \times 10^{-3} \mathrm{~cm} \\
& \delta_{\rho_{\mathrm{s}}}=(0.10)(2.5)=0.25 \mathrm{~g} / \mathrm{cm}^{3} \\
& \delta_{\rho_{\ell}}=(0.10)(1.0)=0.10 \mathrm{~g} / \mathrm{cm}^{3} \\
& \delta w_{p}=\left[\left(\left(\frac{1.74}{2}\left[\frac{(980.66)(2.5)}{1 \times 10^{-2}(1)}\right)-\left(\frac{980.66}{1 \times 10^{-2}}\right)\right]^{1 / 2} 1 \times 10^{-3}\right)^{2}+\left(\frac{1.74}{2}\left(\frac{(980.66)\left(1 \times 10^{-2}\right)}{(1)(1.5)}\right)^{1 / 2} 0.25\right)^{2}+\left(\frac{-1.74}{2}\left(\frac{(980.66)\left(1 \times 10^{-2}\right)(2.5)^{2}}{(1)(1.5)}\right)^{1 / 2} 0.1\right)^{2}\right]^{1 / 6} \\
& =0.85 \mathrm{~cm} / \mathrm{s} \\
& w_{p}=1.74\left[\frac{(980.66)\left(1 \times 10^{-2}\right)(2.5-1)}{1}\right]^{1 / 2} \pm \delta w p=6.7 \pm 0.9 \mathrm{~cm} / \mathrm{s} \\
& \mathrm{W}=\mathrm{XWp}=\exp \{-5.9(0.30)\} \mathrm{Wp}=1.14 \pm 0.15 \mathrm{~cm} / \mathrm{s}, \mathrm{E}_{\mathrm{w}}=\frac{\delta_{\mathrm{w}}}{\mathrm{w}}=13 \% \\
& \delta_{\bar{\rho}}=\left[((0.3)(0.25))^{2}+((0.7)(0.1))^{2}\right]^{1 / 2}=0.10 \mathrm{~g} / \mathrm{cm}^{3} \\
& \bar{\rho}=(0.3)(2.5)+(0.7)(1) \pm \delta_{\overline{\mathrm{e}}}=1.45 \pm 0.10 \mathrm{~g} / \mathrm{cm}^{3} \\
& E_{u_{c}}=\left(E_{w}^{2}+E_{\bar{\rho}}^{2}+E_{\rho_{\ell}}^{2}+\left(0.14 E_{\eta}\right)^{2}+\left(0.14 E_{\mu}\right)^{2}\right)^{1 / 2}=18 \% \\
& U_{c}=80.75(1.14)\left(\frac{1}{1.45}\right)\left[\frac{10}{1}\right]^{0.14}=87.6 \mathrm{~cm} / \mathrm{s}=2.88 \mathrm{ft} / \mathrm{s} \\
& \delta_{u_{c}}=\mathrm{Eu}_{\mathrm{c}} \mathrm{Uc}=(.18)(2.88)=0.52 \mathrm{ft} / \mathrm{s} \\
& \mathrm{U}_{\mathrm{c}}=2.88 \pm 0.52 \mathrm{ft} / \mathrm{s}
\end{aligned}
$$




\section{Mixer Pump Equation}

$$
\begin{gathered}
\frac{E C R}{U_{0} D}=K \tau^{-n} \\
v=\pi h(E C R)^{2} \\
v=\pi h\left(U_{0} D K \tau^{-n}\right)^{2} \\
\frac{d v}{d \tau}=-2 n \pi h^{2}\left(U_{o} D\right)^{2} \tau^{-2 n-1} \\
\left|\frac{d v}{d \tau}\right|=\left|-2 n \pi h K^{2}\left(U_{0} D\right)^{2} \tau^{-2 n-1}\right| \\
\epsilon_{v}=\frac{\left|\frac{d v}{\tau}\right| \delta v}{v} \quad \text { where } \delta_{v}=\epsilon_{v} V
\end{gathered}
$$

let $\tau=20,000$ dynes $/ \mathrm{cm}^{2}$

$\mathrm{E}_{\tau}=10 \%$

$\mathrm{h}=100 \mathrm{~cm}$

$\mathrm{U}_{\mathrm{o}} \mathrm{D}=25.0 \mathrm{~cm} \times 1000 \mathrm{~cm} / \mathrm{s}=25000 \mathrm{~cm}^{2} / \mathrm{s}$

$\mathrm{n} \quad=0.41$

$\mathrm{k} \quad=2.3$

- Neglect the distance between pump centerline and nozzle tip.

- Assume centrally-located mixer pump.

- Assume vertical sludge bank.

$$
\begin{gathered}
\mathrm{v}=\pi|100|\left(25000|2.3| 20000^{-.41}\right)^{2}=3087.15922 \mathrm{~cm}^{3} \\
\delta_{\mathrm{v}}=20,000(0.1)=2000 \text { dynes } / \mathrm{cm}^{2}
\end{gathered}
$$




$$
\begin{gathered}
\left|\frac{d v}{d \tau}\right|=2(0.41) \pi(100)(2.3)^{2}\left(U_{\circ} D\right)^{2} 20000^{-1.82}=12657 \frac{\mathrm{cm}^{3}}{\text { dynes } / \mathrm{cm}^{2}} \\
\epsilon_{v}=\frac{(12660)(2000)}{308700000}=8.2 \% \\
v=308 \pm 25 \mathrm{~m}^{3}
\end{gathered}
$$

D. 6 


\section{Distribution}

No. of

Copies

OFFSITE

12 DOE/Office of Scientific and Technical Information

\section{ONSITE}

5 DOE Richland Operations Office

W. R. Wrzesinski (5)

S7-53

ICF Kaiser Hanford Company

Q. H. Nguyen

E6-21

18 Westinghouse Hanford Company

D. E. Ball

H5-61

G. R. Bloom (5)

G. L. Crawford

R. F. Eggers

G. D. Forehand

L. A. Fort
No. of

Copies

P. W. Gibbons

H5-61

M. M. Hall

H5-61

R. L. Hand

H5-61

D. L. Lamberd

H5-61

L. B. McDaniel

H5-61

G. A. Meyer

H5-36

C. A. Rieck

J. E. Van Beek

S2-48

$\mathrm{S} 2-48$

19 Pacific Northwest Laboratory

J. A. Bamberger

K7-15

M. R. Beckette

P7-19

C. J. Call

P7-20

E. A. Daymo

P7-19

F. F. Erian

K7-15

C. M. Gates (5)

G. R. Golcar

P7-19

P7-20

R. L. McKay

P7-20

M. R. Powell

P7-19

P. A. Scott

R3-87

Publishing Coordination

Technical Report Files (5)

K1-06 